\title{
Financial accounting information and corporate governance
}

\author{
Robert M. Bushman ${ }^{\mathrm{a}, *}$, Abbie J. Smith ${ }^{\mathrm{b}}$ \\ ${ }^{a}$ Kenan-Flagler Business School, University of North Carolina, Chapel Hill, NC 27599-3490, USA \\ ${ }^{\mathrm{b}}$ Graduate School of Business, University of Chicago, USA
}

Received 4 October 1999; received in revised form 4 April 2001

\begin{abstract}
This paper reviews and proposes additional research concerning the role of publicly reported financial accounting information in the governance processes of corporations. We first discuss research on the use of financial accounting in managerial incentive plans and explore future research directions. We then propose that governance research be extended to explore more comprehensively the use of financial accounting information in additional corporate control mechanisms, and suggest opportunities for expanding such research. We also propose cross-country research to investigate more directly the effects of financial accounting information on economic performance through its role in governance and more generally. (C) 2001 Elsevier Science B.V. All rights reserved.
\end{abstract}

JEL: D8; F3; G3; J3; M4

Keywords: Financial accounting; Corporate governance; Agency; Moral hazard; Compensation

\footnotetext{
${ }^{2}$ We thank Thomas Dyckman, Thomas Hemmer, Edward Lazear, Thomas Lys (Editor), Joseph McConnell, Raghuram Rajan, Richard Sloan (Discussant), Ross Watts, Jerry Zimmerman (Editor), Luigi Zingales, and seminar participants at Carnegie Mellon University, Columbia University, Cornell University, and the 2000 Journal of Accounting \& Economics Conference for their helpful comments. We also would like to thank Xia Chen for her valuable research assistance. Abbie Smith thanks the Institute of Professional Accounting of the Graduate School of Business, University of Chicago, and Robert Bushman thanks The Pricewaterhouse Coopers Faculty Fellowship Fund for financial support.
}

*Corresponding author. Tel.: + 1-919-962-9809.

E-mail address: bushmanr@bschool.unc.edu (R.M. Bushman). 


\section{Introduction}

In this paper we evaluate and propose additional economics-based empirical research concerning the governance role of financial accounting information. We define the governance role of financial accounting information as the use of externally reported financial accounting data in control mechanisms that promote the efficient governance of corporations.

We adopt the classic agency perspective that the separation of corporate managers from outside investors involves an inherent conflict. Corporate control mechanisms are the means by which managers are disciplined to act in the investors' interest. Control mechanisms include both internal mechanisms, such as managerial incentive plans, director monitoring, and the internal labor market, and external mechanisms, such as outside shareholder or debtholder monitoring, the market for corporate control, competition in the product market, the external managerial labor market, and securities laws that protect outside investors against expropriation by corporate insiders.

Financial accounting information is the product of corporate accounting and external reporting systems that measure and publicly disclose audited, quantitative data concerning the financial position and performance of publicly held firms. Financial accounting systems provide direct input to corporate control mechanisms, as well as providing indirect input to corporate control mechanisms by contributing to the information contained in stock prices. A fundamental objective of governance research in accounting is to provide evidence on the extent to which information provided by financial accounting systems mitigate agency problems due to the separation of managers and outside investors, facilitating the efficient flow of scarce human and financial capital to promising investment opportunities. We believe that governance research is important for developing a complete understanding of the impact of financial accounting information on the allocation and utilization of resources in an economy.

The largest body of governance research in accounting concerns the role of financial accounting information in managerial incentive contracts. The heavy emphasis on managerial compensation derives from the widespread use of compensation contracts in publicly traded U.S. corporations, the availability of top executive compensation data in the U.S. as a result of existing disclosure requirements, and the success of principal-agent models in supplying testable predictions of the relations between available performance measures and optimal compensation contracts.

In Section 2, we review and critique the existing compensation literature in accounting, including the literature examining the role of accounting information in determining managerial turnover. Our discussion develops the theoretical framework underlying much of this work and evaluates existing empirical evidence. We also provide an historical overview to trace the economic roots of compensation research in accounting, discuss empirical 
research concerning the prevalence and trends in the use of financial accounting numbers in managerial compensation plans, and offer suggestions for future compensation research.

While Section 2 focuses on one particular control mechanism, managerial compensation plans, researchers also have examined the role of accounting information in the operation of other governance mechanisms. Examples include takeovers (Palepu, 1986), proxy contests (DeAngelo, 1988), boards of directors (Dechow et al., 1996; Beasley, 1996), shareholder litigation (Kellogg, 1984; Francis et al., 1994; Skinner, 1994), debt contracts (Smith and Warner, 1979; Leftwich, 1981; Press and Weintrop, 1990; Sweeney, 1994), and the audit function (Feltham et al., 1991; DeFond and Subramanyam, 1998). ${ }^{1}$ A detailed review of this extended literature is beyond the scope of this paper. However, in Section 3, we provide examples of such research and suggest ideas for direct extensions. These suggestions include a more comprehensive investigation of the use of financial accounting information in a variety of control mechanisms, the consideration of interactions among control mechanisms, and the impact of limitations of financial accounting information on the structure of control mechanisms.

The research discussed in Sections 2 and 3 suggests that the governance use of financial accounting information likely affects the allocation and utilization of resources in an economy. In Section 4, we propose empirical research to investigate more directly the effects of financial accounting information on economic performance, with an emphasis on the governance effects of accounting.

We begin Section 4 by discussing three channels through which financial accounting information can affect the investments, productivity, and value added of firms. The first channel involves the use of financial accounting information to identify good versus bad projects by managers and investors (project identification). ${ }^{2}$ The second channel is the use of financial accounting information in corporate control mechanisms that discipline managers to direct resources toward projects identified as good and away from projects identified as bad (governance channel). The third channel is the use of financial accounting information to reduce information asymmetries among investors (adverse selection).

The research proposed in Section 4 concerns four issues. The first issue is the aggregate economic effects of financial accounting information through

\footnotetext{
${ }^{1}$ We thank Richard Sloan for supplying these citations and for encouraging us to include them in our review.

${ }^{2}$ The use of financial accounting information for the identification of good versus bad projects is broader than just identifying good and bad opportunities for investing financial capital. It also includes the identification of opportunities for increasing the productivity of assets in place, and the identification of good versus bad opportunities for current and potential managers and other employees to invest their human capital. Hence, the first channel is a means through which financial accounting information can enhance the allocation and utilization of both financial and human capital.
} 
all three channels. The second issue is the economic effects of financial accounting information specifically through the governance channel. The third issue is how the economic effects of financial accounting information through all channels, and through the governance channel alone, vary with other factors, including the auditing regime, communication networks, financial analyst following, relative importance of financing from capital markets relative to banks, legal environment and other corporate control mechanisms, the concentration of production within versus across firms, political influence over business activities, and human capital. The fourth issue is how the economic effects of financial accounting data through the governance channel, and in total, vary with specific properties of financial accounting systems.

Cross-country designs represent a powerful setting for investigating the four issues proposed in Section 4 because of significant cross-country differences in both financial accounting regimes and economic performance. In addition, vast cross-country differences in the legal protection of investors' rights, communication networks, and other institutional characteristics enable researchers to explore how the economic effects of financial accounting information vary with other factors.

Recent research in economics has laid important groundwork for the research proposed in Section 4. Economic and finance theories linking information, financial development, and economic growth motivate investigation of the relation between financial accounting information and economic performance. And recent empirical research in economics and finance has developed designs and databases for testing the cross-country relation between a variety of institutional characteristics and economic performance.

Furthermore, this emerging literature in economics and finance has generated new evidence that the protection of investors against expropriation by corporate insiders is an important economic issue. La Porta et al. (1997, 1998) document substantial cross-country differences in the protection of investors against expropriation by insiders from laws and their enforcement. Beginning with these influential papers, there has been a surge of empirical research concerning the economic effects of the differential legal protection of investors' rights from country to country. ${ }^{3}$ Collectively, this research

\footnotetext{
${ }^{3}$ These papers document that at least some aspect of a country's legal protection of investors' rights is related to, among other things, economic growth (e.g. Rajan and Zingales, 1998a; Carlin and Mayer, 2000; Demirguc-Kunt and Maksimovic, 1998), level of corporate investments in physical capital and R\&D (Carlin and Mayer, 2000), allocation of corporate funds to the highest valued investments (e.g. Wurgler, 2000), dividend policies (e.g. La Porta et al., 2000), firm valuation and the ratio of stock prices to cash flows and book value (La Porta et al., 1999b; Lombardo and Pagano, 1999), beta-adjusted stock returns (Lombardo and Pagano, 1999), the amount of firmspecific information impounded in stock prices (Morck et al., 2000), cross-listings and home country equity offerings (Reese and Weisbach, 2000), and IPO underpricing (Lombardo and Pagano, 1999).
} 
documents a significant relation between a country's protection of investors against expropriation by corporate insiders and the domestic development and efficiency of financial markets, costs of external capital, and economic growth and efficiency. Such evidence supports the La Porta et al. (1997, 1998) view that the protection of investors against expropriation by insiders has important economic effects. Together this evidence, along with new evidence of a positive relation between financial accounting information and economic performance (Rajan and Zingales, 1998a; Carlin and Mayer, 2000), suggest that the governance role of financial accounting information is likely to generate firstorder economic effects.

We expect the research proposed in Section 4 to generate new evidence on the significance of the economic effects of financial accounting information from all sources, and from the governance role of financial accounting information specifically. We also expect the proposed research to identify institutional factors that influence the total economic effects of financial accounting information, as well as the factors that influence the economic effects of financial accounting information through its governance role. Finally, we expect the proposed research to generate new evidence on the properties of high- versus low-quality financial accounting systems from the standpoint of the total economic effects, and from the standpoint of the economic effects of financial accounting information through the governance function.

In Section 5, we describe the relation between governance research and other economic-based research in accounting. We argue that future research on the connection between the governance use and capital markets use of financial accounting information is important for developing a more complete understanding of the effects of financial accounting information on economic performance, and make suggestions for exploring this connection. In Section 5, we also make further suggestions for future capital markets research that naturally emerge from our consideration of the channels through which financial accounting information affects the economy, and from consideration of the potential interactions between financial accounting regimes and other institutional characteristics.

In Section 6, we provide a summary, and an important caveat to help put our suggestions for future research in perspective. As we indicate there, we do not intend that our suggestions for future research be viewed as complete in terms of either the hypotheses or empirical designs that can be used to investigate the governance role of financial accounting information. Nor are we certain that our suggestions will stand up to scrutiny. Our hope is that our suggestions will stimulate other accounting researchers to reflect on new possibilities for testing the efficiency effects of financial accounting information. 


\section{Accounting information and managerial incentive contracts}

This section contains our review and critique of existing research on managerial incentive contracts and accounting information. Much of the empirical research in this area focuses on the cash compensation (annual salary plus bonus) of top executives (most often CEOs) of public firms in the United States. This literature is at a mature stage of development, with the same basic compensation data set underlying many of the studies. Further progress will require creativity and a broader perspective to isolate research designs that significantly advance our understanding. In addition to the literature on top U.S. executives, there are developing literatures focused on compensation of business-unit managers within the hierarchies of large firms and of top executives of non-U.S. firms. These developing literatures hold significant promise, although data availability will continue to represent a fundamental constraint on progress here. In what follows, we develop the theoretical framework underlying much of this research, provide a general discussion of empirical design and econometric issues, and review and analyze existing research studies. Our objective is to analyze critically what has been accomplished in order to set the stage for further advancement.

Before turning to our main discussion, we first offer some broad impressions of the existing literature. Overall, this literature has produced a rich portrait of executive compensation contracts. It documents that financial accounting measures, especially measures of profitability, are extensively used in executive compensation contracts. There is evidence of widespread, explicit use of profitability measures in the annual bonus plans and in the long-term performance plans of corporate executives. The implicit use of profitability measures in the board of director's evaluation and compensation of top officers is supported by a robust, positive statistical relation between profitability measures and various measures of executive pay, including managerial turnover probabilities.

The literature also documents important trends in the use of accounting numbers in top executive compensation contracts in the U.S. There is statistical evidence that over the last three decades, accounting profitability measures have become relatively less important in determining cash compensation of top executives, as these plans have shifted toward the use of alternative performance measures. In addition, cash compensation itself appears to have become a less important component of the overall pay-performance sensitivities of top executives. Evidence shows that in recent years, the total sensitivity of executive wealth to changes in shareholder wealth has become dominated by executives' stock and stock option portfolios, as opposed to cash compensation or other components of executives' pay packages. The sensitivity deriving from cash compensation is generally swamped by that deriving from stock and stock option portfolios. The reasons for these shifts in compensation 
plan design are not well understood. There is clearly a challenge here for accounting researchers to understand this decline in the "market share" of accounting information in top executive compensation, including an understanding of cross-sectional differences in the declining importance of cash compensation. It is also the case that future compensation research focused on the role of accounting information in the cash compensation of top U.S. executives must be prepared to defend its relevance in the face of this decline in market share.

Finally, a substantial theory-based empirical literature investigates implications of the tradeoff between risk and incentives derived from standard principal-agent models. A primary implication of this theory is that contracts should substitute away from accounting numbers as the "noise" in accounting measures relative to the noise in alternative performance measures increases. Overall, the evidence on this issue is mixed: some studies find evidence of a shift, others do not. The mixed nature of these results is consistent with similar findings in the economics literature (see the discussions in Prendergast, 1999a). This suggests the possibility that empirical proxies used are not capturing the true noise construct, or that the classical principal-agent model, with its emphasis on risk-incentive trade-offs, does not fully capture the contracting environments under study. Beyond these mixed noise results, the literature reveals systematic patterns on when and where accounting numbers have relatively more or less contracting value. For example, there is evidence that firms substitute away from accounting earnings towards alternative performance measures as firms' growth opportunities increase, that the incentive weight on earnings increases with the intensity with which earnings are impounded into stock price, and that boards of directors distinguish among components of earnings in determining annual bonuses.

Before proceeding, it is important to note that this paper does not offer a complete overview of research into incentive compensation. Research into incentive compensation is vast and spans a number of disciplines including economics, finance, sociology, and psychology. For the interested reader, there are a number of excellent recent reviews of the broader economics literature. For example, Rosen (1992) and Prendergast (1999a) discuss the broad sweep of theoretical structures developed in economics to explain incentives in firms (e.g., sorting models, incentive compensation contracts, tournament theory, subjective performance evaluation, career concerns, etc.) and evaluate the empirical evidence brought to bear on the validity of these theories. Gibbons (1998) evaluates four strands of agency theory research: static models of objective performance measurement; repeated models of subjective performance assessments; incentives for skill development; and incentive contracts between versus within organizations. Murphy (1999b) introduces and surveys research on executive compensation, including a vast array of statistical information drawn from publicly available sources and survey instruments. 
Pavlik et al. (1993) usefully catalogue the empirical executive compensation literature. Finally, Indjejikian (1999) provides a discussion of the compensation literature from a managerial accounting perspective. We complement these existing papers by providing an evaluation of economics-based compensation research directly concerning accounting issues.

\subsection{Historical perspective on executive compensation research}

A substantial literature examines the use of accounting information in incentive compensation contracts. Much of this work relies on economic theory, and is best understood in the context of the broad sweep of economic research on executive compensation. The roots of corporate governance research can be traced back to at least Berle and Means (1932), who argued that management ownership in large firms is insufficient to create managerial incentives for value maximization. Given the widespread existence of firms characterized by the separation of control over capital from ownership of capital, corporate governance research has focused on understanding the mechanisms that mitigate agency problems and support this form of economic organization. Scholars have isolated a number of pure market forces that discipline managerial behavior. These include product market competition (Alchian, 1950; Stigler, 1958), the market for corporate control (Manne, 1965), and labor market pressure (Fama, 1980). However, despite these market forces, there evidently remains a residual demand for additional governance mechanisms that can be tailored to the specific circumstances of individual firms. This demand is documented in the large body of economics research examining boards of directors, compensation contracts, concentrated ownership, debt contracts, and the role of securities law in disciplining managers to act in the interests of capital suppliers (see Shleifer and Vishny (1997) for an insightful review of this literature). A separate compensation literature has evolved as a branch of governance research.

The early compensation literature addresses the structure and level of compensation, with some focus on the nature of the firms' objective function (Marris, 1963; Williamson, 1964; Baumol, 1967). These early papers empirically examine whether the level of executive pay responds more to the profitability of the firm (posited as the shareholders' objective) or sales (where size was assumed to be the opportunistic objective of managers). These studies use a variety of specifications and produce a wide range of results: some find that cross-sectional variation in compensation is more related to firm size than earnings, while others find that profits matter more, and still others that both matter. Rosen (1992) points out conceptual and econometric difficulties in drawing powerful inferences from this line of research. In particular, he notes that this work is plagued by multi-collinearity and serious interpretation problems (e.g., if larger firms are led by managers with larger marginal 
products, then a correlation between size and pay will not necessarily imply opportunistic behavior). An empirical regularity documented in this literature is that the elasticity of annual cash compensation with respect to sales is in the $0.2-0.3$ range. This result appears to be relatively uniform across firms, industries, countries and periods of time (see the discussion in Rosen, 1992). More recently, Holthausen et al. (1995a) found that the compensation levels of business unit managers at large U.S. companies also exhibit a positive elasticity of approximately 0.30 with the size of the business unit.

More recent compensation research evolved concurrently with significant developments in the information economics literature, and in particular the principal-agent model. Principal-agent theory formally models issues of performance measurement in an optimal contracting framework under conditions of asymmetric information (Ross, 1973; Mirrlees, 1976; Harris and Raviv, 1979; Holmstrom, 1979). Classical principal-agent models study the trade-off between risk sharing and incentives in the optimal design of compensation contracts. This theory has inspired an empirical literature that focuses on establishing the economic determinants of observed incentive contracts. The availability of compensation data on top U.S. executives driven by SEC reporting requirements elevates executive compensation as a key laboratory for examining implications of the theory.

Given the theory's strong prediction that executive compensation should be based on firm performance, some studies address econometric concerns with the earlier work, and convincingly establish an empirical relation between pay and performance (e.g., Murphy, 1985; Coughlin and Schmidt, 1985; Benston, 1985). More recent research focuses on the magnitude of pay-performance sensitivities. For example, Jensen and Murphy (1990) directly estimate the sensitivity of dollar changes in top executive pay in the U.S. to dollar changes in shareholder wealth. Using a comprehensive measure of top executive pay (cash compensation, salary revisions, outstanding stock options, stock ownership and performance-related dismissals) they estimate that executive pay changes by roughly $\$ 3.25$ for every $\$ 1000$ change in shareholder wealth, and argue that this is too low to provide adequate managerial incentives. However, as their critics note, it is difficult to evaluate the level of pay-performance sensitivity without considering the underlying, economic determinants of sensitivity.

In response to Jensen and Murphy, Haubrich (1994) demonstrates that the documented pay-performance sensitivities can be optimal for large firms, given sufficient managerial risk aversion. Hall and Leibman (1998) expand compensation to include changes in the value of executives' stock and option portfolio, and show through simulations that estimated pay-performance sensitivities impose substantial lifetime consumption risk on executives.

Baker and Hall (1998) enter this debate by asking: what is the appropriate measure of incentives for top executives? They question whether 
pay-performance sensitivity as estimated by Jensen and Murphy (1990) is the proper measure of the strength of executives' incentives, as it does not consider the executive's marginal product of effort. That is, small estimated payperformance sensitivities do not necessarily imply low incentives for executives at large firms, as the marginal product of managerial effort can increase with firm size. An executive's actual incentives are theoretically measured by the Jensen and Murphy pay-performance sensitivity times the executive's marginal product of effort. They document that the Jensen and Murphy payperformance sensitivity measure (dollar change in executive wealth per dollar change in shareholder wealth) is strictly decreasing in firm size (see also Schaefer, 1998), while an alternative incentive intensity measure, the value of the executive's equity stake, increases in firm size by roughly the same magnitude. They argue that the validity of either as a measure of overall incentives depends on underlying assumptions about the elasticity of the executive's marginal product of effort with respect to firm size (i.e., Jensen and Murphy assume that marginal productivity is invariant to firm size (elasticity=zero), while the value of equity stakes assumes that marginal productivity scales proportionally with size (elasticity=one)). They estimate the true elasticity in their sample to be somewhere in between these extremes (0.4), which they interpret as implying that executives perform a variety of tasks that scale with size in different degrees. ${ }^{4}$ They argue that smaller payperformance sensitivities for large firms are substantially offset by larger marginal products of effort. This paper adds insight into distinguishing between pay-performance sensitivity and pay-effort sensitivity (incentive intensity).

The debate surrounding Jensen and Murphy (1990), and the Haubrich (1994), Hall and Leibman (1998) and Baker and Hall (1998) follow-ups, illustrate the difficulties involved in evaluating agency theory by examining the average size of estimated incentive coefficients. A more powerful approach examines comparative static predictions from formal principal-agent models. The trade-off between risk sharing and incentive provision in optimal contract design which lies at the heart of these models, implies a number of basic comparative static results that provide a basis for investigating the crosssectional determinants of incentive contracts. The basic agency model predicts that ceteris paribus, pay-performance sensitivity should decrease in the variance of noise in the performance measure. Using a variety of measures for compensation and performance, Aggarawal and Samwick (1999a) extend

\footnotetext{
${ }^{4}$ An example of a decision that does not scale with size is the purchase of corporate jet. That is, a CEO with a $1 \%$ claim on the firm's wealth can buy the jet at a $99 \%$ discount regardless of firm size. An example of a decision that does scale with size is a firm-wide strategic activity. That is, the wealth impact of strategic planning activities is likely to be greater at large firms than small ones (see Rosen (1992) for a discussion of this "chain letter" or "superstar" effect).
} 
Jensen and Murphy (1990) and document a robust, inverse relation between pay-performance sensitivity and the variance of the performance measure (see also Garen, 1994). They show that ignoring cross-sectional variation in the variance of performance biases the estimate of pay-performance sensitivity towards zero. Incorporating variance, their estimates of pay-performance sensitivities are substantially larger than those of Jensen and Murphy (1990), who ignore variance (and significantly larger than those estimated with their own data when variance is ignored).

Much of the empirical compensation research in accounting is at least implicitly inspired by comparative static predictions from principal-agent models. Accounting research on incentive compensation can be roughly organized around three distinct approaches. The first, and most prevalent approach, cross-sectionally examines principal-agent inspired predictions using observed or statistically estimated pay-performance sensitivities. The second approach does not directly address the optimality of observed contracts, but rather takes the contract as exogenous and examines earnings management behavior motivated by the contract structure. The third approach examines the impact of the adoption of accounting-based incentive plans on firm performance.

The first approach relies primarily on implications of the "informativeness principle" attributed to Holmstrom (1979). This principle (intuitively) states that any (costless) performance measure which is marginally informative about a manager's actions, given other available performance measures, should be included in the contract. However, this statement gives little direct guidance on which performance measures we should expect to observe in actual contracts. In essence, the study of accounting's role in contracting is driven by the prevalence of its use in actual contracts, not by the theory. While several recent papers attempt to explain explicit performance measure choice in contracts, most accounting research posits a set of performance measures without knowing the actual performance measures being used, and then proceeds to study the estimated incentive weights on the posited variables. This raises issues related to measurement error and omitted variables. Despite limitations in the approach, this research overall has documented robust patterns in the data consistent with the theory, which we discuss in detail below. This research also allows a deeper understanding of accounting numbers themselves by isolating determinants of the use of accounting numbers in incentive contracting. In our discussion below, we develop the theoretical framework underlying this work, highlight its main predictions, and evaluate the basic research findings in the context of the formal model.

The second approach flows from the "positive accounting theory" literature (Watts and Zimmerman, 1986; Watts, 1977). A main objective of this literature is to develop an empirically testable theory of accounting policy choice based on the value of accounting numbers in formal contracting arrangements 
(e.g., debt contracts, compensation contracts). A subset of papers in this literature treat compensation contracts as exogenous, and examine implications of the contract form for the earnings management behavior of managers. These studies play off observed nonlinearities in annual bonus plans, in particular, the existence of lower thresholds and upper limits on bonus payments. ${ }^{5}$ The focus is on isolating the existence of earnings management, while remaining silent on contract design issues and other efficiency issues relating to observed earnings management. This literature is cited in the economics literature as evidence of dysfunctional response to compensation schemes (e.g., Prendergast, 1999a; Abowd and Kaplan, 1999).

However, while isolating the existence of earnings management behavior adds to our knowledge of contracting related behavior, this research begs the question of why these contracts and earnings management behavior exist in the first place. Most of these studies use data from the largest, most sophisticated firms in the world. Are the observed contracts at these firms nonoptimal? Is the observed earnings management dysfunctional behavior? After all, any incentives for earnings management could be mitigated by offering flat wage contracts, rather than the observed nonlinear bonus schemes that lie at the heart of the earnings management results. An economic answer to these questions must fully consider the equilibrium from which the empirical observations are drawn. That is, if the observed world reflects optimizing economic behavior, observed earnings management would arise endogenously in an equilibrium where the contract designer rationally anticipates earnings management possibilities and reflects them in contract design.

In fact, a recent theory literature in accounting derives equilibrium contracting demands for earnings management behavior. In general, these papers demonstrate conditions under which suppressing information reduces agency costs. Earnings management is interpreted as an information suppression mechanism. For example, information suppression can substitute for a principal's inability to commit to not fire employees (Arya et al., 1998), to not renegotiate contracts (Demski and Frimor, 1999), or to not ratchet up performance standards (Indjejikian and Nanda, 1999), while less frequent reporting of information can restrict managers' opportunistic possibilities (Gigler and Hemmer, 1998). Of course, it is possible that while earnings management reduces agency costs, information suppression can create efficiency losses on other dimensions. This is precisely the issue raised in Gjesdal (1981). The point is that empirical research following the "exogenous

\footnotetext{
${ }^{5}$ Papers investigating the incentive contract/earnings management relation are Healy (1985), Gaver and Gaver (1995), Holthausen et al. (1995b), Guidry et al. (1999), Leone and Rock (1999), and Murphy (1999b). This literature is reviewed in Watts and Zimmerman (1986, 1990), Murphy (1999b), Healy and Wahlen (1999) and Fields et al. (2001). Guidry et al. (1999) present a detailed comparison of empirical designs adopted in this literature. As a result, we do not review the earnings management literature in this paper.
} 
contract" approach can only document existence of earnings management, while leaving issues of economic efficiency unaddressed.

Finally, a third approach taken in the literature focuses on the adoption of specific compensation plan features, and examines the impact of adoption on firms' resource allocation decisions and performance. This is a relatively small literature. Larcker (1983) finds that firms adopting performance plans exhibit (relative to nonadopters) significant growth in capital expenditures and a favorable security price reaction to the announcement of plan adoption. Wallace (1997) and Hogan and Lewis (1999) focus on the adoption of residual income performance measures. Wallace (1997) finds that relative to a control sample, residual income plan adopters decreased new investment and increased asset dispositions, increased share repurchases, and increased asset turnover (ratio of sales to assets). While these changes are consistent with reduced agency costs from the incentive use of residual income measures, they can also be associated with sub-optimal decisions (i.e., reducing investment in positive NPV projects to avoid the capital charge). Hogan and Lewis (1999) also document significant improvements in operating performance following residual income plan adoption. However, a matched sample of nonadopters realizes similar changes in operating and stock price performance during the same period. They conclude that residual income-based plans are no better than traditional plans that combine earnings bonuses and equity stakes in the firm.

While establishing how changes in compensation plans drive changes in real decisions is an important research objective, the research approach used in the three studies just discussed has serious problems. As discussed in Larcker (1983) and Hogan and Lewis (1999), it is difficult to attribute changes in observed decisions to incentive effects of the plan change. The change in the incentive plan and the change in corporate decisions could both simply reflect an underlying change in the firm's strategy, and controlling for these other changes is difficult due to data limitations. ${ }^{6}$ This point goes to the issue of the optimality of observed contracts. If the observed world reflects optimal contracts at all times, a change in contract must reflect some change in the underlying environment. In this case, this research approach cannot speak to the inherent superiority of the contract feature chosen, as the research is just documenting the optimal matching of contracts to environments. Authors that want to argue from their results to the inherent superiority of particular contract features have the burden of explaining why these superior features have not already been chosen.

\footnotetext{
${ }^{6}$ Lazear (1999a) and Ichniowski et al. (1997) are illustrative of the care that needs to be taken to convincingly rule out correlated omitted variables using this research approach.
} 


\subsection{Prevalence of financial accounting numbers in managerial contracts}

Empirical designs in this literature typically follow either an explicit contract or implicit contract approach. In the explicit approach, the researcher has detailed information on actual performance measures used and potentially other contract terms. In the implicit contract approach, the researcher does not know the details of actual contracts and has no data on the actual performance measures used in the contract. Instead, a set of performance measures is chosen by the researcher, and the contract to be studied is estimated by regressing a compensation variable on the posited measures. We discuss next the evidence documented by these two approaches on the use of accounting numbers in executive compensation. While most of the evidence relates to top executives of U.S. public companies, we also document the use of accounting numbers in the compensation of top executives in Japan and Germany, division managers at U.S. public companies, and in financing contracts written between venture capital firms and entrepreneurs.

\subsubsection{Explicit contracts}

The extensive and explicit use of accounting numbers in top executive compensation plans at publicly traded firms in the U.S. is well documented. Murphy (1998) reports data from a survey conducted by Towers Perrin in 1996-1997. The survey contains detailed information on the annual bonus plans for 177 publicly traded U.S. companies. Murphy reports that 161 of the 177 sample firms explicitly use at least one measure of accounting profits in their annual bonus plans. Of the 68 companies in the survey that use a single performance measure in their annual bonus plan, 65 use a measure of accounting profits. While the accounting measure used is often the dollar value of profits, Murphy also reports common use of profits on a per-share basis, as a margin, return, or expressed as a growth rate. Ittner et al. (1997), using proxy statements and proprietary survey data, collect detailed performance measure information for the annual bonus plans of 317 U.S. firms for the 1993-1994 time period. The firms are drawn from 48 different two-digit SIC codes. Ittner et al. document that 312 of the 317 firms report using at least one financial measure in their annual plans. Earnings per share, net income and operating income are the most common financial measure, each being used by more than a quarter of the sample. They also report the weight placed on financial measures in determining the bonus payout. The mean percentage of annual bonus based on financial performance is $86.6 \%$ across the whole sample, and $62.9 \%$ for the 114 firms that put nonzero weight on nonfinancial measures. Murphy (1999b) and Ittner et al. (1997) find no evidence that stock price information is explicitly used in annual bonus plans. 
There is also evidence that a number of publicly traded firms have adopted residual income-based incentive plans. Wallace (1997) and Hogan and Lewis (1999) together are able to document adoption of these plans by about 60 publicly traded companies. Finally, several papers document the use of accounting information in incentive contracts at the business unit level. Vancil (1978) reports that the annual bonus plans of 90 percent of the 317 profit-center managers in his survey depend on accounting performance of the division. Bushman et al. (1995) document that approximately $50 \%$ of the annual bonus payout for group and division-level CEOs at large U.S. public companies is determined by the subunit's own-level performance. Keating (1997), using survey data on 78 division managers from 78 U.S. public companies, documents significant use of division-level and company-wide performance measures in evaluating the performance of division managers. He also documents that the compensation contracts of business unit managers depends significantly more on accounting measures than stock price (see also Guidry et al. (1999) for a similar finding for a single firm).

Recent evidence also documents the explicit use of accounting numbers in contracts between pre-IPO entrepreneurs and venture capital firms. Kaplan and Stromberg (1999) study detailed data on 201 venture capital investments in 118 portfolio companies by 14 venture capital firms. They provide data on many intricate aspects of these contracting arrangements. Kaplan and Stromberg show that allocations of cash flow rights and control rights along with the mechanism by which they are allocated, are also key elements in these venture capital financing deals. ${ }^{7}$ Most interesting for purposes of our paper, is that the Kaplan and Stromberg data reveal that the allocation of both control and cash flow rights plays out over multiple rounds of financing, and that the allocation of control rights can be contingent on observable measures of financial and nonfinancial performance, as well as being contingent on certain observable actions taken by the entrepreneur (e.g., hiring new executives, developing new facilities) or the sale of securities. The financial measures appear to be comprised of standard measures from the financial accounting

\footnotetext{
${ }^{7}$ These control rights include voting rights, board seats and liquidation rights. Note that the standard principal-agent approach deriving from Holmstrom (1979) focuses on the provision of monetary incentives or cash flow rights to the manager. However, a recent theory literature studies the optimal allocations of both cash flow rights and control rights contingent on measures of performance, where control rights determine who chooses the actions the firm will take. Kaplan and Stromberg argue that the complex process of control rights allocations observed in their data are most broadly consistent with control models of security design in incomplete contracting settings (e.g., Aghion and Bolton, 1992; Dewatripont and Tirole, 1994). They note, however, that no existing theories explain the multi-dimensional nature of the observed control rights allocations (voting rights, board rights, liquidation rights), nor the complexity with which these different control rights shift from $\mathrm{VC}$ to entrepreneur at different levels of performance.
} 
system including earnings before interest and taxes, operating profits, net worth and revenues. For example, observed contingencies include: the venture capitalist (VC) can only vote for all owned shares if realized earnings before interest and taxes fall below a threshold value, in which case the VC gets voting control; if net worth falls below a threshold, VC gets 3 more board seats; employee shares vest if revenue goals are achieved; and VC warrants expire if revenue goals achieved. The first two examples indicate that VCs write contracts in which control rights are contingent on output independently of cash flow rights. They document that roughly $20 \%$ of the individual venture capital investments in their sample include contract provisions that are contingent on subsequent financial performance, and $12 \%$ contingent on subsequent nonfinancial performance. They also find that the nature of contingencies differ depending on whether the financing is startup stage or later stage financing.

Finally, even with explicit contracts, care must be taken in approaching cross-sectional research designs. This point is illustrated by Hemmer (1996) in the context of customer satisfaction measures. Hemmer considers contracts based on two performance measures, an accounting measure and a customer satisfaction measure. He then considers two different mechanical constructions of the satisfaction measure. He shows that these differently constructed satisfaction measures lead to radically different optimal contracts, although both contracts lead to the same expected payoffs to the principal. The point is that simple mechanical differences in performance measure construction can lead to large cross-sectional differences in observed contracts.

\subsubsection{Implicit contract approach}

Additional evidence on the use of accounting information in determining the incentive compensation of top executives in publicly traded U.S. firms is provided by numerous studies that regress measures of executive pay on measures of performance to estimate the sensitivity of pay to performance measures. In these studies, the actual performance measures used in the compensation plan are unknown, forcing the researcher to guess at the appropriate measures and to assume identical measures across all firms in the pooled sample. This creates potential for serious errors in variables problems. This also creates potential for omitted variables problems. As formally demonstrated in Demski and Sappington (1999), omitted performance measures can cause significant inference problems due to interactions between measures in the optimal contracts. For example, assume the true contract uses two performance measures, but the researcher omits the second measure from the design. Then the incentive coefficient on the included measure may be significantly influenced by properties of the omitted measure, and these properties can vary cross-sectionally. Most compensation studies in accounting include both accounting-based and stock price-based performance measures in 
incentive coefficient estimations, and thus partially deal with the omitted variables problem. ${ }^{8}$ Focusing on CEO cash compensation, Natarajan (1996) and Bushman et al. (2001) find that inferences regarding the determinants of incentive weights placed on accounting measures are largely invariant to the inclusion of stock price information in the coefficient estimation.

Care also must be taken in cross-sectional estimations as it is well known that contract coefficients can vary dramatically across firms (firm fixed effects (Murphy, 1985), industry variation (Ely, 1991), firm size (Baker and Hall, 1999; Schaefer, 1998), and stock price variance Aggrawal and Samwick, 1999a). This problem has been addressed by estimating coefficients using firm-specific timeseries regressions (e.g., Lambert and Larcker, 1987), pooled, industry time series, and cross-sectional estimation with industry slope interactions (e.g., Bushman et al., 1998, 2001). However, pooling observations over time implicitly assumes that the pay-performance relation is stable over time. Furthermore, Dechow et al. (1994) caution that firm-specific time-series regressions of compensation on earnings using OLS can result in serially correlated residuals (see Gaver and Gaver (1998) for a discussion of econometric responses to this issue).

The use of linear regression also poses potential misspecification problems in the implicit contract approach. It is well documented that compensation plans often exhibit substantial nonlinearities. For example, annual bonus plans often contain lower thresholds and upper bounds (e.g., Healy, 1985; Holthausen et al., 1995b; Murphy, 1999b) and executive stock options are convex with respect to stock price. While many studies uses log compensation or change in log compensation in the coefficient estimation (see Murphy (1999b) for a discussion of common specifications), it is not clear that this completely resolves the shape issue.

Despite these potential problems with the implicit approach, the result that earnings variables load positively and significantly appears robust to specifications and samples. Most studies focus on cash compensation (salary plus bonus) due to data limitations. It is common for these studies to posit two performance measures, one based on earnings and the other on stock price, although some use components of earnings as the measures. Contract parameters are estimated using time series by firm, cross-sectional designs, and pooled cross-section time-series designs. This implies that many

\footnotetext{
${ }^{8}$ The story works as follows. We know from explicit contracts that accounting measures are extensively used in bonus plans, while stock prices are not. It is also the case that efficient markets imply that stock price impounds all available information. Thus, the inclusion of an accounting variable is justified on explicit contract grounds, and stock price measures can be viewed as a proxy for other available performance measures. Of course, this implies that incentive coefficients estimated for stock returns only capture the omitted variables to the extent they are correlated with price, and these correlation likely differ cross-sectionally. It is also the case that this design cannot compensate for the fact that the board of directors may base compensation on private, proprietary information signals not yet impounded in price. See also the discussion in Baker (1987).
} 
estimations capture both bonus payout variation and salary revisions in the dependent variable. While formal bonus plans often explicitly incorporate some variant of accounting information in the contract (although the precise variant is unknown and can vary across firms or within the same firm over time), little is known about the determinants of salary revisions of top executives. Thus, contract parameter estimates embed both explicit and implicit aspects of the contracts. We present next a sampling of the implicit designs used mainly to illustrate the robustness of the accounting-cash compensation connection.

Jensen and Murphy (1990), using the Forbes Executive Compensation Surveys from 1974 through 1986 and pooling all firms together, regress changes in CEO salary plus bonus on changes in shareholder wealth and changes in accounting profits (before extraordinary items). They find that both the earnings and shareholder wealth variables load positively and significantly in the regression, that the implied pay-performance sensitivity for accounting profits is roughly comparable to the pay-performance sensitivity for shareholder wealth changes, and that changes in accounting earnings add significant explanatory power over and above changes in shareholder wealth. Many papers in the accounting literature also use the Forbes data. Example specifications using Forbes data include Lambert and Larcker (1987), who run firm-specific regressions of change in salary plus bonus on stock returns and change in accounting return on equity; Natarajan (1996) and Gaver and Gaver (1998), who run firm-specific regressions of the level of salary plus bonus on the level of earnings and working capital from operations (Natarajan) and the level of earnings disaggregated into components to isolate nonrecurring items (Gaver and Gaver); and Bushman et al. (1998, 2001) who run time-series industry-specific regressions of percentage change in salary and bonus on changes in earnings scaled by beginning market value and on stock returns. ${ }^{9}$

It also has been documented that poor earnings performance appears to increase the probability of executive turnover. Studies that find an inverse relation between accounting performance and CEO turnover include Weisbach (1988), Murphy and Zimmerman (1993), Lehn and Makhija (1997) and DeFond and Park (1999), while Blackwell et al. (1994) document a similar relation for subsidiary bank managers within multi-bank holding companies. ${ }^{10}$

\footnotetext{
${ }^{9}$ For other papers documenting the use of accounting measures using Forbes data see also Sloan (1993), Healy et al. (1987), DeFeo et al. (1989), Dechow et al. (1994), and using other compensation data sources see Baber et al. (1996), Clinch (1991), and Antle and Smith (1986).

${ }^{10}$ In contrast, Barro and Barro (1990) do not find a relation between accounting-based measures and turnover for a sample of large bank CEOs, but do find an inverse relation between stock price performance and turnover. A number of papers also examine the relation between the probability of executive turnover and stock price performance. These include Coughlin and Schmidt (1985), Warner et al. (1988), and Gibbons and Murphy (1990). See Murphy (1999b) for an extensive discussion of this literature along with additional empirical analysis.
} 
Weisbach (1988) and Murphy and Zimmerman (1993) include both accounting and stock price performance in the estimation of turnover probability. Weisbach finds that accounting performance appears to be more important than stock price performance in explaining turnover, while Murphy and Zimmerman find a significant inverse relation between both performance measures and turnover. ${ }^{11}$ Weisbach (1988) conjectures, and Hermalin and Weisbach (1998) show analytically, that reliance on accounting can be explained by the idea that stock price embeds the market's expectations of the future, including value implications of possibly hiring a new CEO, leaving earnings as a cleaner signal of the current CEO's talent than price (a related idea is found in Barclay et al., 1997).

Finally, Kaplan (1994a) using data on 119 Japanese firms and Kaplan (1994b) using data on 42 large German companies, find that turnover probabilities for both Japanese and German executives, and changes in cash compensation for top Japanese executives, are significantly related to stock price performance and earnings performance. The performance measures considered are stock returns, sales growth, changes in pre-tax earnings and an indicator variable for negative pre-tax income. Regression estimates of turnover probability in both countries indicate that stock returns and negative earnings are significant determinants of turnover, while sales growth is not. ${ }^{12}$ Regressions using changes in cash compensation of Japanese executives document a significant impact for pre-tax earnings and negative earnings, but not for stock returns and sales growth. Kaplan (1994a) also compares the regression results for Japanese executives with 146 U.S. CEOs from Fortune's 1980 list of the 500 largest industrials, and finds the relations to be very similar across countries. The main difference is that turnover probabilities for Japanese executives appear more sensitive to negative earnings than for U.S. CEOs. He notes that this relative difference in the importance of negative earnings, along with significantly lower stock ownership for Japanese executives relative to their U.S. counterparts, is suggestive of a significant monitoring role for a Japanese firm's main banks when a firm produces insufficient funds to service the bank's loans. He presents evidence consistent with this story, documenting that firms are more likely to receive new directors associated with financial institutions following negative earnings and poor stock price performance.

\footnotetext{
${ }^{11}$ Note that Kaplan (1994a) includes both stock returns and earnings performance in turnover regressions for 146 U.S. CEOs from Fortune's 1980 list of the 500 largest industrials, and finds that the earnings variables are insignificant. He conjectures that differences with these other studies may result from differences in the composition of the samples across studies. Note that there has been no work exploring where earnings information has relatively more or less importance in explaining turnover.

${ }^{12}$ See also Kang and Shivdisani (1995) for evidence that top executive turnover in Japan is related to accounting performance.
} 


\subsection{Trends in the use of accounting numbers for contracting with managers}

While the evidence documents significant use of accounting numbers in determining cash compensation, both the determinants of cash compensation and the importance of cash compensation in the overall incentive package appear to be changing over time. Bushman et al. (1998) use the Forbes data set to examine trends in the determinants of cash compensation over the 19701995 time period. They document that although the incentive coefficient on accounting earnings before special items remains basically constant over the entire time period, there is a significant average increase in the coefficient on stock returns in compensation models which include both stock returns and earnings, a significant decline in the ratio of the coefficient on earnings to the coefficient on stock returns, and a significant increase in the incremental $R^{2}$ of stock returns over and above earnings without a corresponding increase in the incremental $R^{2}$ of earnings over and above stock returns. Together, these results imply that accounting information has progressively become relatively less important in determining the cash compensation of CEOs at large U.S. public companies.

Consistent with the Bushman et al. (1998) evidence that stock returns have become relatively more important than earnings in determining cash compensation, Murphy (1999b), using all CEOs included in the S\&P 500, documents large increases in pay-performance sensitivities of cash compensation with respect to contemporaneous changes in shareholder wealth between 1970 and 1996 (similarly with respect to the elasticity of cash compensation to shareholder wealth). For example, the pay-performance sensitivity of cash compensation with respect to changes in shareholder wealth for S\&P Industrials triples from the 1970s to the 1990s. Financial services firms and utilities also show large increases. The year-to-year variation in these payperformance sensitivities also appears to be much greater in the more recent time periods.

However, not only have earnings apparently become relatively less important in determining cash compensation, the contribution of cash compensation to the overall intensity of top executive incentives appears to have diminished drastically in recent years. The shrinkage is so dramatic that a number of recent studies on top executive pay-performance sensitivity simply ignore the contribution of cash compensation as a second-order effect (e.g., Baker and Hall, 1998). Hall and Leibman (1998) describe changes in salary and bonus as being lost in the "rounding error" in measuring changes in the value of stock and options. In addition to this relative shift, the absolute level of total CEO compensation and its sensitivity to firm performance also have increased dramatically from for the early 1980s to 1994 (Hall and Leibman, 1998).

Several recent studies use the actual stock and stock option portfolios of top executives to construct explicit measures of the sensitivity of the value of these 
portfolios to changes in shareholder wealth, while the sensitivity of cash compensation and long-term incentive plan payouts is estimated by regression (Murphy, 1999b; Hall and Leibman, 1998). These measures attempt to capture the fraction of the overall change in shareholder wealth that accrues to the executive. These studies show that the overall sensitivity of compensation to shareholder wealth creation (or destruction) is dominated by changes in the value of stock and stock option holdings, and that the extent of this domination increases in recent years. For example, Murphy (1999b) estimates that for CEOs of mining and manufacturing firms in the S\&P 500 , the median percentage of total pay-performance sensitivity related to stock and stock options increases from 83\% (45\% options and 38\% stock) of total sensitivity in 1992 to $95 \%$ (64\% options and 31\% stock) in 1996. Similar trends are shown to hold for other S\&P 500 companies as well. This trend is driven by the explosion in stock option grants in recent years. The data in Hall and Leibman (1998), which are carefully constructed from a time series of proxy statements and other sources, is equally dramatic. They also document small pay-performance contributions from cash compensation, and document that the large increase in stock option awards and stock holdings of CEOs has resulted in a doubling of pay-performance sensitivities since 1980 .

Overall, this research implies that cash compensation and long-term performance plans currently appear to contribute only marginally to overall pay-performance sensitivity. However, the aggregate statistics reported likely bury significant cross-sectional variation that has not been explored.

We end this section by noting that the underlying causes of the large shift towards option awards are still open to question. Can the cross-sectional and across time differences in the option granting strategies of firms be explained in terms of optimal contracting theory? There appears to be considerable debate on this topic. Yermack (1995) and Ofek and Yermack (1997) suggest that firms basically grant options randomly, while Yermack (1997), Core and Guay (1998) and Hall and Leibman (1998) suggest that options are controlled opportunistically by managers simply to increase their compensation.

For example, Yermack (1997) argues that managers opportunistically time option grants to capitalize on anticipated announcements of news to the market. However, it is the case that most options grant dates are fixed in advance by the board and not a flexible choice variable of the manager. In a follow-up study, Aboody and Kasznik (1999) argue and document that managers appear to be opportunistically timing their public disclosures around known grant dates. That is, they appear to be postponing announcements of good news and accelerating the timing of bad news. Note that this problem could be dampened by randomizing grant dates, a design that is not documented. Also, Hemmer et al. (1996) provide evidence consistent with 
option grants being used to hedge the risk imposed on CEOs. They find that increases in the value of the CEO's stock and option portfolio leads to small option grants, while decreases in the portfolio value leads to large option grants. However, Hall (1999), finds little evidence of this type of granting behavior. Finally, Abowd and Kaplan (1999) raise the question of whether the significant increase in pay-performance sensitivities documented in Hall and Leibman (1998) and Murphy (1999b) creates perverse incentives for managerial behavior. They speculate that the significant risk that large stock and option holdings place on managers encourages excessively cautious behavior.

Arguing that observed option granting is optimal, Guay (1999) provides evidence that the sensitivity of CEOs' option portfolios to changes in the variance of stock price (an estimate of the convexity of the option package) is positively related to the firms' investment opportunities, and Core and Guay (1998) suggest that option and restricted stock grants effectively provide incentives for future performance, and rewards for prior performance. Also Bryan et al. (2000) provide evidence that granting behavior is consistent with agency-based predictions. It is left to future research to sort out these opposing positions.

\subsection{Theoretical framework}

Given that the objective of shareholders is the maximization of share price, should not it follow that managerial incentives are based only on share price to align interests completely? However, evidence shows that executive incentive plan payoffs actually depend on a complex portfolio of performance measures, including accounting measures. In this section we introduce a simple analytical framework to isolate clearly the theoretical determinants underlying the inclusion of a performance measure in the contract, and the weight an included measure receives in the contract. ${ }^{13}$ The model clearly isolates three fundamental contracting roles for accounting information: directly creating incentives to take actions, filtering common noise from other performance measures (e.g., stock price), and rebalancing managerial effort across multiple activities. We will use this framework in later sections to illustrate the theoretical motivations underlying empirical research designs in accounting compensation research.

\footnotetext{
${ }^{13}$ It is not our objective here to provide a complete review and evaluation of the theoretical research on compensation. Rather, we utilize a framework that provides insight into the main influences of the theoretical literature on the design of empirical studies into the contracting role of accounting numbers. For the interested reader, there exist a number of useful reviews of the theoretical contracting literature. For example, see Baiman (1982, 1990), and Holmstrom and Hart (1987) and Lambert (2001). Also, see Salanie (1998) for a general introduction to the economics of contracting.
} 
The premise of principal-agent models is that a principal (e.g., the owner) designs a compensation contract based on observable and enforceable performance measures to align the incentives of the agent (e.g., executive) with those of the principal. The classic set-up models a risk averse agent taking unobservable actions which influence the statistical distribution over observable performance measures. These distributions are parameterized by the agent's unobservable actions, but do not perfectly reveal the actions. The unobservability of actions, in conjunction with the agent's risk aversion, results in a "second best" contract in which the principal must trade-off the desire to provide incentives against the risk premium that must be paid to the agent for bearing risk imposed by the contract. The theoretical literature has extensively examined intricacies of balancing the trade-off between incentives and risk in optimal contract design and the role of multiple performance measures in alleviating losses to the agency relationship. We will use the following simple framework to extract pertinent ideas from this large body of research.

\subsubsection{Informativeness principle; creating incentives for effort; filtering common noise}

Let the value of the firm be given by $V=v e+\varepsilon_{V}$, where $e$ is the manager's effort choice, $v$ is the marginal product of managerial effort, and $\varepsilon_{V}$ is a stochastic element of firm value that is beyond the manager's control. Assume that $\left.\varepsilon_{V} \sim \mathrm{N}\left(0, \sigma_{V}^{2}\right)\right)$ and is distributed independently of all other random variables in the model. The principal's objective is to maximize $V$ net of compensation paid to the manager. However, in many settings it is difficult to measure firm value directly. Even stock price is only the market's estimate of value, as investor expectations are limited by the extent of available information. As a result, firms often depend on contractible performance measures that imperfectly capture a manager's contribution to firm value. We assume that $V$ is not available for contracting. ${ }^{14}$ This assumption captures, for example, the dynamic nature of the problem where managers are compensated in the present, although value creation resulting from their actions is not fully realized until later periods.

\footnotetext{
${ }^{14}$ The assumption in the early agency literature (e.g., Holmstrom, 1979), that the firm's actual output is available for contracting, is no longer maintained. See Gibbons (1998) for a useful perspective on the import of dropping this assumption. Note that in the single action setting that we analyze in this section, this assumption is innocuous. However, in multi-tasking settings, which we discuss in more detail below, this assumption is quite powerful. Multi-tasking allows the possibility for agents to misallocate effort across activities and states of nature. Two influential papers addressing multi-tasking issues are Holmstrom and Milgrom (1991) and Baker (1992). These papers have spawned a large body of research including, Paul (1992), Bushman and Indjejikian (1993a, b), Bushman et al. (2000a), Feltham and Xie (1994), Hemmer (1996), and Datar et al (2000).
} 
Consider two contractible performance measures, given by

$$
P=p e+\varepsilon_{P}
$$

and

$$
A=a e+\varepsilon_{A},
$$

where $\varepsilon_{j} \sim \mathrm{N}\left(0, \sigma_{j}^{2}\right), j=A, P$. The parameters $p$ and $a$ capture the impact of effort on observable performance measures. Note that this signal structure allows both for the agent's action to impact differentially the performance measures and value, and for noise in the performance measures. One interpretation here is that $P$ represents stock price and $A$ represents accounting information. The wage contract is given by

$$
w=\beta_{0}+\beta_{P} P+\beta_{A} A
$$

and the agent's utility over wages and effort is given by

$$
U=-\exp [-r\{w-C(e)\}],
$$

where $C(e)=1 / 2 C e^{2}$ is the agent's cost of supplying effort, and $r$ measures the risk aversion of the manager. ${ }^{15}$

The unobservability of effort and risk aversion of the agent leads to a second best contract in which the principal must compromise between providing incentives and compensating the agent for bearing risk. The impact of this compromise is clearly present in the agent's choice of effort level. In this model, the agent's utility maximizing second best effort choice is $e^{S B}=\left(\beta_{P} p+\beta_{A} a\right) / C$, where first best effort is given by $e^{F B}=v / C{ }^{16}$ Note that the self-interested agent cares only about the marginal impact of effort on the contractible performance measures $\left(\beta_{P} p+\beta_{A} a\right)$, while the principal cares about the true marginal product of effort $v$. It can be shown that $\left(\beta_{P} p+\beta_{A} a\right) / C<v / C$; the

\footnotetext{
${ }^{15}$ The linear contracting framework, while suppressing important issues related to contract shape, offers the benefit of transparently reflecting the impact of important features of the economic setting on contracts. Holmstrom and Milgrom (1987) utilize a dynamic setting where agents continuously control effort and observe output, and where wealth effects are neutralized to derive the optimality of linear contracts. Of course, many observed contracts are not linear. Executives receive stock options that imply convex payoff profiles, and annual bonus plans often have lower thresholds and upper bounds on compensation (e.g., Murphy, 1999b; Holthausen et al., 1995b; Healy, 1985). Despite these limitations, the linear framework powerfully expresses many of the important themes pertinent to the literature.

${ }^{16}$ Given a contract $\left(\beta_{A}, \beta_{P}\right)$, the self-interested agent chooses effort to maximize his own expected utility, which under the assumptions of the current model is equivalent to maximizing $\beta_{0}+\beta_{A} a e+$ $\beta_{P} p e-C e^{2} / 2-r / 2 \operatorname{Var}(w)$ (the agent's certainty equivalent). Since $\operatorname{Var}(w)$ is independent of effort, maximizing the previous expression with respect to $e$ gives the expression in the text. First best effort maximizes $\mathrm{E}[V-w]$, with no additional constraints.
} 
agent underinvests relative to first best, generating an agency cost of asymmetric information.

Turning to the optimal contract, standard solution techniques lead to the second best contract:

$$
\begin{aligned}
& \beta_{A}=\frac{\operatorname{vrC}\left[a \sigma_{p}^{2}-p \operatorname{Cov}\left(\varepsilon_{A}, \varepsilon_{p}\right)\right]}{\left(a^{2}+r C \sigma_{A}^{2}\right)\left(p^{2}+r C \sigma_{P}^{2}\right)-\left(a p+r C \operatorname{Cov}\left(\varepsilon_{A}, \varepsilon_{p}\right)\right)^{2}}, \\
& \beta_{P}=\frac{\operatorname{vrC}\left[p \sigma_{A}^{2}-a \operatorname{Cov}\left(\varepsilon_{A}, \varepsilon_{p}\right)\right]}{\left(a^{2}+r C \sigma_{A}^{2}\right)\left(p^{2}+r C \sigma_{P}^{2}\right)-\left(a p+r C \operatorname{Cov}\left(\varepsilon_{A}, \varepsilon_{p}\right)\right)^{2}} .
\end{aligned}
$$

Before discussing the intuition behind the contract, it is noteworthy that the incentive coefficients in (1) depend directly on the firm-specific production function, $v$, and manager-specific parameters $r$ and $C$. However, an important issue in cross-sectional empirical compensation tests concerns the extent to which unobservable determinants of the wage contract differ across firms (Murphy, 1985; Lambert and Larcker, 1987). This concern has influenced some studies to use relative slope coefficients in an attempt to alleviate confounding effects in cross-sectional designs. To see why, note that relative slopes are given by

$$
\frac{\beta_{A}}{\beta_{P}}=\frac{\left(a-p\left[\operatorname{Cov}\left(\varepsilon_{A}, \varepsilon_{p}\right) / \sigma_{P}^{2}\right]\right)}{\left(p-a\left[\operatorname{Cov}\left(\varepsilon_{A}, \varepsilon_{p}\right) / \sigma_{A}^{2}\right]\right)} \frac{\sigma_{P}^{2}}{\sigma_{A}^{2}}
$$

and that the parameters $v, r$ and $C$ do not appear in (2). While this approach has merit, it is not without problems. Lambert and Larcker (1987) discuss potential disadvantages of using relative slopes, which include a distribution of the ratio of estimated coefficients that possesses undesirable properties, effects of scale differences among the measures, and the imposition of constraints on the signs of the individual weights in computing the ratio. In addition, the independence of the ratio from the firm and manager specific parameters has been shown to be sensitive to model specifications (e.g., Bushman and Indjejikian, 1993b; Feltham and Xie, 1994; Datar et al., 2000). ${ }^{17}$

Expression (2) illustrates a key result of the theory which underlies much of the empirical compensation research in accounting. The incentive weight on $A$ relative to that on $P$ can be described as the ratio of the "sensitivity" of each measure to managerial action, times the ratio of the precision of each measure. The general structure of the sensitivity measures are: Sensitivity $A=(\mathrm{d} E[A \mid e] / \mathrm{d} e)-\left(\operatorname{cov}(A, P) / \sigma_{P}^{2}\right)(\mathrm{d} E[P \mid e] / \mathrm{d} e), \quad$ Sensitivity

\footnotetext{
${ }^{17}$ Bushman et al. (2001) conduct cross-sectional tests using shifts between time periods in model variables to control for omitted variables under the plausible assumption that managerial attitudes toward effort and risk are stable within an industry or firm over time.
} 
$P=(\mathrm{d} E[P \mid e] / \mathrm{d} e)-\left(\operatorname{cov}(A, P) / \sigma_{A}^{2}\right)(\mathrm{d} E[A \mid e] / \mathrm{d} e) .{ }^{18}$ Note that the contract exploits the correlation structure of the performance measures through the second term of each sensitivity measure. This is the mechanism by which adding a second measure to the contract allows common noise to be filtered out in the contract. Observe that if the first term of a signal's sensitivity measure is zero, the only role played by that signal is in filtering common noise to reduce the risk imposed on the agent. In this case, managerial action has no effect on the signal, and the signal's entire contracting value derives from its correlation with the other measure. This observation is a central insight underlying the literature on relative performance evaluation, which we will discuss in some detail in Section 2.5.6.

Finally, to see clearly the basic tradeoff between incentives and risk, rewrite (2) assuming $\operatorname{cov}\left(\varepsilon_{A}, \varepsilon_{P}\right)=0$ to yield

$$
\frac{\beta_{A}}{\beta_{P}}=\frac{a \sigma_{P}^{2}}{p \sigma_{A}^{2}} .
$$

Parameters $a$ and $p$ capture the direct impact of effort on the respective signals, and the ratio of precisions captures the relative noise in each signal. Thus, ceteris paribus, the weight on $A$ increases in $a$ (the signal is more sensitive to action) and decreases in $\sigma_{A}^{2}$ (the signal is a noisier measure of action), and similarly for $P$. The signal $A$ is marginally useful in the contract given the signal $P$, because $P$ reflects effort with noise, and $a>0, \sigma_{A}^{2}<\infty$ implies that $A$ contains incremental information on effort. This is just a manifestation of Holmstrom's (1979) "Informativeness Principle”.

\subsubsection{Creating incentives to balance effort across managerial activities}

In the single task setting just developed, the signal $A$, interpreted as accounting information, can create incentives for effort and filter away common noise. But additional incentive problems can arise when managers must allocate effort across multiple activities. We next show that multi-tasking creates a wedge between stock price as the market's unbiased assessment of payoffs and the adequacy of stock price as a stand-alone performance measure. This wedge creates the possibility that accounting information can serve a valuable role in addition to stock price, by helping to balance managerial incentives across different activities.

\footnotetext{
${ }^{18}$ This result can be traced back to Banker and Datar (1989). Their study is also notable for formally distinguishing performance measure design from contract design, a distinction that is transparent in a linear contracting framework. Note that the term sensitivity as used here refers to a characteristic of a performance measure, where the expression pay-performance sensitivity as used in Jensen and Murphy (1990) and others, refers to the incentive weight placed on the measure in the contract. In this section, we will refer to the slope coefficient on a performance measure in the contract as the incentive weight or incentive coefficient, and will reserve the term sensitivity to refer to the terms in brackets in expression (2).
} 
To see this, consider an extension to a multi-action setting. Let value be given by $V=v_{1} e_{1}+v_{2} e_{2}+\varepsilon_{v_{1}}+\varepsilon_{v_{2}}$, and let stock price be given by $P=$ $p_{1} e_{1}+p_{2} e_{2}+\varepsilon_{P}$. Interpret $e_{1}$ and $e_{2}$ as two different dimensions of managerial activity across which the manager can allocate effort. For example, $e_{1}$ can represent effort expended managing projects in place, while $e_{2}$ represents strategic planning activities. Assume again that $V$ is not contractible and only $P$ is available for contracting.

The principal would like the agent to set $e_{1} / e_{2}=v_{1} / v_{2}$ to reflect the relative marginal products of each activity. However, since only $P$ is available for contracting, the manager will choose $e_{1} / e_{2}=p_{1} / p_{2}$ to maximize utility. ${ }^{19}$ The manager thus misallocates effort across activities, creating a role for additional performance measures to aid in rebalancing incentives. The misweighting of efforts in price relative to optimal contracting weights has been argued by Paul (1992) to follow directly from the price formation process, implying that this is likely to be an inherent contracting property of stock price.

To see Paul's argument, we introduce a simple model of stock price formation to show how the market's use of information to value the firm naturally leads to a market clearing price that mis-weights the individual efforts from an incentive balancing standpoint. Assume that the market observes two information signals, $x$ and $y$, and sets $P=\mathrm{E}[V \mid x, y]$. The signals $x$ and $y$ result from information collection activities of investors, and are not directly available themselves for contracting purposes. However, they can be used indirectly as they will be impounded in price through market clearing. Let $x=e_{1}+\varepsilon_{v_{1}}+\varepsilon_{x}$ and $y=e_{2}+\varepsilon_{v_{2}}+\varepsilon_{y}$, where all random variables are independently and normally distributed. ${ }^{20}$ Then $P=b+p_{1} x+p_{2} y$, with ${ }^{21}$

$$
p_{1}=\frac{\operatorname{cov}(V, x)}{\operatorname{var}(x)}=\frac{\operatorname{var}\left(\varepsilon_{v_{1}}\right)}{\operatorname{var}\left(\varepsilon_{v_{1}}\right)+\operatorname{var}\left(\varepsilon_{x}\right)}
$$

\footnotetext{
${ }^{19}$ The relation between the impact of an agent's actions on value and their impact on contractible performance measures has been termed the "congruity" of a performance measure by Feltham and Xie (1994). This fundamental limitation of performance measurement was first explicitly analyzed in Holmstrom and Milgrom (1991) and Baker (1992), where lack of congruity is shown to lead to low powered incentive contracts and to have implications for task assignment and organizational structure.

${ }^{20}$ The two noise terms were included in $V$ to allow a simple formulation of market price formulation to facilitate illustration of the Paul (1992) insights. In essence, the market observes two signals, where each signal contains one of these payoff relevant uncertainty terms. The market then uses these signals to infer the uncertainty terms for valuation purposes, which in turn drives the weight on each measure in stock price.

${ }^{21}$ These represent simple regression coefficients assuming that each error term is statistically independent of all other errors. This independence implies, for example, that $\operatorname{cov}(V, x)=\operatorname{var}\left(\varepsilon_{v 1}\right)$.
} 
and

$$
p_{2}=\frac{\operatorname{cov}(V, y)}{\operatorname{var}(y)}=\frac{\operatorname{var}\left(\varepsilon_{v_{2}}\right)}{\operatorname{var}\left(\varepsilon_{v_{2}}\right)+\operatorname{var}\left(\varepsilon_{y}\right)} .
$$

Note that these coefficients are independent of the marginal products of effort, $v_{i}$. Thus, in general $v_{1} / v_{2} \neq p_{1} / p_{2}$, and contracting on stock price alone will result in effort misallocation. ${ }^{22}$ This result is reminiscent of Gjesdal (1981), and occurs because the market uses information to make inferences about the stochastic elements of value rather than to assess the manager's contribution to value. Therefore, price will not in general be sufficient for contracting, creating an effort balancing role for accounting and other performance measures in optimal contracting.

To summarize this section, we have presented a theoretical apparatus with which to motivate the empirical design of studies investigating the use of accounting numbers in incentive contracting. We illustrated the informativeness principle and isolated three fundamental roles for accounting information in incentive contracts: directly creating incentives to take actions, filtering common noise from other performance measures, and balancing managerial effort across multiple activities. We now turn to a discussion of the empirical evidence. In what follows, we will adapt the theoretical apparatus as necessary to highlight the essential aspects of individual empirical designs.

\subsection{Determinants of incentive weights on performance measures: empirical evidence}

We organize the following discussion around a number of themes which we believe capture important commonalties among subsets of papers in the literature.

\subsubsection{Operationalizing the theory}

The theory developed in Section 2.4 identifies managerial wealth as a key concern of managers. However, many of the studies in the literature use cash compensation as the measure of executive compensation, typically due to data availability issues. Therefore, the slope coefficients estimated from cash compensation on performance measures does not have the theoretical interpretations derived from the model (Baker, 1987).

\footnotetext{
${ }^{22}$ Paul (1992) also shows that this result holds even when investors make endogenous, private information gathering decisions. Bushman and Indjejikian (1993b) show that this problem also arises even with a more sophisticated price formation process that incorporates earnings into price. A number of papers extend Paul to consider the role of other performance measures in balancing incentives across activities including Bushman and Indjejikian (1993a, b), Feltham and Xie (1994), and Datar et al. (2000), among others.
} 
Next, recall that Eq. (2) states that two performance measures should be weighted according to the ratio of the sensitivity times precision of each measure. Note that (2) only describes the way two given performance measures should optimally be weighted in the contract, and does not offer direct guidance on which measures we should expect to observe. Thus, relying on (2), a common research approach posits two specific performance measures, estimates the respective incentive coefficients, generates proxies for sensitivity and precision, and then examines whether the relative incentive weights behave cross-sectionally as predicted by (2). Some studies focus on the relative weights, while others focus on absolute coefficients, although (2) only speaks to relative weights.

As can be seen from (2), sensitivity of a given performance measure is a complex construct that reflects properties of the performance measure itself (e.g., sensitivity of $A$ depends on $a$ ), but which also reflects properties of other performance measures used in the contract when the covariance between the performance measures is nonzero (e.g., sensitivity of $A$ depends on $\left.p\left(\operatorname{Cov}\left(\varepsilon_{A}, \varepsilon_{p}\right) / \sigma_{P}^{2}\right)\right)$. While some papers explicitly incorporate the entire variance-covariance matrix of the performance measures into the empirical representation of sensitivity (e.g., Sloan, 1993; Natarajan, 1996), others do not (e.g., Clinch, 1991; Baber et al., 1996; Bushman et al., 2001).

A common approach to operationalizing sensitivity relies on the Myers (1977) depiction of a firm as consisting of assets in place and future investment options, and proxies for sensitivity with measures of firms' investment opportunity sets. The measures used include sales growth, market to book ratios, price-earnings ratios, research and development costs, consensus investment choices of growth fund managers, length of product development cycles, new product introductions, and measures based on factor analyzing combinations of individual measures. This approach is consistent with Smith and Watts (1992), who argue that as the proportion of firm value represented by growth options increases, the observability of managerial actions decreases. This occurs because it is difficult for outside investors to ascertain fully the menu of investment opportunities available to the firm. Smith and Watts (1992), using industry level data, predict and find a higher incidence of marketbased incentive plans (e.g., stock options, restricted stock) for growth firms relative to nongrowth firms. ${ }^{23}$ They, however, make no predictions about the incidence of accounting-based bonus plans. Although the existence of growth

\footnotetext{
${ }^{23}$ See Gaver and Gaver (1993) for a similar analysis at the firm level. Smith and Watts (1992) and Baker (1987) note that the investment opportunity set is itself a choice variable, and that treating it as exogenous may be problematic. Most studies that we discuss follow Smith and Watts (1992) and treat the investment opportunity set as exogenous. An exception is Holthausen et al. (1995a), who model investment opportunities (innovation measures) as a function of the compensation contract, and the compensation contract as a function of innovation. We discuss this paper in more detail below.
} 
options suggests a higher demand for incentive plans of all kinds, the presence of significant investment opportunities implies that earnings poorly reflect the long-term consequences of important current managerial actions and thus have low contracting value. Principal-agent-based compensation research conjectures that for firms with significant growth opportunities, expansive investment opportunity sets, and long-term investment strategies, accounting earnings are likely to exhibit low sensitivity, while stock returns will have high sensitivity in these settings. In these settings, it is conjectured that current earnings will poorly reflect future period consequences of current managerial actions, and thus exhibit low sensitivity relative to important dimensions of managerial activities.

Although these papers do not explicitly reference multi-tasking models, such models clearly illustrate the "earnings poorly reflects long-term consequences of current managerial actions" stories underlying the sensitivity proxies chosen. For example, assume firm value is given by $V=v_{1} e_{1}+v_{2} e_{2}+\varepsilon_{V}$. For simplicity, assume that all random variables in the model are independent of each other. Current earnings, given by $A=a e_{1}+\varepsilon_{A}$, does not reflect $e_{2}$, and so current earnings are not sensitive to current strategic planning activities. It can be shown that for a wage contract $w=\beta_{0}+\beta_{V} V+\beta_{A} A$, the ratio $\beta_{A} / \beta_{V}$ is decreasing in $v_{2}$, the sensitivity of $V$ to $e_{2}$ : incentive weight shifts away from accounting towards stock price as the importance of $e_{2}$ to value creation increases. Using this idea, empirical studies predict that the incentive weight on earnings will decrease relative to the weight on stock price measures as proxies for the importance to value of actions missing from earnings increase. Stock price-based measures are conjectured to reflect these important activities more completely than earnings and to become relatively more important as investment opportunities increase.

The second construct reflected in (2) is precision of the performance measures (inverse of variance). The simple effort-plus-noise signal formulation typically used in formal models of contracting naturally lead to the variance of the signal as the appropriate measure of noise. Thus, it is common that precision is measured as the time-series standard deviation of the respective measures. ${ }^{24}$ The total standard deviation is sometimes split into its firm-specific and systematic components. A problem with time-series generated proxies for noise is that they basically assume that optimal effort levels are constant over time. However, if optimal effort varies over time in response to random changes in the environment, this variation will be picked up as part of the overall time-series variation, and not represent noise from the standpoint of inferring managerial actions.

\footnotetext{
${ }^{24}$ Some papers interpret the variance of stock returns as a measure of investment opportunities, rather than as a measure of noise in the performance signal. See for example, Gaver and Gaver (1993) and Smith and Watts (1992).
} 


\subsubsection{Relative incentives weights on accounting and stock price measures}

The seminal paper in this genre is Lambert and Larcker (1987), who using cash compensation data from Forbes (1970-1984), estimate firm-specific incentive coefficients on stock returns and changes in accounting return-onequity (ROE). They rely on the theory as illustrated in Eq. (2), and focus on the ratio of the estimated slope coefficients on the two performance measures. While, as discussed above, the use of the ratio of coefficient estimates may reduce factors that confound the cross-sectional analysis, ${ }^{25}$ the underlying distributional properties of the ratio of two random variables can be complicated and possess undesirable properties (e.g., ratios of estimated coefficients can be very sensitive to measurement error, near zero values in the denominator, and negative coefficients). Proxying for sensitivity with real growth in assets and sales, they find some evidence that high growth firms tend to place more incentive weight on stock returns relative to ROE. They also find some evidence that the incentive weight on stock returns relative to ROE is positively related to the ratio of noise in ROE to noise in stock returns (captured in a latent variables analysis by the ratio of time-series variances of the measures and the ratio of the systematic components of the respective variances). Finally, they also find that the incentive weight on stock returns relative to ROE is positively associated with the correlation between stock returns and ROE (e.g., $\rho(A, P)$ ) and negatively related to CEO stockholdings in the firm. ${ }^{26}$ While Lambert and Larcker do find results consistent with the agency model, the results are fragile and vary across specifications.

Sloan (1993) focuses on understanding why earnings are used in addition to stock price in executive compensation plans. He interprets his results as indicating that the role of earnings is to shield executive compensation from market-wide movements in stock price. While the term "shielding" seems to indicate that earnings is playing a noise filtering role similar in spirit to relative performance evaluation, we use the theoretical framework developed in Section 2.4 to interpret his results as showing that earnings are valuable because two noisy signals about the same managerial effort are better than one signal.

Perhaps more importantly, Sloan attempts to refine empirical measures of "noise" in a performance measure for contracting purposes. He notes that the

\footnotetext{
${ }^{25}$ As discussed earlier, production function and manager specific parameters may cancel out in the ratio.

${ }^{26} \mathrm{~A}$ low $\rho(A, P)$ sometimes has been interpreted as measuring noise in accounting earnings relative to assessing firm value. However, the Lambert and Larcker result is that the incentive weight on earnings increases as this correlation gets smaller. Lambert and Larcker (1987) suggest that this may be a manifestation of the Gjesdal (1981) result that a performance measure may rank differently across uses. Sloan (1993), discussed next, follows up on the Lambert and Larcker result.
} 
weak evidence found in Lambert and Larcker (1987) for their noise proxies may be driven by the fact that the time-series variance of a performance measure does not represent noise for contracting purposes, as some of the variation captures changes in optimal effort levels over time. Sloan's empirical design attempts to distinguish between the overall variance of a performance measure and that portion of the variance which captures noise in the performance measure.

Sloan's design posits that earnings and returns take the form $A=x(e)+\varepsilon_{A}$ and $P=x(e)+\varepsilon_{P}$, where $x(e)$ is an independently distributed random variable parameterized by the manager's effort $e$, and the $\varepsilon_{i}$ are white noise. Thus, both measures reflect the manager's contribution to value with noise. $x(e)$ is operationalized as the firm-specific portion of stock returns and estimates $\varepsilon_{A}$ as the scaled residual from a regression of changes in earnings per share (or ROA) on estimated $x(e)$. That, is let $P=$ stock returns, $A=$ change in EPS, and let $R_{\mathrm{m}}=$ return on the market portfolio. Then $x(e)$ is estimated as the residual from the firm-specific estimation $P=b_{0}+b_{1} R_{\mathrm{m}}+$ $x(e)$. Since $x(e)$ is assumed to capture all information about managerial actions, the noise in returns for contracting purposes is defined as $\sigma_{P}^{2}=b_{1}^{2} \operatorname{Var}\left(R_{\mathrm{m}}\right)$. Also, noise in accounting is determined by using $x(e)$ from the first stage market model regression to estimate $A=d_{0}+k x(e)+E$. To achieve the structure $A=x(e)+\varepsilon_{A}$, he scales both sides by estimated $k$ yielding $A_{\mathrm{s}}=x \times$ $(e)+d_{0}+E / k$. Noise in accounting is then captured by $\sigma_{A}^{2}=\operatorname{Var}(E) / k^{2}$ (and $\left.\rho\left(\varepsilon_{A}, \varepsilon_{P}\right)=\rho\left(E / k, b_{1} R_{\mathrm{m}}\right)\right) .^{27}$

Noting that in this formulation,

$$
\frac{\mathrm{d} E[A \mid e]}{\mathrm{d} e}=\frac{\mathrm{d} E[P \mid e]}{\mathrm{d} e},
$$

expression (2) above becomes

$$
\frac{\beta_{A}}{\beta_{P}}=\frac{\left(1-\left[\operatorname{Cov}\left(\varepsilon_{A}, \varepsilon_{p}\right) / \sigma_{P}^{2}\right]\right) \sigma_{P}^{2}}{\left(1-\left[\operatorname{Cov}\left(\varepsilon_{A}, \varepsilon_{p}\right) / \sigma_{A}^{2}\right]\right) \sigma_{A}^{2}} .
$$

It is noteworthy that in expression (4), only the variances of the noise terms $\left(\left\{\sigma_{A}^{2}, \sigma_{P}^{2}\right\}\right)$ and their covariance appears, rather than $\operatorname{Var}(A), \operatorname{Var}(P)$, and $\operatorname{Cov}(A, P)$, as $\operatorname{Var}(x(e))$ cancels out of the expression. Lambert and Larcker (1987) use $\operatorname{Var}(A), \operatorname{Var}(P)$, and $\operatorname{Cov}(A, P)$ in their design, in contrast to Sloan's attempt to parcel out the "noise" element in a measure.

Sloan applies the structure just defined to the Forbes compensation data for CEOs (1970-1988) and finds evidence that $\operatorname{Cov}\left(\varepsilon_{A}, \varepsilon_{p}\right) / \sigma_{P}^{2}<1$. This result is key to his conclusion that the role of earnings is to "shield" executives from

\footnotetext{
${ }^{27}$ Lambert (1993) provides an insightful discussion of the econometric problems associated with this approach, and the implications for interpreting the results of the paper. In particular, he notes that measurement error in capturing managers' contribution to value $(x(e))$ may result in understating estimates of noise in returns $\left(\sigma_{P}^{2}\right)$ and overstating noise in accounting $\left(\sigma_{A}^{2}\right)$.
} 
market-wide movements in price. ${ }^{28}$ However, inspection of the numerator in expression (4) shows that $\operatorname{Cov}\left(\varepsilon_{A}, \varepsilon_{p}\right) / \sigma_{P}^{2}<1$ basically implies that $A$ is marginally informative given $P$, and that the marginal impact of effort on $A$ (the 1 in the numerator) dominates the noise filtering effect via correlation in the noise terms of the signals. In fact, if $\operatorname{Cov}\left(\varepsilon_{A}, \varepsilon_{p}\right) / \sigma_{P}^{2}>1$, accounting would receive a negative weight in the contract as now its dominant role would be filtering common noise from price.

In comparison to Lambert and Larcker (1987), Sloan also finds that his measures of noise $\operatorname{Var}\left(b_{1} R_{\mathrm{m}}\right) / \operatorname{Var}(E / k)$ and covariance of noise $\rho\left(\varepsilon_{A}, \varepsilon_{P}\right)=$ $\rho\left(E / k, b_{1} R_{\mathrm{m}}\right)$ appears to work better than variances and covariances of the raw performance measures $(\operatorname{Var}(P) / \operatorname{Var}(A), \rho(A, P))$ in explaining compensation contracts.

To complete the discussion of Sloan (1993), we note an interpretation problem with the paper. If the firm-specific portion of stock returns is the proper measure of managerial actions $(x(e))$, why do not firms simply remove market fluctuations directly? Given that firms do use earnings, it raises questions about interpreting the firm-specific component of returns as the measure of managers' contribution to value. Sloan's Table 8 shows that accounting earnings get positive incentive weight even when the firm-specific portion of stock returns is directly included in the regression! Despite this criticism (and other econometric subtleties discussed in detail in Lambert, 1993), this paper raises fundamental questions about the proper empirical measure of noise for contracting purposes which have not been explored further in the literature subsequent to Sloan.

In related studies, Clinch (1991) and Baber et al. (1996) examine the relation between investment opportunity sets, and incentive weightings on accounting and stock price performance measures, while remaining silent on issues concerning relative noise across measures. The pooled, cross-sectional designs used in these two studies, and in Sloan (1993), should be interpreted with caution given substantial evidence that incentive coefficients can differ significantly across firms. Hypotheses in both papers are consistent with arguments made in Smith and Watts (1992) and Lambert and Larcker (1987) (i.e., higher investment opportunities imply more unobservability and potential missing actions in earnings), and predict a shift towards stock-based compensation as investment opportunities increase. Clinch proxies for investment opportunities with R\&D expenditures, while Baber et al. (1996) use factor analysis to expand on the measure introduced by Gaver and Gaver

\footnotetext{
${ }^{28}$ This condition also can be interpreted in Sloan's framework as follows. Consider the following two firm-specific regressions: $A=d_{0}+k x(e)+E$ and $A=c_{0}+z b_{1} R_{\mathrm{m}}+n o i s e$. Then, it can be shown with Sloan's assumptions that $\operatorname{Cov}\left(\varepsilon_{A}, \varepsilon_{p}\right) / \sigma_{P}^{2}<1$ is equivalent to the statement that $z<k$. Sloan describes this latter condition as earnings performance being more sensitive to the firmspecific component of stock returns than to the market-wide component of returns.
} 
(1993). ${ }^{29}$ Finally, both studies examine cash compensation as well as more comprehensive measures that supplement cash compensation with estimates of stock option grants, restricted stock grants and long-term incentive plan grants, and use stock returns and accounting ROE as the performance measures. Clinch finds that the incentive weights on both stock returns and ROE increase with $R \& D$, and weak evidence that the ratio of the incentive weight on stock returns to that on ROE declines with R\&D. Clinch's result appear to be driven by the small firms in his sample. Partitioning the sample, he finds that the incentive coefficient on ROE is unrelated to R\&D for large firms. ${ }^{30}$ Baber et al. (1996) find that the weight on stock returns increases relative to the weight on ROE as their measure of investment opportunities increases (they find no relation between investment opportunities and incentive weights using cash compensation as the compensation measure).

\subsubsection{Relations between the valuation and governance roles of accounting information}

Financial accounting information has many potential uses. A deep understanding of economic connections across the variety of roles played by accounting information is necessary for a complete evaluation of alternative financial reporting regimes. It is widely accepted that reported earnings play a fundamental role in both determining stock prices, and in evaluating and compensating executives. However, the relation between the governance and value relevance of earnings is not well understood. Gjesdal (1981) illustrates the subtlety of understanding such connections by demonstrating that the ranking of information systems for valuation purposes may not coincide with the ranking of information systems for control purposes.

Bushman (2001) theoretically and empirically investigate potential linkages between the weights placed on accounting earnings in executive compensation contracts and in stock price formation. They conjecture that the marginal product of current period managerial actions is a connecting link between the weights placed on earnings in the two uses, and present formal models to illustrate how this linkage could come about.

The main idea is quite simple. Holding everything else constant, a principal naturally desires a manager to take higher effort as the marginal product of

\footnotetext{
${ }^{29}$ Baber et al. (1996) apply factor analysis to an extensive list of proxies for investment opportunities which include, investment intensity, growth in market value of assets, market-tobook ratio, R\&D expenditures, earnings-to-price ratio, and variance of return on market value of equity.

${ }^{30}$ Using cash compensation, Clinch finds little relation between the incentive weight on stock returns and $R \& D$, but a positive relation between the weight on ROE and R\&D for small firms. Note that Clinch also finds the incidence of stock option plans, but not annual bonus plans, to be higher for high R\&D firms. He also attempts, with limited success, to distinguish moral hazard explanations for incentive contracting from both adverse selection and tax-related explanations.
} 
effort increases. Thus, in designing compensation contracts, the principal will generally put a higher compensation weight on earnings as the marginal product of effort increases. On the other hand, a firm's stock price capitalizes the full valuation implications of reported earnings. Because earnings depend on managerial actions, the coefficient on earnings in valuation may capture the market's assessment of the marginal product of effort. To the extent that it does, we would expect a positive correlation between weights.

Bushman et al. (2001) present two simple models that capture this intuition. In the first, they adapt the classic valuation framework and linear information dynamic analyzed in Ohlson (1995) to include moral hazard. Here current earnings parameterizes a stochastic process whose properties are used to compute expectations of future earnings and so managerial actions have multiperiod effects. In this case, the valuation weight on earnings captures the discounted, all-in effect of the manager's current effort on all future periods, and is thus a component of the marginal product of current period effort not captured by current period earnings. The incentive weight on current period earnings increases as the multi-period impact of current period action increases, and the valuation weight on earnings precisely captures the discounted marginal product of this multi-period effect missing from current earnings.

Secondly, they analyze a model in which the true marginal product of effort and the sensitivity of earnings to managerial effort are both random variables. Following Baker (1992) and Bushman et al. (2000a), the manager receives private information after signing the contract but before choosing effort. The connection between the governance and valuation role of earnings differs subtly from the previous model. Now for contracting, the role of earnings is to motivate the manager to take actions consistent with the true marginal product of effort, while for valuation purposes earnings is used by the market to make inferences about the true marginal product. This connection leads to the weights on earnings in compensation and valuation to be similarly impacted by a number of elements, although the weights differ along other dimensions.

Bushman et al. (2001), using CEO cash compensation over the period 19711995 from the Forbes annual compensation data and several complementary empirical specifications, examine cross-sectional relations between incentive weights on earnings and the valuation weight on earnings. They find that the incentive weight on earnings is positively associated with the valuation weight. They also find that changes in the incentive weight on earnings are positively associated with changes in earnings persistence.

In a related study, Baber et al. (1998) show in a pooled, cross-sectional analysis of CEO cash compensation that the incentive weight on earnings increases in the persistence of earnings. They conjecture that this reflects the board's effort to mitigate managers' myopic decision focus. However, as discussed above, it is not clear how this story fits into a formal economic 
framework. The modeling exercises in Bushman et al. (2001) allows a reinterpretation of their results. While the existence of multi-period effects can be framed as a myopia problem, it seems more natural to view it as an issue of properly measuring marginal product of current period actions that impact current earnings. It seems more natural because it is well known from principal-agent models that compensation coefficients always increase in the marginal product of effort. The multi-period impact of actions is simply factored into the definition of marginal product through the valuation weight on earnings.

\subsubsection{Estimating the relation between components of earnings and cash compensation}

Another approach assumes that actual contracts are consistent with (1) and (2) where the performance measures are posited to be components of earnings. The incentive coefficients on the posited measures then are estimated in the usual way by regressing compensation on earnings components, where the researcher has no knowledge of the true measures defined by the explicit contract. These papers examine the prospect that different components of earnings can possess different levels of usefulness as performance measures. In essence, these papers ask whether compensation committees distinguish among components of earnings in setting CEO pay. Some of these papers also relax the assumption of optimal contracting and ask whether estimated compensation relations imply opportunistic behavior on the part of managers and boards. Studies in this genre follow two closely related approaches. In the first, research examines the degree to which components of earnings are used in contracts, then examines whether the incentive weights on these earnings components are consistent with predictions of principal-agent models. In the second, the research investigates whether certain items are removed from earnings for purposes of performance evaluation of managers. In essence, all papers in this area implicitly use Eq. (2) to frame their investigation of earnings components.

Natarajan (1996) examines whether working capital from operations and cash flow from operations provide information over and above aggregate earnings in determining CEO cash compensation. Running firm-specific estimations using Forbes data, he finds that earnings and working capital from operations together have a better association with CEO cash compensation than does aggregate earnings alone. Cash flow from operations and current accruals (e.g., working capital accounts) are not treated differently in the compensation contract, implying that long-term accruals (e.g., depreciation expense) are used differently in the contract than cash flow from operations and current accruals. Then, in the spirit of the Lambert and Larcker (1987) study, Natarajan uses a variant of Eqs. (1) and (2) above to test whether crosssectional differences in the estimated incentive weights on earnings and 
working capital from operations can be explained by agency theory predictions. Assuming that the mean of each performance measure is directly proportional to the manager's effort, and estimating the variance-covariance matrix of the two signals, he estimates the sensitivity and precision of each signal. He then shows that these measures of stewardship value are significantly associated with the incentive weights placed on earnings and working capital from operations in the contract.

Clinch and Magliolo (1993) explore the relation between components of earnings and the cash compensation of CEOs of bank holding companies. They disaggregate earnings into three components: earnings from recurring operations, discretionary nonoperating earnings that have direct cash flow implications (e.g., gains from selling a credit card portfolio), and discretionary earnings with no cash flow consequences (e.g., settlement of pension plan liabilities through the purchase of annuities). They find that discretionary items with cash flow effects are reflected in the compensation function, while discretionary items with no cash flow implications do not appear to enter into the compensation function. Healy et al. (1987) find that compensation contracts do not appear to be adjusted for the effect of switching from accelerated to straight-line depreciation, and Defeo et al. (1989) find that gains associated with equity-for-debt swaps receive no special treatment in the compensation contract. These studies imply that compensation committees see through cosmetic accounting effects when setting compensation.

However, Dechow et al. (1994) find that executive compensation is shielded from the negative effects of restructuring charges. Finally, Gaver and Gaver (1998) partition net income into "above the line" and "below the line" items, where below the line items consist of results from discontinued items and extraordinary items. They regress CEO cash compensation on above the line earnings, below the line items that increase income, and below the line items that decrease income. They find that above the line earnings are positively related to cash compensation if the earnings are positive, and unrelated if they are losses. They also find that below the line items that increase income are related to compensation, while below the line items that decrease income are unrelated to compensation. These studies document that compensation committees distinguish among elements comprising net income in determining executive cash compensation, and these distinctions appear to favor managers. The extent to which these findings represent opportunistic behavior resulting from a CEO's control over the board of directors, or shareholder value enhancing adjustments by the board is still an open question.

\subsubsection{Explicit choice of performance measures}

Recall that the informativeness principle implies that any performance measures, which on the margin convey information about managers' effort levels, should be used in the contract. However, the derivation of this result 
ignores the costs of producing information signals, as well as costs associated with the complexity of multi-performance measure contracts and the integrity of signals. The costs to shareholders and directors of collecting and processing audited, standardized signals from the accounting system are in many cases low relative to alternative performance measures. As a result, it is more likely that firms will substitute towards additional, costly signals to the incentive contract only when accounting information and stock price taken together do a poor job in capturing the contribution of important elements of managerial action to firm value. Bushman et al. (1996) and Ittner et al. (1997) use this idea as the basis for empirical investigations into firms' actual performance measure choices.

The main idea underlying these studies can be illustrated simply. Firm value $V=v_{1} e_{1}+v_{2} e_{2}+\varepsilon_{V}$ is noncontractible, and contractible signal $S=a e_{1}+\varepsilon_{A}$ represents a sufficient statistic for accounting information and stock price with respect to the actions $e_{1}$ and $e_{2}$. The sufficient statistic $S$ conveys no information about action $e_{2}$. This can occur, for example, if stock price is not strong-form efficient, and does not reflect proprietary information privately possessed by a firm's executives. If $v_{2}$ is large enough, the incentive benefits from supplementing $S$ with additional, costly performance measures informative about $e_{2}$ outweighs the costs.

Bushman et al. (1996) study the use of "individual performance evaluation" in determining annual CEO bonuses. They use managerial compensation data from Hewitt Associates' annual compensation surveys of large, U.S. companies. This data set provides the percentage of a CEO's annual bonus determined by individual performance evaluation (IPE). IPE is generally a conglomeration of performance measures including subjective evaluations of individual performance. As discussed above, many empirical studies have used various measures of investment opportunities to explain incentive weights on stock price relative to accounting measures, arguing that accounting measures poorly reflect important aspects of managerial activities in firms with extensive investment opportunities. Similar arguments apply in explaining the use of IPE and other nonfinancial measures in contracts. While the existence of extensive investment opportunities implies that stock price is more inclusive of managerial actions than accounting measures, it need not be inclusive of all important activities, leading to a demand for nonfinancial performance measures. Bushman et al. (1996) proxy for the investment opportunity set with market-to-book ratios, and the length of product development and product life cycles. They find that IPE is positively and significantly related to both measures of investment opportunities. They find no significant relation between noise, measured as time-series standard deviations in stock price and accounting measures, and the use of IPE.

Ittner et al. (1997) expand on Bushman et al. (1996) by specifically considering the use of nonfinancial performance measures. Using a 
combination of proprietary survey and proxy statement data, they estimate the extent to which CEO bonus plans depend on nonfinancial performance measures. The mean weight on nonfinancial measures across all firms in their sample is $13.4 \%$ and $37.1 \%$ for all firms with a nonzero weight on nonfinancial measures. They construct their measure of investment opportunities (called organizational strategy in their paper) using multiple indicators including: R\&D expenditures, market-to-book ratio, and number of new product and service introductions. ${ }^{31}$ They find that the use of nonfinancial performance measures increases with their measure of investment behavior (or strategy), and find no relation with noise in accounting and stock price measured as timeseries standard deviations. ${ }^{32}$

Bushman et al. (1996) and Ittner et al. (1997) play off the idea that certain performance measures used in contracts are not directly observable by the market. Hayes and Schaefer (2000) derive implications of this insight for the relation between executive compensation and future firm performance. If firms are optimally using unobservable measures of performance that are correlated with future observable measures of performance, then variation in current compensation that is not explained by variation in current observable performance measures should predict future variation in observable performance measures. Further, compensation should be more positively associated with future earnings when observable measures of performance are noisier and, hence, less useful for contracting. They test these assertions using panel data on CEO cash compensation from Forbes, and show that current compensation is related to future ROE after controlling for current and lagged performance measures and analyst consensus forecasts of future accounting performance. They find no time trend in the relation between current compensation and future performance. This stability in the relationship is noteworthy given the significant increases in the use of option grants documented by Hall and Leibman (1998) and Murphy (1999b). Boards of directors apparently have not delegated the complete determination of CEO rewards to the market, and still fine tune rewards using private information. Hayes and Schaefer also find that current compensation is more positively related to future performance when the variances of the firm's market and accounting returns are higher.

\subsubsection{Relative performance evaluation ( $R P E$ )}

A major empirical prediction of agency theory concerns the reduction of extraneous noise from compensation contracts through the use of relative

\footnotetext{
${ }^{31}$ They also consider a firm's quality strategy, regulatory environment, financial distress, CEO influence and noise as other determinants of nonfinancial performance measure use.

${ }^{32}$ They also find a negative relation between use of nonfinancial performance measures and the correlation between accounting returns and stock returns, and find that regulated companies use more nonfinancial performance measurement (e.g., safety, customer satisfaction).
} 
performance evaluation (Holmstrom, 1982). However, empirical research to date has provided only weak evidence in support of the theory. ${ }^{33} \mathrm{We}$ begin by illustrating the theory of RPE and its empirical predictions. We then discuss the evidence on RPE, emphasizing recent research that relaxes assumptions of standard RPE theory by allowing managerial actions to potentially impact peer group as well as own-firm performance.

We define two available performance measures for contracting as $P=$ $e+\varepsilon_{P}$, and $I=\varepsilon_{I}$, where the contract is given by $w=\beta_{0}+\beta_{P} P+\beta_{I} I$. The measure $I$ does not depend on managerial actions, and represents a measure of peer group performance. $\operatorname{Cov}\left(\varepsilon_{P}, \varepsilon_{I}\right)>0$ implies the existence of common shocks impacting both the firm and its peers. Adapting Eq. (1) derived above yields the optimal contract:

$$
\begin{aligned}
& \beta_{I}=\frac{\operatorname{vrC}\left[-\operatorname{Cov}\left(\varepsilon_{I}, \varepsilon_{p}\right)\right]}{\left(r C \sigma_{I}^{2}\right)\left(1+r C \sigma_{P}^{2}\right)-\left(r C \operatorname{Cov}\left(\varepsilon_{I}, \varepsilon_{p}\right)\right)^{2}}<0, \\
& \beta_{P}=\frac{\operatorname{vrC}\left[\sigma_{I}^{2}\right]}{\left(r C \sigma_{I}^{2}\right)\left(1+r C \sigma_{P}^{2}\right)-\left(r C \operatorname{Cov}\left(\varepsilon_{I}, \varepsilon_{p}\right)\right)^{2}}>0 .
\end{aligned}
$$

To understand this result, note first that expression (9) implies that

$$
\beta_{I}+b \beta_{P}=0 \text {, }
$$

where $b=\operatorname{Cov}\left(\varepsilon_{I}, \varepsilon_{P}\right) / \sigma_{I}^{2}$. It follows that the peer group component of firm performance is completely removed in the contract (Antle and Smith, 1986; Janakiraman et al., 1992; Aggrawal and Samwick, 1999b). To see this, note that $b$ is just the slope coefficient from the regression $P=d+b I+u$ and $u$ is the unsystematic component of $P$. Substituting this expression into the wage contract for $P$ yields $w=\beta_{0}+\beta_{P} d+\beta_{P} u+\left(\beta_{I}+\beta_{P} b\right) I$. Thus, $\beta_{I}+b \beta_{P}=0$ implies that the contract only depends on the unsystematic component of $P$ as all common noise is filtered out.

A number of papers test for RPE using CEO cash compensation. The strongest evidence on the hypothesis that $\beta_{I}<0$ is found in Gibbons and Murphy (1990) and Murphy (1999b). These studies find evidence that CEO cash compensation is negatively related to aggregate market returns, but less so with industry returns. Antle and Smith (1986) also find weak evidence of RPE. However, Barro and Barro (1990), Janakiramin et al. (1992) and Aggarawal and Samwick (1999b) find little evidence of RPE. The latter two studies explicitly examine the constraint $\beta_{I}+b \beta_{P}=0$, as well as the prediction that $\beta_{I}<0$. Blackwell et al. (1994) look for evidence of RPE in the turnover probabilities of subsidiary bank managers in multi-bank holding companies.

\footnotetext{
${ }^{33}$ See Murphy (1999b) for statistics on the prevalence of RPE as reported in a compensation consulting firm's survey. The survey reports that $21 \%$ of industrial companies surveyed use some form of RPE in the annual bonus plan, while $57 \%$ of the financial services firms and $42 \%$ of utilities report using RPE.
} 
Holding own-bank performance constant, they find evidence that turnover increases with holding-company performance, but is unrelated to the performance of other banks in the same region. This is consistent with managers being compared against the performance of other managers within the same holding company.

Overall, the mixed evidence to date is puzzling given that RPE is a fundamental prediction of agency theory. Of course, factors beyond the effortinsurance tradeoff captured in the standard principal-agent model are likely also important in contract design. ${ }^{34}$ Two recent studies, Aggarawal and Samwick (1999b) and DeFond and Park (1999), allow for the possibility that the competitive environment in which a firm operates is an important factor in contract design.

Aggarawal and Samwick (1999b) formally model contract design in an environment of strategic interactions between imperfectly competitive firms. Modeling product market competition as strategic complements (e.g., differentiated Bertrand price competition model), they find that the optimal contract places a positive incentive weight on both own-firm and rival-firm performance, in contrast to the standard RPE prediction. The positive weight on rival-firm performance is designed to soften competition. By increasing pay in the rival's performance, it creates incentives for managers to price less aggressively and thus facilitate collusive behavior which raises returns to shareholders. Their model also predicts that the ratio of the incentive coefficient on own-firm performance to the coefficient on rival firm's performance is a decreasing function of the level of competition (degree of product substitutability) in the industry. ${ }^{35}$ While they have not modeled formally tradeoffs between RPE and strategic considerations in contract design, their model indicates that strategic considerations work against the use of RPE by implying both a positive incentive weight on rival-firm performance and by predicting that this positive weight will be relatively more extreme as competition increases.

They use industry concentration ratios (Herfindahl Indices) to measure competition (higher concentration interpreted as lower product substitutability) and measure compensation as annual cash compensation plus the value of long-term compensation grants (restricted stock and stock option grants,

\footnotetext{
${ }^{34}$ For example, see Dye (1992).

${ }^{35}$ They also model output as strategic substitutes as in a differentiated Cournot model. In this model, the incentive weight on own-firm performance is positive, while the weight on rival-firm performance is negative. While the negative weight on rival-firm performance is consistent with RPE, it appears for a different economic reason. Here, the negative weight commits the manager to produce more aggressively. In this model, as competition increases, relatively more negative weight is put on the rival and less positive weight is put on own firm. The empirical results are most consistent with the strategic complements case, so we do not discuss the strategic substitutes case further.
} 
long-term plan payouts, and all other compensation). They find that compensation is positively related to both own and rival-firm performance (industry returns), and that the ratio of own- to rival-firm pay-performance sensitivity is lower in more competitive industries. This is consistent with their model of strategic substitutes. Even if the forces of RPE are present, this result implies that strategic considerations swamp RPE. In some specifications using cash compensation, they find that the incentive weight on rival-performance is negative, but that the extent of RPE is lower in more competitive industries.

DeFond and Park (1999), while not presenting a formal model, hypothesize that RPE will be more valuable in more competitive industries. DeFond and Park argue that in more competitive industries where large numbers of firms operate in a similar environment, peer group performance will better capture common noise, and the actions of any given manager will not impact the output of other firms (a similar story is told by Parrino (1997) in the context of CEO succession). This story ignores the strategic considerations modeled in Aggarawal and Samwick (1999b), and makes predictions completely opposite to the evidence in Aggrawal and Samwick. Unfortunately, it is difficult to compare the results of DeFond and Park with those of Aggrawal and Samwick.

DeFond and Park focus on CEO turnover rather than compensation, but also use Herfindahl Indices to measure competition. They find that CEO turnover is higher in more competitive industries regardless of performance, which they interpret as RPE improving a board of director's ability to detect poorly performing CEOs in highly competitive industries (again Parrino (1997) finds a similar result using a measure of heterogeneity within an industry rather than Herfindahl Indices). While Aggrawal and Samwick include the Herfindahl Index as a stand-alone variable and find less competitive firms have higher compensation (analogous to the DeFond and Park result of lower turnover), their model offers no prediction on this variable. This result at best represents indirect evidence of RPE. In addition, DeFond and Park only include performance measures already adjusted for rival-firm performance (i.e., market-adjusted returns, industry-relative earnings, and analyst forecast errors), rather than including own- and rival-firm performance separately as is typical in RPE studies. In fact, it is very difficult to see how this design gets at RPE. As we showed above, RPE implies that the wage contract can be expressed as $w=\beta_{0}+\beta_{P} d+\beta_{P} u+\left(\beta_{I}+\beta_{P} b\right) I$, where $u$ is index-adjusted returns from the single factor index model $P=d+b I+u$. The DeFond and Park design can be interpreted as using index-adjusted returns as the performance measure, estimating $w=\gamma+\gamma_{1} u$, and showing that $\gamma_{1}$ increases with competition. But the main predictions of RPE are that $\beta_{I}<0$ and $\beta_{I}+$ $b \beta_{P}=0$, neither of which is addressed by this design. Thus, while they have clearly isolated an interesting relation between competition and the role of index-adjusted performance measures in explaining CEO turnover, 
the interpretation in terms of RPE is not clear. This implies an opportunity for further research into the relation between RPE, competition and turnover.

\subsubsection{Contract design for business unit managers}

Modern U.S. corporations are typically hierarchical organizations with a CEO occupying the top position in the hierarchy. As discussed above, there is a large amount of empirical research focused on the compensation plans of executives at the top of the hierarchy. In contrast, a much smaller literature investigates the compensation of middle level executives, due primarily to data availability issues. This represents a rich avenue for future accounting research, subject to data availability. Incentives within organizations are likely to be crucial determinants of firm success. Accounting measurements also are likely to be relatively more important for contracting within the organization. This is because firm-wide performance measures, such as stock price, aggregate all the firm's operations together and so contain significant noise from the perspective of an individual business unit manager (see Keating, 1997; Guidry et al., 1999) for evidence on the use of stock price incentives at the business unit level).

In addition, many interesting interactions between incentive contracting, performance measurement and other organizational features come into play at lower levels in the hierarchy. Complex interactions can exist between incentive contracts written on objective performance measures and promotion ladders, allocations of decision rights, task allocations, divisional interdependencies, and subjective performance evaluation. For example, Lambert et al. (1993) presents evidence that observed business unit managers' compensation across the hierarchy exhibits patterns consistent with both agency theory and tournament theory. Baker et al. (1994a, b) and Gibbs (1995) analyze 20 years of personnel data from a single firm and illustrate the complex relations that can exist among the hierarchy, performance evaluation, promotion policies, wage policies and incentive compensation. Ichniowski et al. (1997) using data on 36 steel mills find that mills which adopt bundles of complementary practices (e.g., incentive compensation, teamwork, skills training, communications) are more productive than firms which either do not adopt these practices or which adopt practices individually rather than together. Accounting research into compensation within the hierarchy, which we discuss next, has addressed empirically issues of inter-divisional interdependencies, task allocation, interactions between compensation and innovation, and ratcheting of performance standards.

Bushman et al. (1995) and Keating (1997) explore the role of interdependencies across divisions within a firm and the structure of business unit executives' incentive contracts. Both papers provide evidence of a positive relation between the weight placed on firm-wide performance measures relative 
to own business unit measures and the extent of interdependencies across divisions within the firm.

Assume a firm has two divisions, and let the profit of divisions 1 and 2 be given by $D_{1}=f_{1} e_{1}+f_{2} e_{2}+\varepsilon_{1}$ and $D_{2}=g_{1} e_{1}+g_{2} e_{2}+\varepsilon_{2}$, respectively. Let $e_{1}$ be the action of the division 1 manager and $e_{2}$ that of the division 2 manager, $\operatorname{Cov}\left(\varepsilon_{1}, \varepsilon_{2}\right)=0$, and preferences be defined in Section 2.4. Note that effort, $e_{1}$, taken by the manager of division 1 impacts both his own division profits, $D_{1}$, and the profits of division $2, D_{2}$. This captures the idea of an interdependency, or spillover effect, between the two divisions. Division 1's profits can in turn be impacted by the actions of manager 2. Define firm-wide profits as $A=$ $D_{1}+D_{2}$, and let the wage contract of division managers be given by $w_{i}=$ $\beta_{0}^{i}+\beta_{D}^{i} D_{i}+\beta_{A}^{i} A, i=1,2$. The role of firm-wide profits in the contract is to create incentives for managers to internalize the entire marginal product of effort on firm value, not just the impact of effort on own division profits. Focus on manager 1. It can be shown (Bushman et al., 1995) that the optimal wage contract for manager 1 can be characterized as ${ }^{36}$

$$
\frac{\beta_{A}^{1}}{\beta_{D}^{1}+\beta_{A}^{1}}=\frac{g_{1}}{f_{1}} \frac{\sigma_{1}^{2}}{\sigma_{2}^{2}} .
$$

Expression (11) predicts that the incentive weight on firm profits, $A$, in manager 1 's contract, will increase relatively as the spillover effect of manager 1's action on division 2 (i.e., $g_{1}$ ) increases.

To investigate this hypothesis, Bushman et al. (1995) use proprietary data on business unit manager compensation plans from 246 public companies. The data contains the percentage of business unit managers' compensation determined by corporate-wide performance measures and the percentage determined by own-unit performance measures. For example, they document that on average $46 \%$ of a division CEO's annual bonus is determined by ownlevel performance, $34 \%$ by aggregated corporate-wide measures, and $20 \%$ by individual performance measures. They proxy for interdependencies with the ratio of the firm's inter-industry segment sales and inter-geographic segment sales to total sales (higher inter-segment sales imply higher spillover effects), and with industry and geographic diversification measures (more diversified implies less spillover). The use of inter-segment sales to proxy for interdependencies should only explain relative incentive weighting on corporate versus own level profits if transfer pricing schemes do not completely solve the spillover problem by determining the profitability measures of the individual business units. They find, as predicted, that the relative incentive weight on aggregated corporate-wide measures is positively and significantly associated with the inter-segment sales measures, and negatively and significantly associated with the diversification measures.

$$
{ }^{36} \text { Or equivalently as } \frac{\beta_{A}^{1}}{\beta_{D}^{1}}=\frac{g_{1} \sigma_{1}^{2}}{f_{1} \sigma_{2}^{2}-g_{1} \sigma_{1}^{2}} \text {. }
$$


Keating (1997), using a survey sample of 78 firms and divisions, also documents that divisional interdependencies impact performance measure choice at the business unit manager level. He finds that the use of firm-wide accounting measures increases as a division manager's impact on other divisions increases and decreases with growth opportunities and other managers' impact on that division. Keating also documents that the use of stock price-based incentives increases as the size of the division relative to the overall size of the firm increases.

Baiman et al. (1995) use a proprietary data set to study differences across firms with respect to the allocation of tasks from the parent firm to its business units and the level of compensation risk imposed on business unit managers. They develop a model in which the agent (business unit manager) is always informed about a productivity parameter, while the principal (corporate CEO) may not be informed about the division's productivity parameter. Their model suggests that an expert principal with superior information will tend to allocate fewer tasks to the agent and instead dictate appropriate actions to the division manager, imposing more compensation risk on the agent to bring out higher effort on those tasks that are allocated. They empirically measure task decentralization using a high or low task allocation metric collected in their survey, and compensation risk as the ratio of contingent annual compensation to total annual compensation. They find that compensation risk increases with the parent's task expertise (high if the parent corporation and business unit have the same 2-digit SIC code, low otherwise) and the relative size of the business unit, while task allocation is decreasing in both factors. Baiman et al. also include the compensation risk imposed on the firmwide $\mathrm{CEO}$ as an independent variable in the business unit manager risk regressions, and find that it loads positively and significantly. While they include it to control for idiosyncratic firm effects, Fisher and Govindarajan (1991) interpret this result as indicating social comparison between managers. Despite interpretation differences, this result raises interesting issues of how incentives given to top management by the board of directors filter down into the hierarchy.

As discussed earlier, many compensation studies include a proxy for the firm's opportunity set as an exogenous, independent variable in explaining compensation contracts. Holthausen et al. (1995a) allow for the possibility that the investment opportunity set is endogenously chosen by a firm's managers as a function of the compensation contract, and that the contract is simultaneously determined by the investment opportunity set. They focus on business unit managers on the premise that most innovation decisions are made at the business unit level. They define the investment opportunity set (or innovative activity) as the number of patents per million dollars of sales for a business unit, and compensation as the ratio of expected long-term compensation to total compensation. They estimate the following nonrecursive 
system:

innovation $_{t+2}=f\left(\right.$ compensation $_{t}$, market structure $_{t}$, firm factors fir $\left._{t}\right)$, compensation $_{t}=g\left(\right.$ innovation $_{t+2}$, firm factors f $_{t}$, division factors $\left.s_{t}\right)$.

They find modest evidence that compensation is positively related to future innovation, but no evidence that compensation as measured has a positive relation with the expected innovation opportunity set.

Finally, Leone and Rock (1999) examine multi-period aspects of business unit manager compensation. Using detailed data on 76 business units of a large multinational corporation, they empirically establish that budgets are revised in a manner consistent with the ratchet principle. Ratcheting is said to occur when positive variances in performance lead to greater absolute changes in the following year's budget than do changes in budgets associated with negative variances of the same magnitude. They operationalize this idea by estimating the evolution of budgeted performance as a function of realized variances from budget as Budget $_{t+1}-$ Budget $_{t}=\alpha+\lambda\left(\right.$ Actual $_{t}-$ Budget $\left._{t}\right)$ $+\lambda_{n} D_{t}\left(\right.$ Actual $_{t}-$ Budget $\left._{t}\right)$. Budgeted and actual performance in each period are stated in terms of accounting quantities, and $D_{t}=1$ if Actual $_{t}<$ Budget $_{t}$ and 0 if Actual $_{t}>$ Budget $_{t}$. They estimate this equation and find that $\lambda>0$ $(0.892)$ and $\lambda_{n}<0(-0.450)$. This implies that when actual performance exceeds budget in a given year, the budgeted performance for next year is increased by almost 90 percent of the variance. In contrast, if actual is below budget, next year's budget is decreased by 44 percent of the variance $\left(\lambda+\lambda_{n}\right)$. That is, budgets increase by almost the entire extent of positive budget variances, but only partially decrease in response to a budget shortfall.

Leone and Rock go on to use this ratcheting result to investigate the earnings management behavior of managers subject to ratcheting budgets. They illustrate in a simple two period model that earnings management behavior (discretionary accruals) designed to maximize bonuses over both periods is very different when managers anticipate ratcheting budgets rather than fixed budgets. On average, bonus maximizing accruals are lower under ratcheting budgets. They find that proxies for discretionary accruals are better explained by bonus maximizing behavior under a ratcheting model than under a fixed budget assumption. In a related paper, Murphy (1999a) assumes ratcheting behavior to hypothesize that firms using internally determined standards will have smoother earnings patterns than firms using externally determined standards. Murphy assumes that internally determined standards are subject to ratcheting and provide incentives to smooth earnings, while external standards (e.g., industry-relative market performance) are not influenced by managerial actions. Murphy reports evidence consistent with this hypothesis.

These papers raise interesting issues of what determines firms' decisions to expose managers to ratcheting or not. That is, what determines cross-sectional differences in performance budget ratcheting? 


\subsection{Discussion and synthesis}

The measurable importance of accounting information in determining the compensation of top executives at publicly traded U.S. companies appears to be shrinking in recent years. Evidence exists that accounting information is becoming relatively less important in determining the annual cash compensation of top executives (Bushman et al., 1998), and that the sensitivity of cash compensation to changes in shareholder wealth is shrinking rapidly relative to the sensitivity of stock and stock option portfolios (Hall and Leibman, 1998; Murphy, 1999b). In addition, in a recent working paper, Core et al. (2000) decompose the variance of changes in CEOs' firm-specific wealth into stock price-based and nonprice-based components. They find that for most CEOs, stock returns is the dominant component of their incentives, documenting that for $65 \%$ of the CEOs in their sample, the variation in wealth changes that is explained by stock returns is at least 10 times greater than the component not explained by stock returns. Thus, while accounting information likely remains key to incentive contracting within corporate hierarchies, these facts represent a significant challenge for future accounting research.

First and foremost, why is the market share of accounting shrinking, and can cross-sectional differences in the extent of shrinkage be explained? To a large extent this is equivalent to asking why the use of stock option grants has been increasing and explaining cross-sectional differences in granting strategies, but there is also the issue of why the role of accounting in annual cash compensation is shrinking. Assuming this is an equilibrium phenomenon, the change in contract design must be caused by changes in the environment. Has the information content of accounting information itself deteriorated, or should we look to more fundamental changes in the economic environment? For example, Milliron (2000) documents a significant shift over the past 20 years in board characteristics measuring director accountability, independence, and effectiveness in the direction consistent with a general increase in directors' incentive alignment with shareholders' interests.

A number of environmental changes are candidates for explaining the observed evolution in contract design and boards. For example, the emergence of institutional investor and other stakeholder activist groups in the 1980s created pressure on firms to choose board structures designed to facilitate more active monitoring and evaluation of managers' performance. In addition, new regulations were instituted by the Securities and Exchange Commission and the Internal Revenue Service in the early 1990s to require that executive pay be disclosed in significantly more detail and be approved by a compensation committee composed entirely of independent directors. It is also the case that the nature of the firm itself may have changed. Recent research notes that conglomerates have broken up and their units spun-off as stand-alone companies, that vertically integrated manufacturers have relinquished direct 
control of their suppliers and moved towards looser forms of collaboration, and that specialized human capital has become more important and also more mobile (e.g., Zingales, 2000; Rajan and Zingales, 2000). Do these environmental changes explain the shrinking role of accounting information in top executive contract design, or does the answer lie elsewhere?

A related question concerns whether the recent evidence implies that accounting information in general has a lower impact on managerial behavior. As documented, for example in Murphy (1999b), the vast majority of executive stock options do not incorporate a market or peer group index, implying that payoffs to executives can depend on many factors beyond their understanding or control. Besides the impact of random macro-economic shocks, stock prices also reflect the private information, interpretations, opinions and expectations of investors. However, executives likely understand the mapping from their actions to accounting numbers better than the mapping from actions to equity value, and accounting numbers along with analyst's forecast of earnings continue to exert a substantial influence on investors' assessments of equity values.

In addition, boards of directors still apparently determine cash compensation based on an intricately designed portfolio of performance measures including individual performance evaluation and nonfinancial performance measurement (Bushman et al., 1996; Ittner et al., 1997). And as noted by Hayes and Schaefer (2000), the ability of unexpected current cash compensation to predict future performance has not declined in recent periods despite the observed shift in other aspects of contract designs. Thus, despite the explosion in stock option grants, the evidence that boards still design intricate cash compensation payouts indicate that this still remains an important channel by which boards communicate expectations to top management. Given that a primary task of the board is to hire and fire top management, the apparent care exercised by boards in determining the basis for cash compensation cannot be dismissed as unimportant just because large stock option portfolios exist. The ultimate importance of cash compensation and its underlying performance measurement issues to the corporate governance process can only be understood as part of a deeper understanding of the process by which boards manifest their fiduciary responsibilities.

It is also important to understand the circumstances under which accounting is relatively more or less important to the contracting process. For example, accounting numbers can become relatively more important in the performance evaluation of top executives when the firm is in trouble, as stock price will reflect the market's assessments of top management's replacement.

Finally, in examining the role of accounting information in incentive contracting, it is useful to consider theoretical structures beyond the classical principal-agent model with its emphasis on the trade-off between risk sharing and incentives. As discussed above, empirical work in economics and 
accounting specifically testing for such a trade-off has met with mixed success, with some studies finding evidence in favor of the trade-off while others do not. While the weak evidence on the relation between risk and observed contracts may result from poor proxies for performance measure noise (e.g., Sloan, 1993), it also may be that the standard principal-agent model is not the right model of top executive pay, or that important features of the environment are missing from the model. Several recent papers in economics raise some interesting issues related to these later possibilities, and should be of interest to researchers interested in understanding observed contracting arrangements.

Lazear (1999b) argues that while incentives matter, research to date has generally ignored the selection or sorting explanations for contract design. Lazear (1999b) considers situations where the main contracting problem is that managers have private information about a firm's prospects that are unavailable to outside investors. Lazear's sorting model implies optimal incentive coefficients on firm performance significantly different from what might be expected from solely considering a pure risk-incentive tradeoff. Prendergast (1999b) considers the possibility that existing theories are missing something about the relation between inducing individuals to exert effort and the riskiness of the environment. He argues that there are reasons why a positive relation exists between risk in the environment and incentive intensity, in contrast to the negative relation implied by standard principal-agent models. While not dismissing the validity of the standard risk-return trade-off, he presents theoretical reasons why this relationship is difficult to find in the data. ${ }^{37}$

In the next section, we turn to a discussion of future research possibilities that focus on the use of accounting information in a broad range of specific governance mechanisms in addition to formal incentive compensation contracts. A number of these ideas also have implications for future compensation contract research.

\section{The role of accounting information in specific governance mechanisms: directions for future research}

We propose ideas for future governance research concerning the use of financial accounting measures in the operation of corporate control mechanisms. The economics and finance literatures identify a number of internal and external control mechanisms to consider. Internal corporate control mechanisms (in additional to managerial incentive plans) include shareholder and

\footnotetext{
${ }^{37}$ This position is similar in spirit to that taken by Aggarawal and Samwick (1999b) in arguing that the competitive environment can cause the incentive weight on rival-firm performance to be positive, swamping any relative performance evaluation.
} 
debtholder monitoring, board monitoring, corporate bylaws and charters, and the internal managerial labor market. External mechanisms include the market for corporate control, the external managerial labor market, competition in the product market, and national legal and judicial systems that protect investors' rights. In what follows, we discuss several promising research directions along with a discussion of pertinent existing research. We discuss these ideas under Sections 3.1-3.3.

\subsection{Interactions across governance mechanisms}

While governance research typically focuses on a particular governance mechanism in isolation, a more complete understanding requires an explicit recognition of interactions across governance mechanisms. Although there are a large number of potential interactions that can be considered, we focus on several promising interactions to illustrate our proposed research concept.

Consider first interactions between product market competition and the use of accounting information in executive compensation contracts and in determining managerial turnover probabilities. As discussed above in the context of RPE (Section 2.5.6), the nature of product market competition can impact both formal compensation contracts and a board's hiring and firing decisions. Aggarawal and Samwick (1999b) argue that in more competitive industries (higher product substitutability) wage contracts are designed to incorporate strategic considerations and attempt to create incentives for less aggressive price competition. DeFond and Park (1999), examining CEO turnover probabilities, posit that in more competitive industries peer group comparisons are more readily available, creating opportunities for more precise performance comparisons. While these papers measure competition by Herfindahl Indices, Parrino (1997), also looking at turnover, makes an argument similar to DeFond and Park (1999), but focuses on the heterogeneity of an industry (as measured by the correlation of stock returns within an industry). Jagannathan and Srinivasan (1999) examine whether product market competition, as measured by whether a firm is a generalist (likely to have more comparable firms) or a specialist (few peers), reduces agency costs in the form of free cash flow problems.

The papers just cited all suggest that the nature of product market competition matters for incentives and the design and operation of incentive mechanisms. There are many research opportunities here. First, note that the strategic contracting story proposed by Aggarawal and Samwick (1999b) predicts higher positive weight on peer group performance as competition increases, while the other stories predict higher negative weight on peer group performance (more RPE) as competition increases. Can these competing stories be resolved? Does the measure of competition used make a difference? If increased competition, however measured, reduces agency costs and creates 
more peer comparison opportunities (including the supply of potential replacement executives), how is the design of incentive contracts impacted? This can encompass examining the role of own-firm and peer group accounting information as a function of competitiveness. It is also possible that more competition can increase the costs to disclosing proprietary information, implying potentially higher levels of private information which in turn can impact the relative governance value of public performance measures. For example, the relative value of accounting performance versus stock price performance in explaining managerial turnover can vary with the level of product market competition.

Next, consider the market for corporate control. Changes in the operation of the market for corporate control alters the pressure on managers, and cause changes to other governance mechanisms. For example, Bertrand and Mullainathan (1998) examine the impact on executive compensation of changes in states' anti-takeover legislation. The idea is that the adoption of anti-takeover legislation reduces pressure on top managers, and causes firms to substitute more intensive incentives elsewhere. They find that pay-forperformance sensitivities and levels of CEO pay increase (the latter possibly to compensate for increased risk imposed on CEOs) after adoption of antitakeover legislation. This design can be refined to look at more intricate changes in contract design, including the portfolio of performance measures used to determine payouts. For example, a change in takeover pressure can alter managerial incentives to distort firms' accounting numbers and thus change their role in contracting and performance evaluation. In a related study, Hubbard and Palia (1995) look at the reaction of executive pay in the banking industry to relaxation of inter-state banking restrictions, and thus the ability of banks to acquire other banks across state borders. A key element in their study is the possibility that this deregulation increased the demand by banks for more talented managers. An increased demand for talent can lead to more scrutiny by boards to discern talent levels of incumbent managers, and thus lead to a change in the relative roles of accounting and stock price performance in determining managerial turnover.

Finally, consider the relation between the structure of the board of directors and managerial turnover. Weisbach (1988) interacts board composition and firm performance in estimating CEO turnover. He finds that CEO turnover is more sensitive to performance (market-adjusted returns and accounting performance) when boards are dominated by outsiders. A possible interpretation of this result is that outsider-dominated boards inherently do a better job of monitoring managers. However, when accounting numbers inherently do a poor job of reflecting managerial performance and other aspects of firm performance, firms may respond by placing a higher proportion of inside directors on the board to substitute insiders' in-depth knowledge of firmspecific activities and the firm's competitive environment (Bushman et al., 
2000b). In this case, outsider-dominated boards will be observed when accounting information is a good measure of managerial talent and performance, implying that accounting performance should be highly correlated with turnover decisions (and vice versa for insider-dominated boards).

The issue of whether the world is in equilibrium or out of equilibrium makes it difficult to draw unambiguous inferences from this research design. (See Hermalin and Weisbach (2000) for an interesting discussion of this issue.) If the observed world reflects optimizing behavior, then prescriptions for improved policies drawn from this research design are problematic because the data are already reflecting optimal choices. Core et al. (1999), who examine the relation between board characteristics, ownership structure, and CEO compensation, link "suboptimal" governance configurations with lower future performance of the firm. This approach raises similar concerns. Why are suboptimal configurations observed in the data? (See Himmelberg et al. (1999) for an interesting empirical approach to this issue and Murphy (1999b) for a useful discussion of the approach.)

\subsection{Financial accounting information and additional corporate control mechanisms}

A natural extension of prior research is to address the role of financial accounting information in the operation of other specific governance mechanisms.

An important example in this respect is DeAngelo's (1988) study of the role of accounting information in proxy fights. She documents a heightened importance of accounting information during proxy fights by providing evidence of the prominent use of accounting numbers. She presents evidence that dissident stockholders typically cite poor earnings performance as evidence of incumbent managers' inefficiency (and rarely cite stock price performance), and that incumbent managers use their accounting discretion to portray a more favorable impression of their performance to voting shareholders. DeAngelo suggests that accounting information may better reflect incumbent managerial performance during proxy fights because stock price anticipates potential benefits from removing underperforming incumbent managers. Other examples of research on specific governance mechanisms include takeovers (Palepu, 1986), boards of directors (Dechow et al., 1996; Beasley, 1996), shareholder litigation (Kellogg, 1984; Francis et al., 1994; Skinner, 1994), debt contracts (Smith and Warner, 1979; Leftwich, 1981; Press and Weintrop, 1990; Sweeney, 1994), and the audit function (Feltham et al., 1991; DeFond and Subramanyam, 1998).

There are many opportunities in this regard. For example, while there exists evidence that boards of directors use accounting information in incentive 
contracts and firing decisions, we actually know very little about the internal operation of boards. Besides setting compensation and hiring/firing CEOs, boards serve a decision ratification role (Fama and Jensen, 1983a,b) and provide input into the strategic planning processes of firms. What information set serves as the basis for the full scope of board operations? What is the relative importance of own-firm accounting information, peer group accounting information, analysts' reports, proprietary internal information, stock price information? Despite the evidence that stock price has become the prime performance measure in top management compensation contracts (Hall and Leibman, 1998; Murphy, 1999b; Core et al., 2000), it is unlikely that boards rely on stock price as the sole information variable.

Another opportunity concerns the role of accounting information in the allocation of both cash flow and control rights in contracts between pre-IPO entrepreneurs and venture capital firms. As discussed in Section 2.2, Kaplan and Stromberg's (1999) analysis of venture capital financing contracts documents that the allocation of both control and cash flow rights plays out over multiple rounds of financing, and that the allocation of control rights can be contingent on observable measures of financial and nonfinancial performance, as well as on certain observable actions. Given the recent explosion in venture capital financing deals in the U.S. and abroad, opportunities for access to interesting data sets probably will increase, opening exciting possibilities for understanding the role of accounting information and other performance measures in the allocation of control rights. This creates the potential for deeper insight into the ways accounting information promotes economic efficiency.

Finally, most governance research focuses on the U.S. While data limitations have been an impediment to international governance research to date, opportunities are likely to increase. As Europe moves to a more equity-based business culture (e.g., Black, 2000b), pressure for additional disclosure and transparency in governance processes is likely to increase. Descriptive data on the degree to which the very existence and operation of control mechanisms vary across countries holds enormous potential. Such data not only would provide useful insights into how the mechanisms by which financial accounting potentially can serve a governance role vary around the world, but also would provide data for testing complementarities between high-quality financial accounting regimes and high-quality control mechanisms in promoting economic efficiency as suggested in Section 4. This potential should not be underestimated. For example, as discussed in more detail below, recently developed data sets on cross-country differences in investor legal protections and legal enforcement efficiencies (e.g., La Porta et al., 1998) have spawned an explosion of research on the role of cross-country differences in governance in impacting the economic efficiency of countries and of specific industries across countries. Such data sets would also allow accounting researchers to 
potentially integrate data about the governance environment with recent research using cross-country data to examine theories of conservatism in financial accounting (e.g., Ball et al., 2000a, b).

\subsection{Limits to accounting information and the endogenous formation of governance structures}

Do limits to the information provided by financial accounting systems in some settings lead to substitution toward costly monitoring mechanisms and/ or statutory constraints on managerial behavior? This is a natural extension of the compensation literature discussed in Section 2.5.5 which documents that firms shift towards the use of more costly performance measures when accounting information has limited usefulness (Bushman et al., 1996; Ittner et al., 1997). In this section, we illustrate this line of inquiry with several recent examples.

The first example is La Porta et al. (1998). This paper argues that protection of investors from opportunistic managerial behavior is a fundamental determinant of investors' willingness to finance firms, of the resulting cost of firms' external capital, and of the concentration of stock ownership. They develop an extensive database of the laws concerning the rights of investors and the enforcement of these laws for 49 countries from Africa, Asia, Australia, Europe, North America, and South America. Interestingly, one of the regimes they suggest affects enforcement of investors' rights is the country's financial accounting regime. They measure quality of the accounting regime with an index developed for each country by the Center for International Financial Analysis and Research (CIFAR). The CIFAR index represents the average number of 90 items included in the annual reports of a sample of domestic companies. La Porta et al. document substantial cross-country differences in the level of investor protection provided by these laws and their enforcement which are related to the colonial origin of the laws, including English, French, German, and Scandinavian origins. They also document that the concentration of stock ownership in a country is significantly negatively related to both the CIFAR index and an index of how powerfully the legal system "favors minority shareholders against managers or dominant shareholders in the corporate decision-making process, including the voting process" (p. 1127), after controlling for the colonial origin of the legal system and other factors. These results are consistent with their prediction that in countries where the accounting and legal systems provide relatively poor investor protection from managerial opportunism, there is a substitution toward costly monitoring by "large" shareholders.

In a related study, Bushman et al. (2000b) document a negative crosssectional relation between the concentration of stock ownership of large public companies in the U.S. and the "timeliness" of earnings. Timeliness is defined as 
in Ball et al. (2000a) as "the extent to which current earnings incorporate current value-relevant information". Bushman et al. (2000b) develop several metrics for earnings timeliness based on traditional and reverse regressions of stock prices and changes in earnings. They view inter-firm differences in the value relevance of earnings as primarily the result of differences in the ability of U.S. GAAP to capture current changes in value within current earnings due to inherent measurability limitations, rather than accounting choices made by a firm's managers. ${ }^{38}$

The results reported in both Bushman et al. (2000b) and La Porta et al. (1998) are consistent with the predicted negative relation between the information provided by financial accounting systems and the demand for costly monitoring by "large" shareholders. The results of both studies, however, must be interpreted with care. The authors cannot completely rule out the possibility that the causality goes in the opposite direction; i.e. that more diffusely held firms in the U.S. choose to report more value relevant earnings given the discretion allowed within U.S. GAAP. These concerns are, perhaps, even more serious in the cross-country analysis of La Porta et al. (1998). For example, cross-country differences in disclosure practices are in some cases politically motivated, perhaps, by a desire to keep control over a country's assets concentrated in the hands of controlling families, banks, or the government (see Rajan and Zingales (1999) for further discussion).

A second example of a corporate control mechanism is monitoring by the board of directors. Following similar reasoning to that above, the demands on the board to undertake costly information acquisition and processing activities are likely to be high in settings where the information provided by the financial accounting system is relatively low. Bushman et al. (2000b) also investigates how a demand for costly information collection and processing activities affects the composition of the board. This study relies on the idea developed in Fama and Jensen (1983a, b) that optimal board structures require both inside directors due to their deep firm-specific knowledge, expertise and information, and outside directors who specialize in advising and policing major strategic decisions. Bushman et al. (2000b) find that both the proportion of inside directors and the proportion of "highly reputable" outside directors are negatively related to the timeliness of earnings, before and after controlling for R\&D, capital intensity and firm growth opportunities. This evidence is consistent with the hypothesis that limits to the information provided by financial accounting measures are associated with a greater demand for firmspecific information from inside directors and high-quality outside directors.

\footnotetext{
${ }^{38}$ Bushman et al. (2000b) argue that the inherent measurability limitations of a given GAAP regime differ across production functions and investment opportunity sets.
} 
We turn now to a discussion of research ideas to examine direct connections between properties of financial accounting information and real managerial decisions.

\section{Future research into financial accounting information and economic performance}

\subsection{Introduction}

\subsubsection{Overview}

The focus of the research discussed in Sections 2 and 3 is specific governance mechanisms, and the role of financial accounting information as an input to these mechanisms. The research discussed in Section 3 also considers the effects of limitations of financial accounting information on board and stock ownership structures and other corporate control mechanisms. The governance research discussed above is interesting, in part, because the effectiveness of corporate control mechanisms is expected to affect real managerial decisions. Hence, the use of financial accounting information in corporate governance mechanisms is one channel by which financial accounting information potentially enhances the investment decisions and productivity of firms.

In this section, we suggest future research that directly examines the effects of financial accounting information on economic performance. We propose empirical research focused on four themes. The first theme is whether the availability of financial accounting information does affect economic performance, and by how much. This research is expected to capture the combined effects of financial accounting information on economic growth and productivity from the more effective operation of corporate governance mechanisms as well as from other sources.

The second theme is the specific channels through which financial accounting information affects economic performance. We suggest research to isolate the economic effects of financial accounting information through specific channels, with an emphasis on isolating the effects of financial accounting information's governance role.

The third theme for future research is how the economic benefits of financial accounting information vary with other factors. That is, to what extent do other factors, such as the legal protection of investors' rights or other corporate control mechanisms, the auditing regime, or the relative importance of securities markets versus bank financing, influence the economic effects of financial accounting information? We expect the interactions between the quality of financial accounting regimes and effectiveness of corporate control mechanisms to provide evidence on the governance effects of financial accounting information per se. We expect the interactions between financial 
accounting regimes and other domestic institutions to provide evidence of the determinants of the total economic value of financial accounting information from better governance as well as other channels.

The fourth theme is how the economic effects vary with specific features of the accounting regimes. For example, which types of disclosures contribute most to economic performance? Does economic performance increase with the frequency of interim reporting? And do differences in accounting methods used to measure the accounting numbers lead to differences in economic performance? We expect this research to provide new evidence on the properties of financial accounting systems that affect their quality for governance purposes in particular, as well as the properties that affect the overall quality of financial accounting systems as reflected in the combined economic effects from all sources.

We organize the remainder of Section 4 as follows. In Section 4.1.2, we describe the channels through which we expect financial accounting information to enhance economic performance. The purpose of this discussion is to motivate the proposed research into the relation between financial accounting information and economic performance, and to provide more specific background for our suggestions for isolating the governance effects of financial accounting information. In Section 4.1.3, we describe why we believe crosscountry designs, the focus of Section 4, represent a promising setting for investigating the effects of financial accounting information on economic performance. In Section 4.2, we describe in greater detail our four themes for future research, and make preliminary suggestions for testing our predictions. In Section 4.3, we consider additional research design issues.

\subsubsection{Channels through which financial accounting information affects economic performance}

We expect financial accounting information to affect economic performance through at least three channels as illustrated in Fig. 1. First, we expect financial accounting information of firms and their competitors to help managers and investors identify and distinguish between good and bad investment opportunities (project identification). ${ }^{39}$ The absence of reliable information in an economy impedes the flow of human and financial capital toward good investments and away from bad, even without moral hazard. Hence, even in the absence of agency conflicts between managers and investors, financial accounting data will enhance efficiency by providing useful information that

\footnotetext{
${ }^{39}$ The use of financial accounting information for the identification of good and bad projects is broader than just identifying good and bad opportunities for investing financial capital. It also includes the identification of opportunities for increasing the productivity of assets in place, and the identification of good versus bad opportunities for current or potential managers and other employees to invest their human capital.
} 


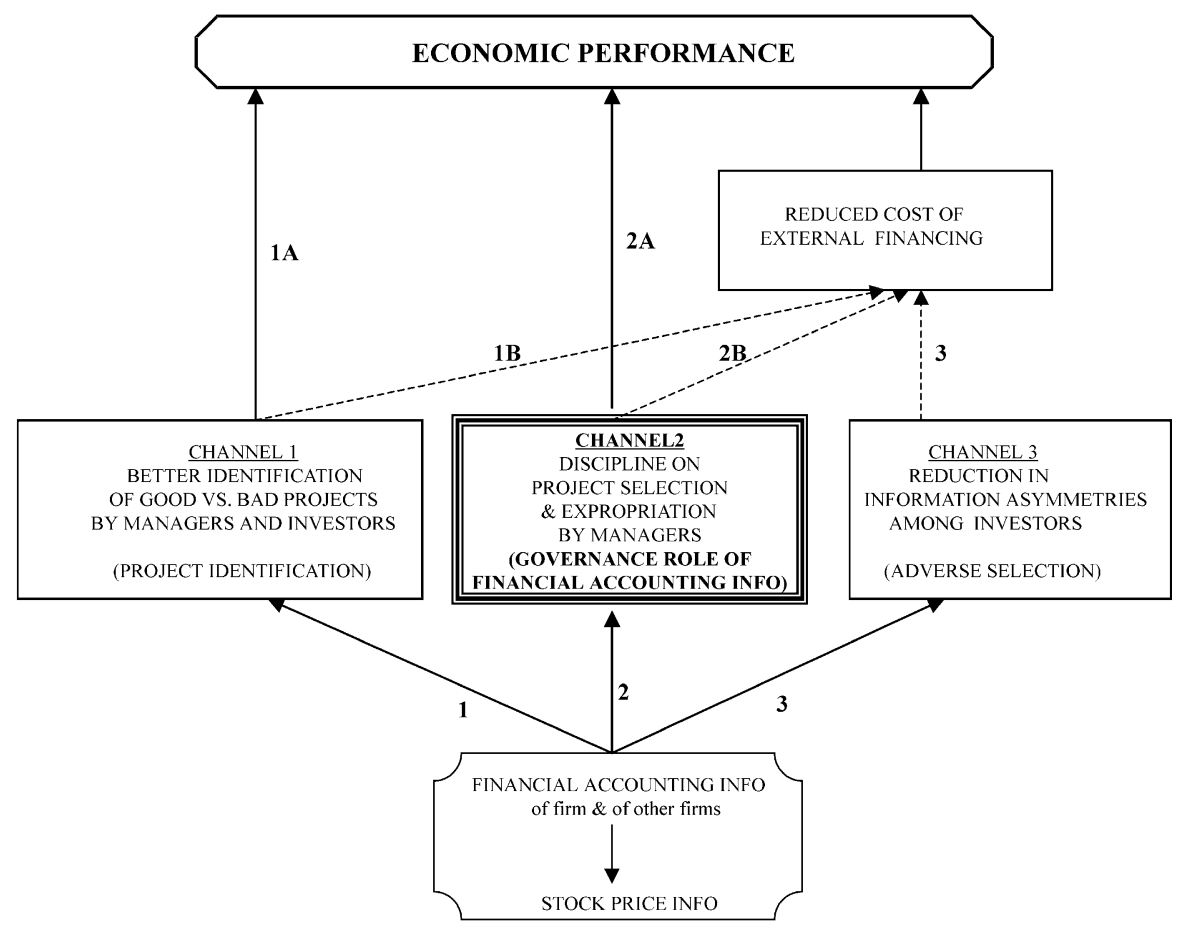

Fig. 1. Three channels through which financial accounting information may affect economic performance. Governance role of financial accounting information operates through channel 2.

enables managers and investors to identify value creation opportunities with less error. This leads directly to the more accurate allocation of capital by investors and managers to their highest valued uses, as indicated by arrow $1 \mathrm{~A}$ in Fig. 1. In addition, the lower estimation risk perceived by investors will likely reduce the cost of capital, further contributing to economic performance as indicated by arrow $1 \mathrm{~B}^{40}$

Financial accounting systems clearly can be a direct source of information to managers and investors about investment opportunities. For example, managers can identify promising new investment opportunities on the basis of the high profit margins reported by other firms. Financial accounting systems also can be an indirect source of information by supporting the informational role played by stock price. ${ }^{41}$ Efficient stock markets in which

\footnotetext{
${ }^{40}$ See Barry and Brown (1985) for a discussion of estimation risk and its potential effect on the cost of capital.

${ }^{41}$ High-quality financial accounting regimes can support the informational role played by stock price in several ways. As argued by Black (2000a), financial accounting information is likely to be a
} 
stock prices reflect all public information about firms' prospects, as well as private information of individual investors, presumably communicate that aggregate information to managers and current and potential investors through stock prices. This represents an example of the process discussed by Hayek (1945) by which price systems aggregate and communicate knowledge dispersed among many individuals, making better use of total existing knowledge. ${ }^{42}$ Hence, high-quality financial accounting regimes can provide information directly to managers and investors about good and bad projects, and provide information indirectly by supporting an active stock market. ${ }^{43}$

The second channel through which we expect financial accounting information to enhance economic performance is its governance role. Financial accounting information is a direct input to corporate control mechanisms designed to discipline managers to guide resources toward projects identified as good and away from projects identified as bad, and to prevent managers from expropriating the wealth of investors. In addition, financial accounting information supports the information aggregation and monitoring functions of stock markets. ${ }^{44}$ For example, managerial compensation contracts tied to accounting measures and informed stock prices can motivate managers to create value. ${ }^{45}$ As another example, well-functioning stock markets can

\footnotetext{
(footnote continued)

prerequisite to the very existence of a vibrant stock market. Second, financial accounting information is impounded in stock price. (See Kothari (2001) for a review of research concerning the impact of financial accounting information on stock prices.) And third, high-quality financial accounting information may encourage analyst following, further contributing to the information reflected in stock prices. Dechow et al. (1996) document evidence that analyst following of specific firms declines when they become the subject of SEC enforcement actions for alleged violations of GAAP, and Chang et al. (2000) document that cross-country differences in analyst following are positively correlated with the quality of financial accounting regimes.

${ }^{42}$ Dow and Gorton (1997) and Dye and Sridhar (2000) consider settings in which the firm's stock price aggregates and communicates information to the firm's managers. This process may be especially useful for managers of firms with new, complex technologies. See Boot and Thakor (1997).

${ }^{43}$ As discussed by Levine (1997), some economists have pointed out that the public goods aspect of stock price may impede the private acquisition of information. He indicates that existing theories have not yet established the complete connection between the functioning of the stock market, the private acquisition of information, and economic growth.

${ }^{44}$ Seminal work on the information production role of stock markets includes Grossman (1976), Grossman and Stiglitz (1980), and Verrecchia (1982). Research on the information production role of stock markets in relation to monitoring management includes Holmstrom and Tirole (1993) and Bushman and Indjejikian (1993a).

${ }^{45}$ Accounting and equity-based incentive plans also may enhance economic performance by directing individuals' investments in human capital to high value sectors, and by attracting highly skilled managers and other workers to firms where their value-added is highest. For example, the high equity values and the employee stock option gains in the high tech sector have affected the MBA student demand for e-commerce courses and have undoubtedly affected the career goals of
} 
facilitate corporate takeovers that replace underperforming managers, the mere threat of which can improve managerial incentives (see, for example, Scharfstein, 1988; Stein, 1988). ${ }^{46}$

The governance role of financial accounting (and stock price) information contributes directly to economic performance from the more efficient management of assets in place, from managers' better selection of investments, and the reduced expropriation of investors' wealth by the managers (arrow 2A). The governance role of financial accounting information also enhances economic performance indirectly by lowering the risk premium demanded by investors to compensate for the risk of loss from expropriation by opportunistic managers (arrow 2B).

The third channel through which we expect financial accounting information to enhance economic performance is by reducing adverse selection and liquidity risk (arrow 3). Firms' pre-commitment to the timely disclosure of high-quality financial accounting information reduces investors' risk of loss from trading with more informed investors, thereby attracting more funds into the capital markets, lowering investors' liquidity risk (see Diamond and Verrecchia, 1991; Baiman and Verrecchia, 1996; Leuz and Verrecchia, 2000; Verrecchia, 2001). Capital markets with low liquidity risk for individual investors can facilitate high-return, long-term (illiquid) corporate investments, including long-term investments in high-return technologies, without requiring individual investors to commit their resources over the long term (Levine, 1997). ${ }^{47}$ Hence, well developed, liquid capital markets are expected to enhance economic growth by facilitating corporate investments that are high risk, high return, long term, and more likely to lead to technological innovations, and high-quality financial accounting regimes provide important support for this capital market function.

\footnotetext{
(footnote continued)

this talent pool. We thank Eddie Lazear for this observation. The role of incentive contracts in attracting and sorting talent is an important theme in the economics literature (e.g., Lazear, 1999a, b).

${ }^{46}$ However, it is possible that a well-functioning stock market may reduce the efficiency of resource allocation. For example, Shleifer and Summers (1988) suggest that corporate takeovers allow new managers to break prior implicit contracts with managers, other employees and suppliers. Hence, to the extent that a liquid stock market facilitates such takeovers, the efficiency of resource allocation may decline due to the potential violation of implicit contracts by the new managers.

${ }^{47}$ In contrast, Shleifer and Vishny (1986) and Bhide (1993) argue that liquid stock markets and diffuse ownership structures can reduce shareholders' incentives to monitor the managers, and thus impede economic efficiency. Levine and Zervos (1998) proxy for liquidity of a country's stock market as the value of stock trading relative to the size of the market (turnover) and the value of trading relative to the size of the economy. Using a cross-country design, they find both measures to be positively and significantly related to rates of economic growth, capital accumulation and productivity growth.
} 
In summary, we expect financial accounting information to enhance economic performance through at least three channels, one of which represents the governance role of financial accounting information. We propose research to capture the economic effects of financial accounting information through distinct channels with an emphasis on isolating the governance effects of financial accounting information.

\subsubsection{Advantages of cross-country designs}

We believe that cross-country analyses are one promising way to assess the effects of financial accounting information on economic performance for several reasons.

First, there are considerable, quantifiable cross-country differences in financial accounting regimes. ${ }^{48}$ Second, evidence from the economics literature suggests that there are dramatic cross-country differences in economic efficiency. Hence, there are meaningful cross-country differences in economic performance to explain. As argued in Rajan and Zingales (1999), Modigliani and Perotti (2000), and Acemoglu et al. (2000), inefficient institutions can be sustained in a given country for a long time due to political agendas other than efficiency. Hence, the possibility of observing grossly inefficient financial accounting and other regimes in the cross-country sample is not ruled out. In contrast, within the U.S. where market forces (e.g. market for corporate control, managerial labor market, competitive product market) and explicit and implicit compensation contracts powerfully motivate and discipline managers, gross inefficiencies are less likely to be captured within the sample.

Third, evidence from the recent economics literature suggests that there are substantial cross-country differences in other institutional factors, such as the legal protection of investors' rights. These differences make it feasible to test hypotheses concerning interactions between financial accounting regimes and other domestic regimes. For example, is publicly disclosed financial accounting information more useful for monitoring and disciplining managers when the laws are designed to protect the shareholders from expropriation by managers?

Research in economics and finance has laid the groundwork for the research proposed here in three important ways. First, theoretical research in economics and finance has developed causal links between the information available to outside suppliers of capital and economic performance. ${ }^{49}$ This theoretical

\footnotetext{
${ }^{48}$ Regime shifts within a country or region of the world (e.g. privatization), however, also may provide rich opportunities for examining the effects of financial accounting information and economic growth and efficiency.

${ }^{49}$ See Levine (1997) for a review of theories linking financial development and economic growth. While many theories consider the beneficial effects of information on economic growth, some theories consider adverse consequences of information. For example, some theories suggest that the early release of public information can destroy risk sharing opportunities (Hirshleifer, 1971; Marshall, 1974); signaling of private information can result in over-investment or other
} 
literature provides a powerful motivation for testing the relation between properties of financial accounting regimes and direct measures of economic performance, as well as for testing the relation between accounting regimes and properties of the supporting capital markets and institutions. ${ }^{50}$

Second, recent research in economics and finance has developed empirical designs and proxies for testing the cross-country relation between domestic institutional factors and economic performance. Empirical proxies include direct measures of economic activity (e.g. GDP growth, capital accumulation, increase in number of business enterprises, R\&D investments, productivity, and sensitivity of corporate investments to their valued-added) as well as measures of the breadth, liquidity, valuation, global integration, and efficiency of the supporting capital markets in each country. This new empirical literature provides guidance and data that lower the barriers to entry for accounting researchers.

Third, preliminary results emerging from this literature provide important new evidence that the protection of investors from expropriation by corporate insiders has significant effects on the development and efficiency of capital markets, the cost of capital, and economic growth and efficiency. Hence, the protection of investors from expropriation by corporate insiders appears to be an important determinant of economic performance. Preliminary results emerging from this literature also provide encouraging new evidence of a positive relation between the quality of financial accounting information and economic performance. Together these two types of evidence suggest that future research into the governance role of financial accounting information has the potential to detect first-order economic effects.

Accounting researchers' detailed knowledge of financial accounting systems and financial accounting issues represents a comparative advantage that can be brought to bear on a research agenda that builds on this emerging literature in economics. Furthermore, this comparative advantage should be exploited because of the high potential to provide new evidence concerning the economic effects of financial accounting information, the channels through which financial accounting information affects economic performance, the factors that influence the economic effects of financial accounting information, and the

\footnotetext{
( footnote continued)

misallocations of capital (Spence, 1973); more frequent reporting of information can increase moral hazard costs by increasing the scope of strategic behavior available to managers (Holmstrom and Milgrom, 1987; Abreu et al., 1991; Gigler and Hemmer, 1998); information release can complicate contract renegotiation and impose costs on the agency if parties cannot commit not to renegotiate contracts (Laffont and Tirole, 1990; Demski and Frimor, 1999).

${ }^{50}$ Research concerning the relation between financial accounting regimes and the properties of domestic capital markets and institutions falls naturally within the boundaries of capital markets research, and, therefore, is not our focus here. In Section 5, we discuss the relation between capital markets research and governance research.
} 
properties of high value financial accounting regimes from the standpoint of enhancing economic performance. Ultimately, the proposed tests and the resulting evidence of the relation between financial accounting information and economic performance will lead to a more complete understanding of the determinants of financial accounting regimes. Finally, by considering the information and limits to the information provided by financial accounting systems to test predictions from economic theories concerning the effects of information per se, the evidence provided from this research will have implications for the underlying economic theories.

As discussed in Section 4.3, there are limits to the potential of this research to test causality, and to rule out the possibility that estimates of the economic effects of accounting are attributable to omitted correlated variables. However, as long as accounting researchers proceed in the design and interpretation of their studies with their "eyes wide open", there is much to learn from this line of inquiry.

\subsection{Four themes for future research into financial accounting information and economic performance}

In this section we discuss in greater detail four themes for future research - the effects of financial accounting information on economic performance, the channels through which financial accounting information affects economic performance, the factors that amplify or dampen the economic effects of financial accounting information, and the characteristics of high-quality financial accounting regimes from the standpoint of economic performance. We also make preliminary suggestions for empirically investigating these four issues.

\subsubsection{Effects of financial accounting information on economic performance}

To provide background for our specific research suggestions, we first describe two recent papers that investigate the relation between financial accounting regimes and economic performance, Rajan and Zingales (1998a) and Carlin and Mayer (2000).

Both Rajan and Zingales (1998a) and Carlin and Mayer (2000) investigate economic effects of financial accounting regimes by exploring the relation between the CIFAR index for sample countries and various aggregate measures of economic inputs and outputs. ${ }^{51}$ The CIFAR index represents the average number of 90 specific items disclosed in the annual reports of at least three companies per country, including items from the income statement, balance sheet, funds flow statement, accounting methods, stock price data,

\footnotetext{
${ }^{51}$ The Center for International Financial Analysis and Research published the CIFAR index in periodic editions of International Accounting and Auditing Trends.
} 
governance information (e.g. identity of directors and officers, executive compensation, large stockholders), and general information. The CIFAR index is interpreted as the quality of the financial accounting information available in an economy, where a larger number of disclosures is a proxy for better financial accounting information.

To examine the relation between financial accounting information and economic performance, Rajan and Zingales (1998a) estimate the following regression model:

$$
\begin{aligned}
\text { Growth }_{j k}= & \text { constant }+\beta_{1 \ldots m} * \text { Country indicators } \\
& +\beta_{m+1 \ldots n} * \text { Industry indicators } \\
& +\beta_{n+1} * \text { Industry j's share of value added in manufacturing } \\
& \text { in country } k \text { in } 1980 \\
& +\beta_{n+2} *(\text { External financing dependence of industry } j * \\
& \text { Financial development of country } k)+\varepsilon_{j k}
\end{aligned}
$$

where Growth $_{j k}$, is real GDP growth of manufacturing industry $j$ in country $k$ during $1980-1990 .{ }^{52}$ Country and industry indicators are $0-1$ dummy variables for country and industry, and industry $j$ 's share of value added in the manufacturing sector in country $k$ is based on the GDP of the industry at the beginning of the test period (1980). The dependence on external financing, assumed to be an inherent (exogenous) characteristic of each industry regardless of location, is estimated on the basis of actual financing activities for each industry in the U.S. where capital market frictions are relatively small. The CIFAR index for each country in 1990 is used as a measure of financial development.

\footnotetext{
${ }^{52}$ Empirical studies that examine the relation between the development of the financial sector and indicators of the health of the associated economies often consider growth in the economic indicator, such as growth in per capita GDP. An econometric advantage of using growth in the economic indicator is that the levels of GDP are measured with considerable error each year in many countries. Measuring the dependent variable on the basis of differences in the economic indicator is intended to reduce the measurement error. The independent variables are expressed in levels, however. While there is fairly widespread support for the view that financial development enhances corporate investing and economic output, it is less clear that this should lead to higher growth rates. One channel by which financial development can be argued to increase economic growth is through its facilitation of investments in new technologies that have a positive cumulative effect on rate of return on investment in that economy. In spite of the somewhat tenuous theoretical link between financial development and economic growth, Levine and Zervos (1993) suggest that, although results of cross-country regressions of economic growth are often very sensitive to the set of variables included in the models, the relation between economic growth and measures of financial development are relatively robust. Following the lead of the economists, studies of the relation between an accounting regime and economic indicators that we propose may be best performed on the basis of the growth in the economic indicators.
} 
Rajan and Zingales (1998a) document a significant positive coefficient on the interaction between industry-level demand for external financing and the country-level CIFAR index $\left(\beta_{n+2}\right)$. This result supports the prediction that the growth in GDP is disproportionately higher in industries with a strong exogenous demand for external financing in countries with a large CIFAR index, after controlling for fixed industry and country effects. They also find that the growth in the number of new enterprises is disproportionately high in industries with a high demand for external financing in countries with a large CIFAR index.

Using a similar design, Carlin and Mayer (2000) find that the growth in GDP and the growth in $R \& D$ spending as a share of value added are disproportionately higher in industries with a high demand for external equity financing in countries with a large CIFAR index. Together the results of Rajan and Zingales (1998a) and Carlin and Mayer (2000) are consistent with the interpretation that high-quality accounting regimes promote GDP growth and firm entry by lowering the cost of external financing. Furthermore, the lower cost of equity capital associated with high-quality accounting regimes is particularly useful for the stimulation of high-risk, long-term investments in R\&D. ${ }^{53}$

There are three natural ways to extend Rajan and Zingales (1998a) and Carlin and Mayer (2000). An assumption underlying these studies is that there are severe barriers to raising external capital outside the home country. Over the last decade barriers to external financing outside the home country have declined as evidenced by the increasing number of cross-listings. A second, and perhaps related trend is the development and gradual acceptance of International Accounting Standards. Future research could explore whether these trends reduce the impact of home country financial accounting standards on the costs of external financing.

A second extension is to investigate the combined effects on economic performance of cross-country differences in financial accounting systems from all sources. Rajan and Zingales (1998a) and Carlin and Mayer (2000) investigate the effects of financial accounting regimes specifically through the reduction in the cost of external financing. However, as illustrated in Fig. 1, we do not expect all effects of financial accounting information on economic performance to result from a reduction in the cost of capital. To examine the effects of financial accounting information on economic performance from all sources, we suggest that future researchers estimate more traditional crosscountry regressions widely used in the economics literature, as indicated

\footnotetext{
${ }^{53}$ The negative relation between the CIFAR index and IPO underpricing documented by Lombardo and Pagano (1999) provides further evidence that high-quality financial accounting regimes reduce the cost of external equity financing.
} 
in $(13):{ }^{54}$

$$
\begin{aligned}
& \text { Economicperformance }_{k} \\
& =\text { constant }+\left[\beta_{1} * A C C T G_{-} Q U A L_{k}\right]+\left[\Sigma_{i=2, n} \beta_{i} * X_{i k}\right]+\varepsilon_{k},
\end{aligned}
$$

where an aggregate measure of economic performance for each country $k$ is the dependent variable, $A C C T G_{-} Q U A L_{k}$ is an index of the quality of the financial accounting regime in each country $k$, and $X_{i k}, i=2, n$ represents other country level control variables expected to affect economic performance. ${ }^{55} \beta_{1}$ reflects the combined economic effects of financial accounting information from a reduction in the cost of capital as well as other sources.

A third extension is to investigate the relation between financial accounting information and additional measures of economic performance. Both Rajan and Zingales (1998a) and Carlin and Mayer (2000) consider value added during a given time period as measured on the basis of real gross domestic product (GDP). Real GDP represents the market value of all final goods and services produced during a specific period of time, adjusted for inflation. Large GDP can result from large corporate investments and/or high productivity of firms' investments (rate of return). Rajan and Zingales (1998a) and Carlin and Mayer (2000) consider the growth in real GDP and the growth in some types of corporate investments. It would be interesting to explore the relation between financial accounting information and productivity of corporate investments (see Tadesse (2000) for a recent paper along these lines).

We expect the input of high-quality financial accounting information to corporate control mechanisms to improve the productivity of investments by increasing the efficiency with which assets in place are managed, by encouraging investments in high return projects, by reducing investments in low return projects, and by reducing the expropriation of investors' wealth. ${ }^{56}$ High-quality financial accounting information also enhances the productivity of investments by reducing the error with which managers and investors identify good versus bad investments. Finally, high-quality financial accounting information enhances productivity by lowering the cost of financing investments in new, productivity enhancing technologies.

\footnotetext{
${ }^{54}$ In Section 4.3, we discuss the advantages and disadvantages of the traditional cross-country regression model as illustrated in Eq. (13) and the Rajan and Zingales (1998a) regression model as illustrated in Eq. (12).

${ }^{55}$ As discussed in Section 4.3, in traditional cross-country regressions (i.e. no fixed country effects), it is important to control for a variety of determinants of economic performance such as human capital. See Levine and Zervos $(1993,1998)$.

${ }^{56}$ The likelihood of wealth expropriation by government will also impact incentives for firms to seek maximum efficiency. If the government is likely to expropriate gains from efficiency, why seek these gains in the first place. Cross-sectional designs will be confounded to the extent that the propensity for governments to expropriate differs across countries and across industries within a country.
} 
The productivity of investments at the firm, industry, or country-wide level can be measured by the ratio of the output to investment (rate of return). In addition, an approach developed by Wurgler (2000) can be used to examine the extent to which capital in each country is allocated to value creating opportunities and withdrawn from value destroying ones. Wurgler (2000) estimates the elasticity of gross investment to value added as a measure of the efficiency of resource allocation in each country from

$$
\ln I_{j k t} / I_{j k t-1}=\alpha_{k}+\eta_{k} \ln V_{j k t} / V_{j k t-1},
$$

where $I_{j k t}$ is the gross fixed capital formation in industry $j$, country $k$, year $t$, $V_{j k t}$ is value added in industry $j$, country $k$, year $t$. He interprets the elasticity for each country $k, \eta_{k}$, as a measure of the extent to which country $k$ reduces investment in declining industries and increases investment in growing industries. Using the elasticity measure for each country as his dependent variable, he tests for a positive relation between elasticity and measures of financial development in each country. A similar approach can be used to examine the relation between the elasticity measure for each country and the quality of the financial accounting regime, using $\eta_{k}$ as a dependent variable in model (13).

As predicted, Wurgler (2000) documents a significant positive relation between value added elasticities and financial development as measured by the ratio of the stock market capitalization to GDP and the ratio of credit outstanding to GDP. He also finds a positive relation between value-added elasticities and an index of investor rights from La Porta et al. (1998), and a significant negative relation between elasticities and the fraction of an economy's output due to state-owned enterprises. ${ }^{57}$ Most interesting for our purposes, however, is that he documents a significant relation between elasticities and a measure proxying for the amount of firm-specific information impounded in stock prices in a given economy, supporting the hypothesis that more informed stock prices provide better direction for managers' investment decisions. ${ }^{58} \mathrm{We}$ are not aware of any direct evidence concerning the relation

\footnotetext{
${ }^{57}$ Wurgler's index of investor rights is the product of two measures from La Porta et al. (1998). The first measure is an integer from 0 to 10 representing the number of shareholder protections that are included in the commercial code of each country plus the number of creditor protections that are included in the bankruptcy and reorganization laws. The second measure is a continuous variable between 0 and 1 that measures the domestic "rule of law" (i.e. quality of domestic enforcement of the law).

${ }^{58}$ The proxy is the fraction of stocks in a country whose prices move in the same direction in a given week as reported in Morck et al. (2000). Following Morck et al. (2000), stock market synchronicity is interpreted as a low amount of firm-specific information impounded in stock prices in a given country. Wurgler (2000) represents one of the few "direct" tests (of which we are aware) of whether the informational efficiency of the stock market enhances the efficiency with which corporate resources are directed toward value creating opportunities. We return to this issue in Section 5. Also see Durnev et al. (2000).
} 
between the quality of financial accounting regimes and the sensitivity of corporate investments to value-added. This is an interesting issue for future research.

\subsubsection{Channels through which financial accounting information affects economic performance}

The research described above does not isolate the effects on economic performance of the governance role of financial accounting information. Prior research supports the prediction that high-quality financial accounting regimes reduce the cost of external financing. However, as illustrated in Fig. 1, the governance role of financial accounting information (channel 2) is just one of several channels through which financial accounting information reduces the cost of capital. Furthermore, prior research does not capture the direct effects on managerial actions of the governance role of financial accounting information depicted by arrow 2A in Fig. 1.

Our second theme for future research is to explore specific channels through which financial accounting information affects economic performance. Of particular interest here are the opportunities to isolate the economic effects of financial accounting information through its governance role. We offer two preliminary suggestions.

The first suggestion builds on Wurgler's (2000) approach for estimating the elasticity of investment to value added in each country, ( $\eta_{k}$ from Eq. (14)) as a measure of the extent to which country $k$ reduces investment in declining industries and increases investment in growing industries. These investment elasticities depend upon the extent to which managers identify value creating and destroying opportunities, the extent to which managers are motivated to allocate capital to value creating investments and withdraw capital from value destroying investments, and the extent to which capital is available to invest in value creating opportunities. Hence, financial accounting information will increase investment elasticities through any of the three channels depicted in Fig. 1.

Additional analysis in Wurgler (2000) suggests a way to isolate the effects of financial accounting information on managerial incentives to allocate capital to the highest valued uses. Specifically, Wurgler estimates value added elasticities in each country $k$ separately for industry-year observations reflecting increasing $\left(\eta_{k}^{+}\right)$versus decreasing $\left(\eta_{k}^{-}\right)$value added, and computes the difference $\left(\eta_{k}^{+}-\eta_{k}^{-}\right)$. The magnitude of the difference in each country is viewed as a measure of the severity of the control problem, because self-serving managers are less likely to downsize investments in declining projects than they are to increase investments in growth opportunities (see Jensen, 1986). As predicted he finds that these differences are greater in countries with relatively weak legal protection of investors against expropriation by corporate insiders. His results support this prediction, and he interprets these results as evidence of the role of 
investors' rights in limiting managers' tendency to overinvest free cash flows in declining opportunities. A similar analysis can be used to test the effects of financial accounting information in limiting managers' tendency to overinvest free cash flows in declining opportunities, by using the difference, $\eta_{k}^{+}-\eta_{k}^{-}$, as a dependent variable in model (13).

A second suggestion is to develop proxies for the relative magnitude of the inherent potential agency costs from shareholder-manager conflicts for each industry, regardless of where the industry is located. Because the U.S. has welldeveloped corporate control mechanisms, the U.S. is a promising setting for estimating proxies to capture inter-industry differences in the potential benefits from effective governance mechanisms. For example, there are considerable inter-industry differences in the U.S. in the extent to which compensation packages impose risk on executives for incentive purposes. The average incentive-intensity of the compensation packages of executives in each industry in the U.S. can be used as an estimate of the relative magnitude of inherent agency costs for each industry $j$, regardless of location. ${ }^{59}$ Measures of economic performance for each industry within each country (excluding the U.S.) can be regressed against the interaction of the inherent agency costs for the industry and the quality of the financial accounting regime in the country, as illustrated in the following:

$$
\begin{aligned}
& E C O N_{-} P E R F_{j k} \\
& =\text { constant }+\beta_{1 \ldots m} * \text { Country indicators }+\beta_{m+1 \ldots n} * \text { Industry indicators } \\
& \quad+\beta_{n+1} *\left(A G E N C Y_{-} C O N F L I C T j * A C C T G_{-} Q U A L k\right)+\varepsilon_{j k},
\end{aligned}
$$

where $E C O N_{-} P E R F_{j k}$ is a measure of economic performance for industry $j$ in country $k, A G E N C Y_{-} C O N F L I C T_{j}$ is a measure of the inherent agency costs in industry $j$, and $A C C T G_{-} Q U A L_{k}$ is a measure of the quality of the financial accounting regime in country $k$. The slope, $\beta_{n+1}$, captures the interaction between the relative magnitude of the agency conflict in industry $j$ and the quality of the financial accounting regime in country $k . \beta_{n+1}$ reflects the effects on economic performance of high-quality accounting information through the governance channel, after controlling for industry and country effects.

\subsubsection{Factors influencing the effects of financial accounting information on economic performance}

A third theme for future research is how the economic effects of financial accounting information vary with other factors. We expect that there are powerful interactions between the financial accounting regime and other

\footnotetext{
${ }^{59}$ The approach suggested here for isolating the governance effects of financial accounting information is patterned after the approach that Rajan and Zingales (1998a) use to isolate the economic effects of financial accounting information resulting from the reduction in the cost of external financing.
} 


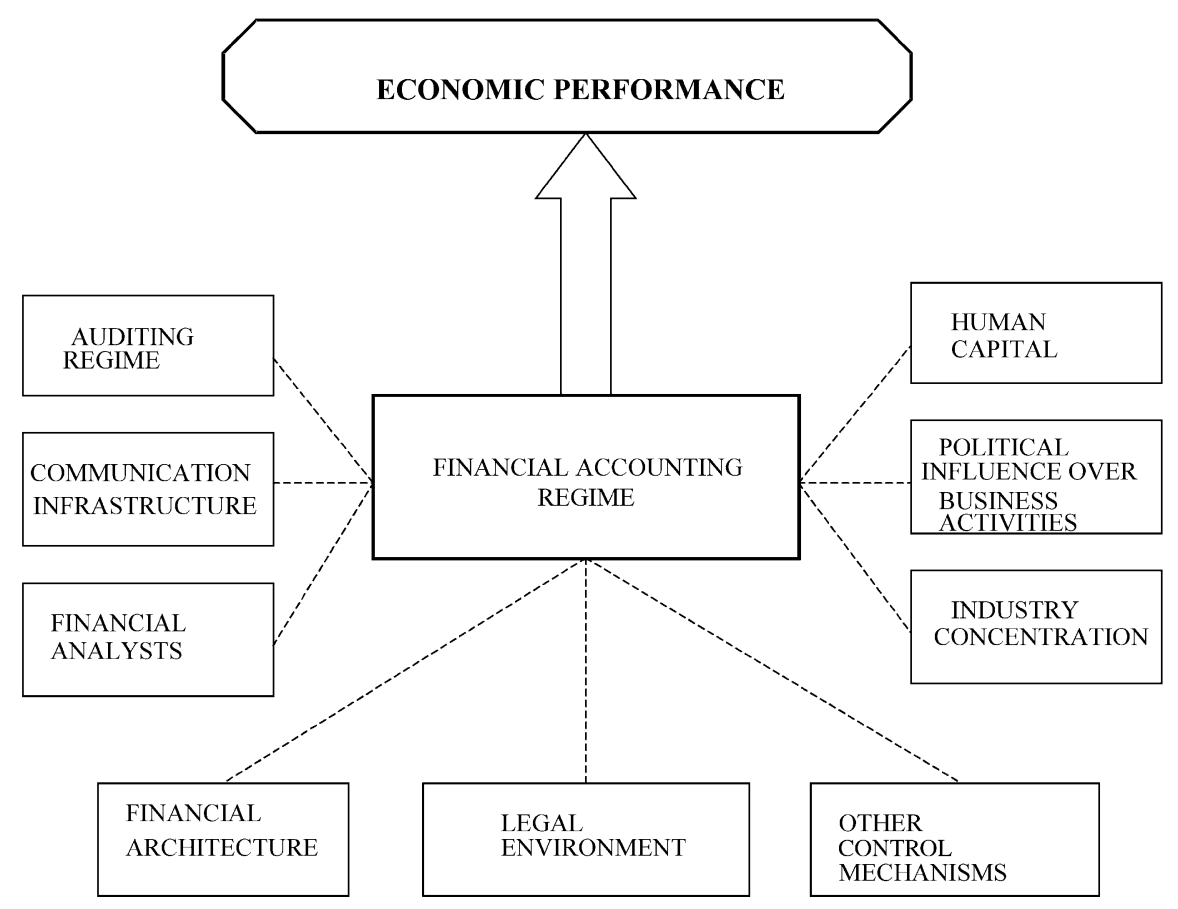

Fig. 2. Predicted interactions between financial accounting regimes and other factors in affecting economic performance.

institutional characteristics, as illustrated in Fig. 2. These institutional characteristics include the auditing regime, the communication infrastructure, analyst following, the financial architecture, the legal environment (including the existence of laws protecting investors against expropriation by corporate insiders and the enforcement of basic property and contract rights), corporate control mechanisms other than legal protection of investors' rights, industry concentration, political influence over business activities (including the ability and propensity of wealth expropriation from firms through the political process), and human capital.

Many of these institutional characteristics are likely to influence the economic effects of financial accounting information generated through all three channels depicted in Fig. 1. For example, a high-quality auditing regime is likely to increase the accuracy with which accounting data help managers and investors identify good and bad investments (channel 1), the effectiveness with which accounting data discipline managers (channel 2), and the extent to which accounting data reduce adverse selection among investors (channel 3). However, the predicted interactions between the quality of the financial 
accounting regime and corporate control mechanisms reflect the governance effects of financial accounting information specifically (channel 2). Hence, examining the interactions between the quality of the financial accounting regime in each country and the quality of such corporate control mechanisms in each country represents another way to isolate the governance effects of financial accounting information. Examining the additional interactions presented in Fig. 2 can contribute more generally to the development of a theory of the total value of financial accounting information to an economy resulting from the combined effects of all three channels illustrated in Fig. 1. We now discuss each interaction illustrated in Fig. 2.

4.2.3.1. Auditing regime. We expect the economic benefits of financial accounting disclosures to increase with the rigor which with the reported accounting numbers are audited. Accounting numbers that are audited rigorously are likely to be less distorted by managerial reporting biases and errors. Hence, we expect rigorously audited accounting data to provide better information for identifying good and bad investments, disciplining managers, and reducing adverse selection among investors. Furthermore, we expect that the enhanced credibility of the accounting data resulting from rigorous audit regimes increases the reliance on accounting data by economic agents (e.g. investors, directors, managers, competitors, acquirers, etc.).

4.2.3.2. Communication infrastructure. We expect the economic effects of financial accounting information to increase with the extent to which an extensive communication infrastructure makes the information widely, quickly, and cheaply available to economic agents. For example, we expect the benefits of financial accounting information to increase with the dissemination of the accounting data through various communication channels such as the financial press, radio, television, and the Internet.

4.2.3.3. Financial analyst community. We expect the effects of financial accounting information on economic performance to vary with the sophistication and size of the financial analyst community. However, whether financial accounting information and analysts' activities are substitutes or complements is not clear ex ante. On the one hand, financial analysts facilitate the interpretation and dissemination of the information provided by financial accounting data, amplifying the economic benefits of a high-quality accounting regime. In addition, detailed financial accounting disclosures are likely to increase the accuracy of analysts' earnings forecasts and recommendations. The arguments above suggest that financial accounting disclosures and analyst activities are complements.

On the other hand, information collection and processing activities by financial analysts helps economic agents to overcome some of the limitations of 
poor financial accounting information. And in the limit, high-quality financial accounting information may reduce the need for analysts' research activities. These arguments suggest that financial accounting disclosures and analyst activities are substitutes. ${ }^{60}$ The net effect of these forces is an interesting empirical issue.

4.2.3.4. Financial system architecture. We expect the economic benefits of financial accounting information to vary with a country's financial system architecture. For example, we expect the economic benefits of financial accounting information to decline with the importance of intermediated financing (e.g., bank debt) relative to securities markets in providing financing to firms. Theoretical work in finance suggests that information problems associated with bank loans differ from information problems associated with securities traded in capital markets. (See, for example, Diamond, 1984; Boot and Thakor, 1997; Modigliani and Perotti, 2000.) These arguments suggest that centralized information acquisition and monitoring activities by banks, and long-term bank-borrower relationships make banks less dependent than investors in capital markets on public disclosures of financial accounting information in performing their services to the economy.

In addition, as argued in Rajan and Zingales (1998b), relationship-based investing systems may be designed to preserve a lack of transparency in order to protect the relationships from the threat of competition. They argue that relationship-based systems ensure a return to a financier by granting some form of monopoly power over the firm being financed (e.g., ownership, or position as main lender, supplier or customer). Limitations on competition do not just give the financier power, but also strengthen incentives to co-operate with the borrower. For example, monopoly relationships allow intertemporal cross-subsidies, where low interest rates are charged during bad times and compensated for with higher rates during good times. But maintaining a monopoly requires barriers to entry, which includes poor external disclosure to prevent potential entrants from discerning profitable investment opportunities. Thus, it is not just that relationship investors are less dependent on public information. They may require poor external reporting as a condition of the relationship.

4.2.3.5. Legal environment. We expect the economic benefits of financial accounting information to vary with the legal environment. There are at least two related aspects of the legal environment that we expect to affect the economic benefits of financial accounting information. One aspect is the extent

\footnotetext{
${ }^{60}$ Although our discussion is focused on interactions, the main effects of analysts' activities are potentially interesting also. We are not aware of any direct evidence in the U.S. or elsewhere concerning the relation between analysts' outputs and the decisions and productivity of firms.
} 
to which laws protect investors from expropriation by corporate insiders. The effectiveness of financial accounting information in limiting expropriation of investors' wealth by corporate insiders is likely to be greater when investors are armed with stronger legal rights. And investors with better financial accounting information about managerial decisions and outcomes are in a better position to exercise their legal rights against expropriation by corporate insiders. A significant positive interaction between the quality of the financial accounting regime and the legal protection of investors' rights can be interpreted as evidence of governance effects of financial accounting information.

A second aspect is the extent to which general property and contract rights of firms and individuals are enforced. This includes protection of private property from government expropriation. An important way in which financial accounting information enhances efficiency is by providing information that attracts entrepreneurs and capital to engage in productive activities in an economy. Lack of effective protection of the property and contract rights of firms and investors is likely to impede this process. ${ }^{61}$ For example, to the extent that governments can routinely expropriate wealth from firms, even excellent information about investment opportunities may not attract investors.

4.2.3.6. Other corporate control mechanisms. We expect the economic benefits of financial accounting information to increase in the presence of additional corporate control mechanisms beyond investors' legal rights, such as managerial incentive plans and an active market for corporate control. ${ }^{62}$ As discussed in Section 3 and illustrated in Fig. 1 (channel 2), we expect that a potentially important channel through which financial accounting information can enhance economic performance is by providing input to a variety of corporate control mechanisms. Hence, the existence of powerful control mechanisms is expected to amplify the economic benefits of financial accounting information. A significant positive interaction between the quality of the financial accounting regime and the quality of control mechanisms can be interpreted as additional support for the governance effects of financial accounting information.

\footnotetext{
${ }^{61}$ Data on laws protecting investors' rights as well as data on more general enforcement of laws are available for 49 countries in La Porta et al. $(1997,1998)$.

${ }^{62}$ While data are readily available on cross-country differences in laws protecting investors' rights from La Porta et al. $(1997,1998)$, we are not aware of readily available sources of data on crosscountry differences in other corporate control mechanisms. Future research into cross-country differences in corporate control mechanisms such as that suggested in Section 3 may generate such data. Alternatively, researchers can use as a proxy for investors' risk of expropriation by insiders the presence of a controlling shareholder whose objectives deviate from shareholder maximization (see La Porta et al., 1999a).
} 
4.2.3.7. Industry concentration. We expect the economic benefits of financial accounting information to decline with the concentration of productive activity in an economy among a small number of firms. The idea here is that one way in which financial accounting disclosures enhances efficiency is by providing public information that allows other firms in the economy to identify good and bad investment opportunities. Of course, it is also the case that financial accounting information can be used to regulate concentrated industries.

4.2.3.8. Political influence over business activities. We expect the economic benefits of financial accounting information to vary with political influence on business activities. The ability of politicians and bureaucrats to seek wealth transfers via the political process can differ across countries. As the ability and propensity of politicians to expropriate wealth from profitable companies increases, the efficiency effects of accounting information of a given quality would diminish. The incentives of investors and managers to process and act on information are reduced as the returns to their actions are reduced through the expropriation process. ${ }^{63}$

For example, Djankov et al. (2000) document significant differences in the way countries regulate the entry of new business enterprises. They find that higher costs of entry are associated with weaker political rights, fewer constraints on the power of top government officials, and higher corruption, consistent with the view that strict entry regulation benefits the regulators rather than the economy. To the extent that relatively unconstrained political power, less representative governments, and low political rights impede the flow of capital to its highest valued uses, we expect the economic benefits of financial accounting information to be reduced. We also expect the economic benefits of financial accounting information to decline with the extent to which business enterprises are owned and controlled directly by the state, whereby profit maximization may take a back seat to other political agendas.

4.2.3.9. Human capital. Finally, we expect the economic benefits of financial accounting information to increase with the education level of the population. Well educated managers and investors are more likely to understand the information provided by financial accounting data. In addition, incentive plans and other corporate control mechanisms tied to financial accounting and stock price measures will have more favorable economic effects if employees understand how their actions affect these performance measures.

\footnotetext{
${ }^{63}$ It is recognized in the accounting literature that the ability of rent-seeking regulators to use accounting information to isolate profitable expropriation opportunities can affect the accounting decisions of firms, and thus the information properties of financial accounting reports (see Watts and Zimmerman (1986, Chapter 10) for an indepth discussion). Here, we are not addressing endogenous formation of accounting regimes, but rather the impact of varying political environments on the efficiency effects of accounting information of a given quality.
} 
Each predicted interaction above can be tested by including an interaction between an index of the quality of the financial accounting regime and a given factor of interest in a cross-country model of economic performance as illustrated in the following model:

$$
\begin{aligned}
& \text { Economic performance }_{k} \\
& =\text { constant }+\left[\beta_{1} * A C C T G_{-} Q U A L_{k}\right]+\left[\beta_{2} * \text { FACTOR }_{k}\right] \\
& \quad+\left[\beta_{3} * A C C T G_{-} Q U A L_{k} * F A C T O R_{k}\right] \\
& \quad+\left[\Sigma_{i=4, n} \beta_{i} * X_{i k}\right]+\varepsilon_{k},
\end{aligned}
$$

where economic performance ${ }_{k}$ is a measure of economic performance for country $k, A C C T G_{-} Q U A L_{k}$ is a measure of the quality of the financial accounting regime in country $k, F A C T O R_{k}$ is the factor whose interaction with accounting is of interest, and the $X_{i k}$ are control variables for country $k$ expected to affect economic performance. The coefficient on the interaction term, $\beta_{3}$, can be interpreted as a second derivative; i.e. by how much does a one-unit increase in a given factor increase the impact on economic performance of a one-unit change in the accounting index.

As suggested above, if $F A C T O R_{k}$ is a proxy for the effectiveness of corporate control mechanisms in country $k$, then $\beta_{3}$ isolates the governance effects of financial accounting information. Hence, future research also can investigate how the governance effects of financial accounting information, in particular, vary with other institutional factors by modifying model (16) as follows:

$$
\begin{aligned}
& \text { Economic performance }{ }_{k} \\
& =\text { constant }+\left[\beta_{1} * A C C T G_{-} Q U A L_{k}\right] \\
& +\left[\beta_{2} * \text { CONTROL }_{k}\right]+\left[\beta_{3} * \text { FACTOR } k\right] \\
& +\left[\beta_{4} * A C C T G_{-} Q U A L k * C O N T R O L_{k}\right] \\
& +\left[\beta_{5} * A C C T G_{-} Q U A L_{k} * \text { CONTROL }_{k} * \text { FACTOR }_{k}\right] \\
& +\left[\Sigma_{i=6, n} \beta_{i} * X_{i k}\right]+\varepsilon_{k} \text {, }
\end{aligned}
$$

where CONTROL $L_{k}$ is a proxy for the quality of corporate control mechanisms in country $k$ such as the legal protection of investors' rights, and $F A C T O R_{k}$ is some institutional factor other than the quality of corporate control mechanisms. For example, if the quality of the auditing regime is included as FACTOR $R_{k}$ in model (17), then $\beta_{5}$ can be interpreted as evidence of how the auditing regime influences the governance effects of financial accounting information.

A second way to investigate how a given institutional factor affects the governance effects of financial accounting information is to modify model (15) 
as follows:

$$
\begin{aligned}
& E C O N_{-} P E R F_{j k} \\
& =\text { constant }+\beta_{1 \ldots m} * \text { Country indicators } \\
& +\beta_{m+1 \ldots n} * \text { Industry indicators } \\
& +\beta_{n+1} *\left(\text { AGENCY_CONFLICT } Y_{j} * A C C T G_{-} Q U A L_{k}\right) \backslash \\
& +\beta_{n+2} *\left(A G E N C Y_{-} C O N F L I C T_{j} * A C C T G_{-} Q U A L_{k}\right. \\
& \left.* F A C T O R_{k}\right)+\varepsilon_{j k},
\end{aligned}
$$

where $E C O N_{-} P E R F_{j k}$ is a measure of economic performance of industry $j$ in country $k, A G E N C Y_{-} C O N F L I C T_{j}$ is an exogenous measure of the potential agency conflict in industry $j, A C C T G_{-} Q U A L_{k}$ is a measure of the quality of the accounting regime in country $k$, and $F A C T O R_{k}$ is the factor of interest. The slope, $\beta_{n+2}$, can be interpreted as evidence of how this other factor influences the governance effects of financial accounting information. ${ }^{64}$

The economics literature suggests numerous economic indicators and provides data that can be used as dependent variables in models (16)-(18). For example, these include measures of growth in total value added, growth in value added of existing enterprises, growth in the number of business enterprises, the accumulation of physical and R\&D capital, growth in productivity (i.e. rate of return) of firms' investments, and value added elasticities. Furthermore, the economics literature and the World Bank provide data on the financial architecture, legal and political environments, industry concentration, human capital, communication infrastructure and other factors for numerous countries. An obvious candidate for the index of the quality of the financial accounting regime is the CIFAR index, given its use in the economics and finance literatures. As described below, there are significant opportunities to improve the measurement of the quality of financial accounting information, and to explore which properties of financial accounting systems matter most.

\subsubsection{Properties of high-quality financial accounting regimes}

Our fourth theme for future research concerns how economic effects vary with specific properties of the financial accounting regimes. The CIFAR index used in the economics and finance literatures represents the average number of 90 items disclosed in the annual reports of at least three companies per country, including items from the income statement, balance sheet, funds flow

\footnotetext{
${ }^{64}$ In an analogous fashion, the Rajan and Zingales (1998a) model illustrated in Eq. (12) can be modified to investigate how a given institutional factor such as the quality of the audit regime, influences the effects of financial accounting information on the cost of external financing. This can be done by adding a term to capture the interaction between the demand for external financing, the quality of the financial accounting regime, and a given institutional factor of interest.
} 
statement, accounting methods, stock data, special items, and general information (see La Porta et al., 1997). Such an index, however, ignores the differential information content of different types of disclosures within the annual report; for example, accounting versus nonaccounting disclosures, required versus voluntary disclosures, summary accounting measures versus components, income statement versus balance sheet, cash flows versus earnings, or segment disclosures. ${ }^{65}$ The CIFAR index also ignores the effects of the frequency of interim disclosures on economic performance, as well as the differential information content of accounting data attributable to different measurement rules.

The CIFAR index is likely to be a fairly noisy measure of the relative amount of information provided by countries' financial accounting regimes, reducing the power of hypothesis tests. There are substantial opportunities for accounting researchers to use their understanding of financial accounting issues to develop more refined measures of the quality of financial accounting regimes.

In addition, there are opportunities to test hypotheses concerning the differential economic benefits of disclosures of different types, different frequency, and produced by different accounting methods (i.e. measurement). For example, the economic effects of segment disclosures can tested by incorporating in models above indices that reflect the prevalence of segment disclosures in each country. As another example, the effects of different accounting methods such as the use of reserves to smooth earnings, can be tested by incorporating indices that reflect major differences in accounting methods. If the models designed to isolate governance effects of financial accounting information are used for this research (such as models (15), (17), and (18)), researchers can provide new evidence on how the governance effects of financial accounting vary with properties of the accounting regime.

Accounting researchers have a substantial comparative advantage in doing this research as a result of their detailed knowledge of accounting issues and prior capital markets research. The potential payoffs are large for at least two reasons. First, the resulting evidence will provide insight into the characteristics of high performing financial accounting systems. And second, the evidence can be used to construct new measures of the amount of information provided by financial accounting systems, enabling future researchers to conduct more powerful tests of the effects of financial accounting information on economic growth and efficiency.

\footnotetext{
${ }^{65}$ The economic benefits of disclosure requirements is a particularly interesting issue. Requirements enable firms to credibly commit to a disclosure system and are likely to lead to some disclosures that enhance economic efficiency but that are not in the interest of individual firms.
} 


\subsection{Additional empirical design issues}

Cross-country studies of the determinants of economic growth and productivity based on traditional cross-country regression models similar to that illustrated in Eq. (13) are subject to several severe limitations. First, as discussed in Levine and Renelt (1992), there are no well accepted economic theories of growth, capital accumulation, and productivity that clearly specify the complete set of control variables to include in the regression model. Furthermore, measures of the development of the financial sector, such as the CIFAR index, may proxy for any number of important factors. Hence, regression results are likely to be affected by numerous omitted correlated variables, impeding the interpretation of significant tests.

Second, as discussed in Rajan and Zingales (1998a), the explanatory variables in these studies are highly correlated and measured with error, further impeding the interpretation of results. There is no doubt that this is a significant issue for interpreting results on the basis of the CIFAR index. The CIFAR index is highly correlated with numerous other country characteristics that can be expected to affect domestic economic growth. Furthermore, given the crudeness of the CIFAR index, the quality of countries' financial accounting regimes probably are measured with considerable error. A third and related point is that, as demonstrated by Levine and Renelt (1992), test results for a given variable in these economic models often are very sensitive to the set of control variables included. They use an approach called extreme bounds analysis to check whether results on variables of interest are robust with respect to the set of control variables included in the model. However, this does not rule out the impact of measurement error on the results, or the possibility that there still are omitted correlated variables not considered by the researcher.

A fourth limitation of cross-country regressions is that causal inferences are problematic. It is plausible that both measures of financial development, such as the CIFAR index, and measures of economic growth are caused by the same omitted factors. It also is plausible that economic growth stimulates development of extensive financial disclosure systems. In an attempt to address these issues, some researchers check the robustness of their results to the use of instrumental variables. For example, Rajan and Zingales (1998a) use the colonial origin of a country's legal system (i.e. British, French, German, or Scandinavian) to instrument for financial development. However, while colonial origin of a country's legal system is likely exogenous, it arguably affects the subsequent development of so many factors in an economy that it does not provide conclusive evidence about the economic effects of the accounting regime per se. Although some researchers measure financial development prior to the period over which the economic growth is measured in the cross-sectional models, this does not necessarily solve the 
problem. ${ }^{66}$ As suggested by Rajan and Zingales (1998a), a positive relation between at least some measures of financial development (e.g. aggregate market value of the stock market) and subsequent economic growth reflects the capital market's expectations about future growth.

Finally, a fifth limitation is the few degrees of freedom. This is due to both the large number of control variables and the small sample size, constrained by the number of countries with available data for all of the model variables.

These limitations of cross-country designs are well recognized in the economics literature. However, studies using this design that are well motivated, executed, and interpreted appear in first-rate economics journals. Levine and Zervos (1993) conclude that these studies can be "very useful" as long as empirical regularities are interpreted as "suggestive" of the hypothesized relations. Lack of cross-country relations can at a minimum cast doubt on hypothesized relations.

The Rajan and Zingales (1998a) regression model illustrated in Eq. (12) is a useful alternative design. There are several advantages of the Rajan and Zingales design relative to the more traditional cross-country design. A key innovation is the focus on a particular mechanism by which financial development is expected to promote economic growth; i.e. providing low cost outside capital to industries inherently dependent on external financing. By focusing on a specific mechanism by which accounting regimes are expected to enhance economic growth, potential insights are provided about how accounting affects growth, and there are fewer competing explanations for the results. A second advantage of the Rajan and Zingales design is that controls for fixed industry and fixed country effects reduce omitted correlated variables problems, thus reducing data requirements for numerous political and economic factors typically included in cross-country studies. Third, by using observations for industries within each country, their design increases the sample size relative to using countries as the unit of analysis.

These advantages do not imply, however, that there is no role for traditional cross-country designs. The Rajan and Zingales design is an appealing way to examine a specific mechanism by which financial development is expected to affect economic growth. However, it requires the researcher to specify which firms or industries are expected to benefit the most from the mechanism considered, which is not always possible. Furthermore, in some cases the researcher is interested in the total economic benefits from all sources. In these latter settings, cross-country designs are more suitable. Hence, the Rajan and Zingales design and the traditional cross-country design are complementary, and both have potential value for building on the preliminary evidence in the

\footnotetext{
${ }^{66}$ For example, Levine and Zervos (1998) examine the relation between stock market liquidity and both current and future measures of growth, productivity, and capital accumulation.
} 
economics literature of a relation between financial accounting regimes and economic performance.

In closing, it is useful to emphasize the limitations of the proposed crosscountry studies. The most serious limitation concerns the ability to interpret the regression coefficients on the accounting index as a measure of the economic effects of financial accounting information per se. There are at least three problems. First, the CIFAR index is likely to measure the amount of information provided by financial accounting systems with considerable error, biasing the estimated relation between economic indicators and financial accounting information. Second, financial accounting indices are likely to be highly correlated with numerous other determinants of economic growth and productivity. This can lead to problems in testing the relation between financial accounting information and economic indicators due to multicollinearity and omitted correlated variables. And third, the direction of causality may go in the opposite direction; i.e., thriving firms in strong economies disclose more.

Future researchers can address these issues to some extent. As accounting researchers develop more refined measures of the amount of information provided by financial accounting regimes, we expect the measurement error problem to be reduced, but not eliminated. As described above, extreme bounds analysis can be used to check the sensitivity of results to the set of control variables included. And the Rajan and Zingales (1998a) modification to the more traditional cross-country design reduces the likely set of omitted correlated variables. However, the problem of omitted correlated variables is not eliminated by either approach.

We recommend, as a complementary research design, that researchers also consider financial accounting regime shifts as experienced by cross-listing firms or firms switching from home country accounting standards to International Accounting Standards. The effects of financial accounting, per se, are more likely to be isolated by the researcher in these cases. However, inferences from such studies need to consider the possibility that firms' commitment to the "better" accounting regime is not exogenous, and is caused by the same underlying forces that led to observed economic gains.

Finally, while potentially high correlations between accounting regimes and other factors is a nuisance from the standpoint of isolating the potential economic effects of financial accounting information, such correlations are informative. If financial accounting systems 'didn't matter", would they be systematically related to other important determinants of economic growth?

\section{Relation to other accounting research}

In Section 5.1, we describe the relation between governance research and some other economics-based areas of empirical accounting research, including 
positive theory research, managerial accounting research, and capital markets research. In Section 5.2, we argue that future research concerning the connection between capital market and governance uses of financial accounting information is important for developing a more complete understanding of the effects of financial accounting information on economic performance, and make suggestions for exploring this connection. Finally, in Section 5.3 we discuss additional implications of the framework portrayed in Figs. 1 and 2 for future capital markets research opportunities.

\subsection{Relation between governance research and other accounting research}

\subsubsection{Positive accounting theory}

Positive accounting theory research initiated by Watts (1977) and Watts and Zimmerman (1978) investigates how contracts based on financial accounting numbers affect firms' accounting practices. A feature common to this contracting research and governance research is an interest in the use of accounting number in contracts. However, the focus of research in these two areas is different. The positive theory literature usually takes contracts as given, and investigates how the use of accounting numbers in contracts influences firms' measurement of the accounting numbers. Hence, this literature does not address the effects of accounting information on efficiency. In contrast, governance research is concerned with how the information and limits to the information provided by financial accounting measures affect their use in contracts, and how financial accounting information affects firms' resource allocation decisions and productivity through a variety of corporate control mechanisms.

\subsubsection{Managerial accounting research}

Managerial accounting research and capital markets research are motivated, at least in part, by an interest in the efficiency effects of accounting information. Managerial accounting research concerns the use of accounting information for facilitating firms' decision-making and control. Hence, both managerial accounting and governance research investigate the use of accounting information for control purposes. However, managerial accounting research focuses on internally reported accounting information, while governance research concerns the role of externally reported accounting information. The focus on externally reported accounting information enables governance researchers to consider the effects of accounting information on external control mechanisms such as outside shareholder monitoring, the market for corporate control, product markets, and external managerial labor markets.

In spite of the distinction between internal and external reporting, there is likely to be a positive relation between the managerial accounting information 
reported internally and the financial accounting information reported externally. And cross-country differences in the quality of managerial accounting systems will contribute to cross-country differences in economic performance. Hence, managerial accounting systems are a potentially important omitted correlated variable.

However, some of the proposed interactions illustrated in Fig. 2 allow the effects of externally reported accounting information to be largely isolated from effects of internally reported accounting information. For example, we predict that the economic benefits of financial accounting information increase with its dissemination throughout the economy through well-developed communication channels (e.g. financial press, radio, television, etc.). In contrast, we do not expect the media to disseminate internally reported managerial accounting information to the same degree. Hence, if results suggest that the economic effects of financial accounting information increase with the communication infrastructure, this is likely to reflect the favorable economic effects of the widespread dissemination of externally reported accounting information. As another example, we predict that the economic benefits of externally reported accounting information increase with the importance of capital markets relative to intermediated financing because investors in the capital markets are more dependent on public accounting disclosures than are banks. If it is found that economic effects of domestic accounting regimes increase with the importance of capital markets relative to bank financing, this likely reflects the differential quality of public accounting disclosures.

Although the arguments above distinguish managerial accounting information from financial accounting information on the basis of whether the information is internally or externally reported, this distinction is imperfect. Firms may voluntarily disclose information generated by their managerial accounting systems that have no direct relation to financial accounting data. Furthermore, some activities typically associated with managerial accounting, such as cost allocation schemes and transfer pricing, can directly affect published financial accounting disclosures, for example, through inventory carrying values, reported gross margins, or segment profits. These measurement differences will be comingled with other differences in financial accounting regimes, and impossible to disentangle through the interactions discussed above. However, in principle, research into the properties of highquality financial accounting regimes, the fourth research issue proposed in Section 4, can investigate the economic effects of specific measurement principles.

\subsubsection{Capital markets research}

Capital markets research concerns the role of financial accounting information in facilitating the assessments and decisions of investors as 
reflected in the behavior of stock prices and returns, trading volume, or other capital market characteristics. Capital markets research is focused on channels 1 and 3 in the bottom half of Fig. 1. In contrast, governance research concerns the role of financial accounting information in disciplining those who govern firms. Governance research that investigates the use of financial accounting information as an input to corporate control mechanisms is focused on channel 2 in the bottom half of Fig. 1. The governance research proposed in Section 4 that examines the relation between economic performance and the interaction between the quality of financial accounting regimes and corporate control mechanisms is focused on channel 2 in the top half of Fig. 1.

The distinction between governance research and capital markets research is clear, and the two literatures have evolved independently for the most part. However, there are opportunities to explore connections between the two areas. Furthermore, to develop a more complete understanding of the effects of financial accounting information on economic performance, it is important to explore this connection.

\subsection{Research suggestions for exploring the connection between the governance and capital market uses of financial accounting information}

First, to what extent do cross-country differences in the effectiveness of governance mechanisms affect the relation between stock prices and earnings? A growing body of evidence suggests that there are significant cross-country differences in the price-earnings relation (e.g. Alford et al., 1993; Ball et al., $2000 \mathrm{a}, \mathrm{b})$. One motivation for such studies is to get insight into the quality of the accounting practices in different settings. For example, Ball et al. (2000a) find a significantly stronger price-earnings relation in countries with a common law origin which is attributed to greater demand by investors for timely financial accounting information. Hence, the differences are interpreted as a reflection of differences in accounting practices such as the use of hidden reserves to smooth earnings. However, La Porta et al. (1998) documents that the legal protection of shareholders from expropriation by corporate insiders is stronger in common law countries, and it seems reasonable to expect that stronger protection of shareholders' rights is associated with stronger priceearnings sensitivities. As depicted by channel 2B in Fig. 1, we expect investors' reduced risk of loss from expropriation by corporate insiders to lower the cost of equity. In addition, we expect an increase in a given firm's current earnings to cause a greater upward revision in the expected future cash flows to minority shareholders when the shareholders' wealth cannot be expropriated easily by corporate insiders or by politicians and bureaucrats. Preliminary evidence supports these predictions. For example, the legal protection of investors' rights has been found to reduce the cost of equity capital as reflected in IPO underpricing (Lombardo and Pagano, 1999), to increase price-cash flow 
multiples and Tobin's Q (La Porta et al., 1999b), and to increase the explanatory power of returns-earnings regressions (Ali and Hwang, 2000).

A second issue is the extent to which cross-country differences in governance mechanisms affect the breadth and liquidity of the stock market. An investor's willingness to entrust funds with managers requires reasonable assurance that self-serving managers will not expropriate the invested funds (see Levine, 1997). In countries where investor protection is minimal, we do not expect stock markets to thrive. La Porta et al. (1997), for example, finds that the breadth of stock markets is sensitive to the existence of laws protecting investors from expropriation by corporate insiders.

A third issue is the extent to which effective corporate governance mechanisms affects stock market characteristics. For example, Morck et al. (2000) find that less firm-specific information is impounded in stock prices in countries with weaker legal protection of investors' rights.

A final issue is the relation between the properties of high-quality financial reporting regimes for governance purposes (channel 2 in Fig. 1) versus valuation purposes. Gjesdal (1981) shows that the rankings of information systems for control purposes versus valuation purposes need not be the same. The relation between the information content of financial accounting data for control purposes versus valuation purposes has received little attention by empirical researchers. ${ }^{67}$ In Section 4 , we offer several suggestions for isolating the economic effects of financial accounting information through the governance channel. In principle, then, researchers can develop and test hypotheses for the determinants of high- versus low-quality financial accounting regimes specifically for governance purposes. For example, does the pervasive use of hidden reserves within some countries weaken the effects of financial accounting data on economic performance through the governance channel? And does the pervasive use of hidden reserves weaken the effects of financial accounting data on adverse selection in a similar fashion, as reflected, for example, in bid-ask spreads?

\subsection{Additional implications of Figs. 1 and 2 for capital markets research}

The framework illustrated in Figs. 1 and 2 suggest additional research opportunities for capital markets researchers that are not limited to the connection between capital markets research and governance research. First, capital markets researchers can exploit the Rajan and Zingales (1998a) empirical design to investigate the effects of disclosure and measurement on the cost of capital. This represents a promising alternative to measuring the cost of capital effects of financial accounting information on the basis of stock returns and bid-ask spreads.

\footnotetext{
${ }^{67}$ Exceptions include Baber et al. (1998), Bushman et al. (2001), and Bushman et al. (2000b).
} 
Second, an interesting issue for future capital markets research is the extent to which cross-country differences in the strength of the price-earnings relation can be explained by the factors illustrated in Fig. 2, such as communication infrastructure through which financial accounting and other information is disseminated, political risk, or human capital.

Finally, how stock market characteristics affect economic performance is an open, interesting issue. The perceived importance of capital markets research concerning the information content of financial accounting data and the efficiency of the stock market presumably is due, in part, to the assumption that informed stock prices help direct scarce resources in an economy to their highest valued uses. ${ }^{68}$ However, there is little empirical research on the extent to which stock market efficiency in the U.S. or elsewhere contributes to the efficiency of firms' investment and asset management decisions. Durnev et al. (2000) provide preliminary evidence that the functional efficiency of the U.S. stock market varies across industries. It would be interesting to explore the extent to which these differences can be explained by inter-industry differences in the information conveyed by financial accounting data under U.S. GAAP due, for example, to hi-tech versus low tech, maturity of the industry, the importance of intangible assets or investments in R\&D. Cross-country differences in the quality of financial accounting regimes provide another powerful way to investigate whether corporate investments are more sensitive to changes in stock price in the presence of better financial accounting information.

\section{Summary}

We review and critique research concerning the role of accounting information in executive compensation contracts in Section 2. We conclude that the literature provides mixed results concerning the risk-incentives tradeoff implied by the classic principal-agent model, suggesting that empirical researchers should consider other theoretical structures, such as sorting models, to understand the data. Beyond these mixed results, we discuss evidence that the incentive weight on earnings in managerial compensation plans increases with the intensity with which earnings are impounded into stock price, that firms substitute away from accounting earnings towards alternative performance measures as firms' growth opportunities increase, and that boards of directors distinguish among components of earnings in determining annual bonuses. Perhaps most striking is the recent evidence that the direct role of accounting measures in determining the compensation of top

\footnotetext{
${ }^{68}$ Tobin (1982) defines functional stock market efficiency on the basis of the accuracy with which stock prices direct capital to the highest value uses.
} 
U.S. executives has been shrinking in recent years. This evidence raises a number of challenging questions for future research. Two in particular are: Why is the relative importance of accounting measures shrinking, and can cross-sectional differences in the extent of shrinkage be explained? Does this recent evidence imply that accounting information has a lower impact on managerial behavior? We make a number of additional suggestions for extending research on the role of accounting measures in managerial compensation plans throughout the discussion in Section 2.

We propose two additional directions for future governance research in Sections 3 and 4 . The first direction is to explore the use of financial accounting information in additional corporate control mechanisms beyond managerial compensation contracts, the interactions among different control mechanisms, and how corporate governance structures vary with limitations of financial accounting information. The U.S. continues to be an important setting for exploring the use of financial accounting information in corporate control mechanisms because the U.S. has such a well-developed financial accounting regime, a rigorous audit regime that presumably contributes to the governance value of reported accounting data, as well as highly developed control mechanisms. We also think that it would be interesting to explore corporate control mechanisms and their use of financial accounting information in a cross-country setting. La Porta et al. (1997) document significant cross-country differences in one control mechanism-legal protection of investors' rights against expropriation by corporate insiders. There are likely to be others, with important implications for the governance role of financial accounting information in different economies. The research proposed in Section 3 has the potential to provide new evidence of how financial accounting information potentially affects economic growth and efficiency through its use in corporate control mechanisms. Such studies would also provide new cross-country data on corporate control mechanisms for investigating the effects of financial accounting information on economic performance as proposed in Section 4.

The second direction for future research is to examine directly the effects of financial accounting information on economic performance. We propose empirical research focused on four themes. The first theme is whether the availability of financial accounting information affects economic performance, and by how much. This research is expected to capture the overall effects of financial accounting information on economic performance. The second theme is to investigate the specific channels through which financial accounting information affects economic performance, with an emphasis on isolating the effects of the governance role of financial accounting information. The third theme is how the effects of financial accounting information on economic performance vary with other factors, such as the auditing regime, legal protection of investors' rights and other corporate control mechanisms, or the relative importance of securities markets versus bank financing. The 
interactions between financial accounting information and corporate control mechanisms will isolate the governance effects of financial accounting information, and interactions between financial accounting regimes and other domestic institutions will provide new evidence of the determinants of the economic value of financial accounting information more generally. The fourth theme is the economic effects of disclosures of specific types, the frequency of interim reporting, and the accounting principles used to measure the disclosed items. We expect this research to provide new insights into the properties of financial accounting systems that are high- versus low quality from the standpoint of enhancing economic performance.

The cross-country setting is promising for exploring these four issues concerning the effects of financial accounting information on economic performance. There are significant cross-country differences in financial accounting regimes, as well as significant cross-country differences in economic performance to explain. Furthermore, there are cross-country differences in other institutional characteristics such as the legal and political environment that enable researchers to explore how the effects of financial accounting information on economic performance vary with other factors.

Recent research in economics and finance has laid the groundwork for the research suggested in Section 4. Economic and finance theories motivate testing the relation between financial accounting regimes and economic performance. Recent empirical research exploring the cross-country relation between financial development and economic performance provides guidance on research design issues and country-level data on numerous measures of economic performance and institutional factors that lower the barriers to entry for accounting researchers. Recent empirical research also provides evidence that the protection of investors against expropriation by corporate insiders is an important economic issue, as evidenced by the significant cross-country relation between the legal protection of investors against expropriation by corporate insiders and domestic development and efficiency of capital markets, cost of external capital, and economic growth. The preliminary results emerging from this literature also provide evidence of a positive relation between financial accounting information and economic performance. Together this evidence suggests that the governance role of financial accounting information is a channel through which financial accounting information is likely to contribute in an important way to economic performance. Hence, the proposed research into the governance role of financial accounting information has the potential to detect first-order economic effects.

Accounting researchers' detailed knowledge of financial accounting systems and financial accounting issues represents a comparative advantage that can and should be brought to bear on a research agenda that builds on this emerging literature in economics. There is high potential for accounting 
researchers to provide evidence concerning the economic effects of financial accounting information, the channels through which financial accounting information affects economic performance, the factors that influence the economic effects of financial accounting information, and the properties of high value financial accounting regimes from the standpoint of enhancing economic performance. Although there are inherent limits to the potential of this research to test causality, and to rule out the possibility that estimates of the economic effects of accounting are attributable to omitted correlated variables, this is a promising line of inquiry.

In Section 5, we discuss the relation between research on the governance role of financial accounting information and other economics-based empirical research in accounting. We argue that future research concerning the connection between the governance and capital market uses of financial accounting information is important for developing a more complete understanding of the economic effects of financial accounting information, and make suggestions for exploring this connection. Finally we suggest additional ideas for future capital markets research that emerge naturally from our framework illustrated in Figs. 1 and 2.

We do not intend that our suggestions for future research be viewed as "complete" either in terms of hypotheses or empirical designs that can be used to address governance issues. Nor are we sure that the preliminary suggestions above will stand up to scrutiny. Our hope at this stage is that the ideas above stimulate other accounting researchers to reflect on new possibilities for testing the effects of financial accounting information on economic efficiency.

\section{References}

Aboody, D., Kasznik, R., 1999. CEO stock option awards and corporate voluntary disclosures. Working Paper, UCLA and Stanford University.

Abowd, J., Kaplan, D., 1999. Executive compensation: six questions that need answering. NBER Working Paper 7124.

Abreu, D., Milgrom, P., Pearce, D., 1991. Information and timing in repeated partnerships. Econometrica 59 (6), 1713-1733.

Acemoglu, D., Johnson, S., Robinson, J., 2000. The colonial origins of comparative development: an empirical investigation. NBER Working Paper No. W7771.

Aggarawal, R., Samwick, A., 1999a. The other side of the trade-off: the impact of risk on executive compensation. Journal of Political Economy 107, 65-105.

Aggarawal, R., Samwick, A., 1999b. Executive compensation, strategic competition, and relative performance evaluation. The Journal of Finance 54, 1999-2043.

Aghion, P., Bolton, P., 1992. An incomplete contracts approach to financial contracting. Review of Economic Studies 59, 473-494.

Alchian, A., 1950. Uncertainty, evolution, and economic theory. Journal of Political Economy 58, 211-221.

Alford, A., Jones, J., Leftwich, R., Zmijewski, M., 1993. The relative informativeness of accounting disclosures in different countries. Journal of Accounting Research 31 (Suppl.), 183-223. 
Ali, A., Hwang, L., 2000. Country-specific factors related to financial reporting and the value relevance of accounting data. Journal of Accounting Research 38 (1), 1-21.

Antle, R., Smith, A., 1986. An empirical investigation of the relative performance evaluation of corporate executives. Journal of Accounting Research 24, 1-39.

Arya, A., Glover, J., Sunder, S., 1998. Earnings management and the revelation principle. Review of Accounting Studies 3 (1\&2).

Baber, W., Janakiraman, S., Kang, S., 1996. Investment opportunities and the structure of executive compensation. Journal of Accounting and Economics 21, 297-12318.

Baber, W., Kang, S., Kumar, K., 1998. Accounting earnings and executive compensation: the role of earnings persistence. Journal of Accounting and Economics 25, 169-193.

Baiman, S., 1982. Agency research in managerial accounting. Journal of Accounting Literature I, 154-213.

Baiman, S., 1990. Agency research in managerial accounting. Accounting, Organizations and Society $15,341-371$.

Baiman, S., Verrecchia, R., 1996. The relation among capital markets, financial disclosure, production efficiency, and insider trading. Journal of Accounting Research 34 (1), 1-22.

Baiman, S., Larcker, D., Rajan, M., 1995. Organizational design for business unit managers. Journal of Accounting Research 33, 205-230.

Baker, G., 1987. Discussion of an analysis of the use of accounting and market measures of performance in executive compensation contract. Journal of Accounting Research 25 (Suppl.), 126-129.

Baker, G., 1992. Incentive contracts and performance measurement. Journal of Political Economy $100,598-614$.

Baker, G., Hall, B., 1998. CEO incentives and firm size. Working Paper, Harvard.

Baker, G., Gibbs, M., Holmstrom, B., 1994a. The wage policy of a firm. Quarterly Journal of Economics CIX (4), 21-956.

Baker, G., Gibbs, M., Holmstrom, B., 1994b. The internal economics of the firm: evidence from personnel data. Quarterly Journal of Economics CIX (4), 881-920.

Ball, R., Kothari, S.P., Robin, A., 2000a. The effect of international institutional factors on properties of accounting earnings. Journal of Accounting and Economics 29 (1), 1-51.

Ball, R., Robin, A., Wu, J., 2000b. Incentives versus standards: properties of accounting income in four East Asian countries, and implications for acceptance of IAS. Working Paper, University of Rochester.

Banker, R., Datar, S., 1989. Sensitivity, precision, and linear aggregation of signals for performance evaluation. Journal of Accounting Research 27, 21-39.

Barclay, M., Gode, D., Kothari, S.P., 1997. Measuring delivered performance. Working Paper, University of Rochester.

Barro, J., Barro, R., 1990. Pay, performance and turnover of bank CEOs. Journal of Labor Economics 8, 448-481.

Barry, C., Brown, S.J., 1985. Differential information and security market equilibrium. Journal of Financial and Quantitative Analysis 20 (4), 407-422.

Baumol, W., 1967. Business Behavior, Value and Growth, Revised edition.. Harcourt Brace, New York.

Beasley, M., 1996. An empirical analysis of the relation between board of director composition and financial statement fraud. The Accounting Review 71 (4), 443-466.

Benston, G., 1985. The self-serving management hypothesis: some evidence. Journal of Accounting and Economics 7, 67-83.

Berle, A., Means, G., 1932. The Modern Corporation and Private Property. Commerce Clearing House, New York.

Bertrand, M., Mullainathan, S., 1998. Executive compensation and incentives: the impact of takeover legislation. NBER Working Paper 6830. 
Bhide, A., 1993. The hidden cost of stock market liquidity. Journal of Financial Economics 34 (1), $31-51$.

Black, B., 2000a. The legal and institutional preconditions for strong stock markets. Working Paper Stanford Law School, John M. Olin Program in Law and Economics.

Black, B., 2000b. The first international merger wave (and the fifth and last U.S. wave). University of Miami Law Review 54, 799-818.

Blackwell, D., Brickley, J., Weisbach, M., 1994. Accounting information and internal performance evaluation: evidence from Texas banks. Journal of Accounting and Economics 17, 331-358.

Boot, A., Thakor, A., 1997. Financial system architecture. Review of Financial Studies 10, 693733.

Bryan, S., Hwang, L., Lilien, S., 2000. CEO stock-based compensation: An empirical analysis of incentive-intensity, relative mix, and economic determinants. Journal of Business 73 (4), 661-694.

Bushman, R., Engel, E., Milliron, J., Smith, A., 1998. An empirical investigation of trends in the absolute and relative use of earnings in determining CEO cash compensation. Working paper, University of Chicago.

Bushman, R., Indjejikian, R., 1993a. Shareholder demand for "distorted" accounting disclosures. The Accounting Review 68 (4), 765-782.

Bushman, R., Indjejikian, R., 1993b. Accounting income, stock price, and managerial compensation. Journal of Accounting and Economics 16, 1-23.

Bushman, R., Indjejikian, R., Smith, A., 1995. Aggregate performance measurement in business unit compensation: the role of intrafirm interdependencies. Journal of Accounting Research 33 (Suppl.), 101-128.

Bushman, R., Indjejikian, R., Smith, A., 1996. CEO compensation: the role of individual performance evaluation. Journal of Accounting and Economics 21, 161-193.

Bushman, R., Indjejikian, R., Penno, M., 2000a. Private pre-decision information, performance measure congruity and the value of delegation. Contemporary Accounting Research 17(4) (Winter), 561-587.

Bushman, R., Chen, Q., Engel, E., Smith, A., 2000b. The sensitivity of corporate governance systems to the timeliness of accounting earnings. Working Paper, University of Chicago.

Bushman, R., Engel, E., Milliron, J., Smith, A., 2001. An analysis of the relation between the stewardship and valuation roles of earnings. Working Paper, University of Chicago.

Carlin, W., Mayer, C., 2000. Finance, investment and growth. Working Paper, University College London and Said Business School, University of Oxford.

Chang, J., Khanna, T., Palepu, K., 2000. Analyst activity around the world. Working Paper, Harvard Business School.

Clinch, G., 1991. Employee compensation and firms research and development activity. Journal of Accounting Research 29 (1), 59-78.

Clinch, G., Magliolo, J., 1993. CEO compensation and components of earnings in bank holding companies. Journal of Accounting and Economics 16, 241-272.

Core, J., Guay, W., 1998. Estimating the incentive effects of executive stock option portfolios. Working Paper, Wharton.

Core, J., Holthausen, R., Larcker, D., 1999. Corporate governance, chief executive officer compensation, and firm performance. Journal of Financial Economics 51 (3), 371-406.

Core, J., Guay, W., Verrecchia, R., 2000. Are performance measures other than price important to CEO incentives? Working Paper, Wharton.

Coughlin, A., Schmidt, R., 1985. Executive compensation, management turnover, and firm performance: an empirical investigation. Journal of Accounting and Economics 7 (2), 215-226.

Datar, S., Kulp, S., Lambert, R., 2000. Balancing performance measures. Journal of Accounting Research, forthcoming. 
DeAngelo, L., 1988. Managerial competition, information costs, and corporate governance: the use of accounting performance measures in proxy contests. Journal of Accounting and Economics $10(1), 3-36$.

Dechow, P., Huson, M., Sloan, R., 1994. The effect of restructuring charges on executives cash compensation. The Accounting Review 69, 138-156.

Dechow, P., Sloan, R., Sweeney, A., 1996. Causes and consequences of earnings manipulation: an analysis of firms subject to enforcement actions by the SEC. Contemporary Accounting Research 13 (1), 1-36.

Defeo, V., Lambert, R., Larcker, D., 1989. Executive compensation effects of equity for debt swaps. The Accounting Review 64, 201-227.

DeFond, M., Park, C., 1999. The effect of competition on CEO turnover. Journal of Accounting and Economics 27, 35-56.

DeFond, M., Subramanyam, K.R., 1998. Auditor changes and discretionary accruals. Journal of Accounting and Economics 25 (1), 35-67.

Demirguc-Kunt, A., Maksimovic, V., 1998. Law, finance, and firm growth. Journal of Finance 53, 2107-2137.

Demski, J., Frimor, H., 1999. Performance measure garbling under renegotiation in multi-period agencies. Journal of Accounting Research (Suppl.) 37, 187-214.

Demski, J., Sappington, D., 1999. Summarization with errors, A perspective on empirical investigations of agency relationships. Management Accounting Research 10 (1), 21-37.

Dewatripont, M., Tirole, J., 1994. A theory of debt and equity, diversity of securities and managershareholder congruence. Quarterly Journal of Economics 109, 1027-1054.

Diamond, D.W., 1984. Financial intermediation and delegated monitoring. Review of Economic Studies 51 (3), 393-414.

Diamond, D., Verrecchia, R., 1991. Disclosure, liquidity, and the cost of capital. Journal of Finance 46, 1325-1359.

Djankov, S., La Porta, R., de Silanes, F., Shleifer, A., 2000. The regulation of entry. Working Paper, Harvard University.

Dow, J., Gorton, G., 1997. Stock market efficiency and economic efficiency: is there a connection? Journal of Finance 52, 1087-1129.

Durnev, A., Morck, R., Yeung, B., 2000. Do stock prices guide the allocation of capital? Working Paper, University of Michigan Business School.

Dye, R., 1992. Relative performance evaluation and project selection. Journal of Accounting Research 30 (1), 27-52.

Dye, R., Sridhar, S., 2000. Strategy-directing disclosures. Working Paper, Northwestern University.

Ely, K., 1991. Interindustry differences in the relation between compensation and firm performance variables. Journal of Accounting Research 29, 37-58.

Fama, E., 1980. Agency problems and the theory of the firm. Journal of Political Economy 88, 288307.

Fama, E., Jensen, M., 1983a. Agency problems and residual claims. Journal of Law and Economics 26, 327-349.

Fama, E., Jensen, M., 1983b. Separation of ownership and control. Journal of Law and Economics 26, 301-325.

Feltham, G., Xie, J., 1994. Performance measure congruity and diversity in multi-task principal/ agent relations. The Accounting Review 69, 429-453.

Feltham, G., Hughes, J., Simunic, D., 1991. Empirical assessment of the impact of auditor quality on the valuation of new issues. Journal of Accounting and Economics 14 (4), 375-399.

Fields, T., Lys, T., Vincent, L., 2001. Empirical research on accounting policy choice. Journal of Accounting and Economics 31, 255-307. 
Fisher, J., Govindarajan, V., 1991. CEO and profit center manager compensation as a social comparison: an examination of owner and manager controlled firms. Working Paper, Dartmouth College.

Francis, J., Philbrick, D., Schipper, K., 1994. Shareholder litigation and corporate disclosure. Journal of Accounting Research 32 (2), 137-164.

Garen, J., 1994. Executive compensation and principal-agent theory. Journal of Political Economy 102-6, 1175-1199.

Gaver, J., Gaver, K., 1993. Additional evidence on the association between the investment opportunity set and corporate financing, dividend, and compensation policies. Journal of Accounting and Economics 16, 125-160.

Gaver, J., Gaver, K., 1995. Additional evidence on bonus plans and income management. Journal of Accounting and Economics 19, 3-28.

Gaver, J., Gaver, K., 1998. The relation between nonrecurring accounting transactions and CEO cash compensation. The Accounting Review 73, 235-253.

Gibbs, M., 1995. Incentive compensation in a corporate hierarchy. Journal of Accounting and Economics 19, 247-277.

Gibbons, R., 1998. Incentives in organizations. Journal of Economic Perspectives 12, 115-132.

Gibbons, R., Murphy, K.J., 1990. Relative performance evaluation for chief executive officers. Industrial and Labor Relations Review 43, 30S-51S.

Gigler, F., Hemmer, T., 1998. On the frequency, quality, and informational role of mandatory financial reports. Journal of Accounting Research (Suppl.) 36, 117-147.

Gjesdal, F., 1981. Accounting for stewardship. Journal of Accounting Research 19, 208-231.

Grossman, S., 1976. On the efficiency of competitive stock markets where traders have diverse information. Journal of Finance 31, 573-585.

Grossman, S., Stiglitz, J., 1980. On the impossibility of informationally efficient stock markets. American Economic Review 70, 393-408.

Guay, W., 1999. The sensitivity of CEO wealth to equity risk: an analysis of the magnitude and determinants. Journal of Financial Economics 53, 3-71.

Guidry, F., Leone, A., Rock, S., 1999. Earnings-based bonus plans and earnings management by business-unit managers. Journal of Accounting and Economics 26, 113-142.

Hall, B., 1999. The design of multi-year stock option plans. Journal of Applied Corporate Finance 12 (2), 97-106.

Hall, B., Leibman, J., 1998. Are CEOs really paid like bureaucrats? The Quarterly Journal of Economics 103, 653-691.

Harris, M., Raviv, A., 1979. Optimal incentive contracts with imperfect information. Journal of Economic Theory 20, 231-259.

Haubrich, J., 1994. Risk aversion, performance pay, and the principal-agent problem. Journal of Political Economy 102-2, 258-276.

Hayek, F., 1945. The use of knowledge in society. American Economic Review 35, 519-530.

Hayes, R., Schaefer, S., 2000. Implicit contracts and the explanatory power of top executive compensation for future performance. Rand Journal of Economics 31 (2), 273-293.

Healy, P., 1985. The effect of bonus schemes on accounting decisions. Journal of Accounting and Economics 7, 85-107.

Healy, P., Kang, S., Palepu, K., 1987. The effects of accounting procedure changes on CEOs' cash salary and bonus compensation. Journal of Accounting and Economics 9, 7-34.

Hemmer, T., 1996. On the design and choice of "modern" management accounting measures. Journal of Management Accounting Research 8, 87-116.

Hemmer, T., Matsunaga, S., Shevlin, T., 1996. The influence of risk diversification on the early exercise of employee stock options by executive officers. Journal of Accounting and Economics $21,45-68$. 
Hermalin, B., Weisbach, M., 1998. Endogenously chosen boards of directors and their monitoring of the CEO. American Economic Review 88, 96-118.

Hermalin, B., Weisbach, M., 2000. Boards of directors as an endogenously determined institution: a survey of the economic literature. Working Paper, Berkeley and University of Illinois.

Himmelberg, C., Hubbard, R., Palia, D., 1999. Understanding the determinants of managerial ownership and the link between ownership and performance. Journal of Financial Economics 53 (3), 353-384.

Hirshleifer, J., 1971. The private and social value of information and the reward to inventive activity. American Economic Review 61 (4), 561-574.

Hogan, C., Lewis, C., 1999. The long-run performance of firms adopting compensation plans based on economic profits. Working Paper, Owen Graduate School of Management, Vanderbilt University.

Holmstrom, B., 1979. Moral hazard and observability. The Bell Journal of Economics 10, 74-91.

Holmstrom, B., 1982. Moral hazard in teams. The Bell Journal of Economics 13, 324-340.

Holmstrom, B., Hart, O., 1987. The theory of contracts. In: Bewley, T. (Ed.), Advances in Economic Theory, Fifth World Congress, Cambridge University Press, Cambridge.

Holmstrom, B., Milgrom, P., 1987. Aggregation and linearity in the provision of intertemporal incentives. Econometrica 55, 303-328.

Holmstrom, B., Milgrom, P., 1991. Multi-task principal-agent analysis: incentive contracts, asset ownership, and job design. Journal of Law, Economics \& Organization 7 (Special Issue), 24-52.

Holmstrom, B., Tirole, J., 1993. Market liquidity and performance monitoring. Journal of Political Economy 101, 678-709.

Holthausen, R., Larcker, D., Sloan, R., 1995a. Business unit innovation and the structure of executive compensation. Journal of Accounting and Economics 19, 279-313.

Holthausen, R., Larcker, D., Sloan, R., 1995b. Annual bonus schemes and the manipulation of earnings. Journal of Accounting and Economics 19, 29-74.

Hubbard, R., Palia, D., 1995. Executive pay and performance: Evidence from the U.S. banking industry. Journal of Financial Economics 39 (1), 105-130.

Ichniowski, C., Shaw, K., Prennushi, G., 1997. The effects of human resource management practices on productivity: a study of steel finishing lines. American Economic Review 87 (3), 291-313.

Indjejikian, R., 1999. Performance evaluation and compensation research: an agency perspective. Accounting Horizons 13 (2), 147-157.

Indjejikian, R., Nanda, D., 1999. Dynamic incentives and responsibility accounting. Journal of Accounting and Economics 27, 177-201.

Ittner, C., Larcker, D., Rajan, M., 1997. The choice of performance measures in annual bonus contracts. The Accounting Review 72, 231-255.

Jagannathan, R., Srinivasan, S., 1999. Does product market competition reduce agency costs? The North American Journal of Economics and Finance 10, 387-399.

Janakiraman, S., Lambert, R., Larcker, D., 1992. An empirical investigation of the relative performance evaluation hypothesis. Journal of Accounting Research 30 (1), 53-69.

Jensen, M., 1986. Agency costs of free cash flow, corporate finance, and takeovers. American Economic Review 76, 323-329.

Jensen, M., Murphy, K., 1990. Performance pay and top management incentives. Journal of Political Economy 98, 225-264.

Kang, J., Shivdisani, A., 1995. Firm performance, corporate governance, and top executive turnover in Japan. Journal of Financial Economics 38 (1), 29-58.

Kaplan, S., 1994a. Top executive rewards and firm performance: a comparison of Japan and the United States. Journal of Political Economy 102-3, 510-546.

Kaplan, S., 1994b. Top executives, turnover and firm performance in Germany. Journal of Law, Economics \& Organization 10 (1), 142-159. 
Kaplan, S., Stromberg, P., 1999. Financial contracting theory meets the real world: an empirical analysis of venture capital contracts. Working Paper, University of Chicago.

Keating, S., 1997. Determinants of divisional performance evaluation practices. Journal of Accounting and Economics 24, 243-273.

Kellogg, R., 1984. Accounting activities, security prices, and class action lawsuits. Journal of Accounting and Economics 6, 185-204.

Kothari, S.P., 2001. Capital markets research in accounting. Journal of Accounting and Economics $31,105-231$.

Larcker, D., 1983. The association between performance plan adoption and corporate capital investment. Journal of Accounting and Economics 5 (1), 3-30.

Laffont, J.J., Tirole, J., 1990. Adverse selection and renegotiation in procurement. Review of Economic Studies 57 (4), 597-625.

Lambert, R., 1993. The use of accounting and security price measures of performance in managerial compensation contracts, a discussion. Journal of Accounting and Economics 16, 101-123.

Lambert, R., 2001. Contracting theory and accounting. Journal of Accounting and Economics 32, 3-87.

Lambert, R., Larcker, D., 1987. An analysis of the use of accounting and market measures of performance in executive compensation contracts. Journal of Accounting Research 25 (Suppl.), 95-125.

Lambert, R., Larcker, D., Weigelt, K., 1993. The structure of organizational incentives. Administrative Science Quarterly (September), 438-461.

La Porta, R., Lopez-De-Silanes, F., Shleifer, A., Vishny, R., 1997. Legal determinants of external capital. Journal of Finance 52 (3), 1131-1150.

La Porta, R., Lopez-De-Silanes, F., Shleifer, A., Vishny, R., 1998. Law and finance. Journal of Political Economy 106, 1113-1155.

La Porta, R., Lopez-De-Silanes, F., Shleifer, A., 1999a. Corporate ownership around the world. Journal of Finance 54 (2), 471-517.

La Porta, R., Lopez-De-Silanes, F., Shleifer, A., Vishny, R., 1999b. Investor protection and corporate valuation. Working Paper, Harvard University.

La Porta, R., Lopez-De-Silanes, F., Shleifer, A., Vishny, R., 2000. Agency problems and dividend policies around the world. Journal of Finance 55 (1), 1-33.

Lazear, E., 1999a. Performance pay and productivity. Working Paper, Hoover Institution and Stanford University.

Lazear, E., 1999b. Output-based pay: incentives or sorting? Working Paper, Hoover Institution and Stanford University.

Leftwich, R., 1981. Evidence of the impact of mandatory changes in accounting principles on corporate loan agreements. Journal of Accounting and Economics 3 (1), 3-36.

Lehn, K., Makhija, A., 1997. EVA, accounting profits, and CEO turnover: an empirical examination 1985-1994. Journal of Applied Corporate Finance 10 (2), 90-97.

Leone, A., Rock, S., 1999. Empirical tests of the ratchet principle and implications for studies of earnings management. Working Paper, University of Rochester.

Leuz, C., Verrecchia, R., 2000. The economic consequences of increased disclosure. Journal of Accounting Research, forthcoming.

Levine, R., 1997. Financial development and economic growth: views and agenda. Journal of Economic Literature 35 (2), 688-726.

Levine, R., Renelt, D., 1992. A sensitivity analysis of cross-country growth regressions. American Economic Review 82 (4), 942-963.

Levine, R., Zervos, S., 1993. What we have learned about policy and growth from cross-country regressions? American Economic Review 83 (2), 426-443.

Levine, R., Zervos, S., 1998. Stock markets, banks, and economic growth. American Economic Review 88, 537-558. 
Lombardo, D., Pagano, M., 1999. Legal determinants of the return on equity. Università di Salerno, CSEF Working Paper no. 24, and CEPR Discussion Paper no. 2276, November.

Manne, H., 1965. Mergers and the market for corporate control. Journal of Political Economy 73 (2), 110-120.

Marris, R., 1963. A model of the managerial enterprise. Quarterly Journal of Economics 77 (2), 185-209.

Marshall, J., 1974. Private incentives and public information. American Economic Review 64 (3), 373-390.

Milliron, J., 2000. Board of director incentive alignment and the design of executive 7compensation contracts. Working Paper Graduate School of Business, University of Chicago.

Mirrlees, J., 1976. The optimal structure of incentives and authority within an organization. The Bell Journal of Economics 7, 105-131.

Modigliani, F., Perotti, E., 2000. Security versus bank finance: the importance of proper enforcement of legal rules. Working Paper, MIT Sloan School of Management.

Morck, R., Yeung, B., Yu, W., 2000. Why do emerging markets have synchronous stock price movements? Journal of Financial Economics 58 (1-2), 215-260.

Murphy, K.J., 1985. Corporate performance and managerial remuneration: an empirical analysis. Journal of Accounting and Economics 7, 11-42.

Murphy, K., 1999a. Performance standards in incentive contracts. Working Paper, University of Southern California.

Murphy, K.J., 1999b. Executive compensation. In: Orley, A., David, C. (Eds.), Handbook of Labor Economics, Vol. 3. North-Holland, Amsterdam.

Murphy, K.J., Zimmerman, J., 1993. Financial performance surrounding CEO turnover. Journal of Accounting and Economics 16, 273-315.

Myers, S.C., 1977. Determinants of corporate borrowing. Journal of Financial Economics 5, 147175.

Natarajan, R., 1996. Stewardship value of earnings components: additional evidence on the determinants of executive compensation. The Accounting Review 71, 1-22.

Ofek, E., Yermack, D., 1997. Taking stock: does equity-based compensation increase managers' ownership? Working Paper, New York University.

Ohlson, J., 1995. Earnings, book values, and dividends in security valuation. Contemporary Accounting Research 11, 661-687.

Palepu, K., 1986. Predicting takeover targets: a methodological and empirical analysis. Journal of Accounting and Economics 8 (1), 3-36.

Parrino, R., 1997. CEO turnover and outside succession: a cross-sectional analysis. Journal of Financial Economics 46 (2), 165-197.

Paul, J., 1992. On the efficiency of stock-based compensation. Review of Financial Studies 5, 471502.

Pavlik, E., Scott, T., Tiessen, P., 1993. Executive compensation: issues and research. Journal of Accounting Literature 12, 131-189.

Prendergast, C., 1999a. The provision of incentives in firms. Journal of Economic Literature 37, 7-63.

Prendergast, C., 1999b. The tenuous tradeoff of risk and incentives. Working Paper, University of Chicago and NBER.

Press, G., Weintrop, J., 1990. Accounting-based constraints in public and private debt arrangements: their association with leverage and impact on accounting choice. Journal of Accounting and Economics 12 (1-3), 65-95.

Rajan, R., Zingales, L., 1998a. Financial dependence and growth. American Economic Review 88 (3), 559-586.

Rajan, R., Zingales, L., 1998b. Which capitalism? Lessons from the East Asian crisis. Journal of Applied Corporate Finance 11 (3), 40-48. 
Rajan, R., Zingales, L., 1999. The politics of financial development. Working Paper, University of Chicago.

Rajan, R., Zingales, L., 2000. The governance of the new enterprise. In: Vives (Ed.), Corporate Governance, X. Cambridge University Press, Cambridge, forthcoming.

Reese, W., Weisbach, M., 2000. Protection of minority shareholder interests, cross-listings in the United States, and subsequent equity offerings. Working Paper, University of Illinois.

Rosen, S., 1992. Contracts and the market for executives. In: Werin, L., Wijkander, H. (Eds.), Contract Economics. Basil Blackwell, Oxford, pp. 181-211.

Ross, S., 1973. The economic theory of agency: the principal's problem. American Economic Review 63, 134-139.

Salanie, B., 1998. The Economics of Contracting. The MIT Press, Cambridge, MA.

Schaefer, S., 1998. The dependence of pay-performance sensitivity on the size of the firm. The Review of Economics and Statistics 80 (3), 436-443.

Scharfstein, D., 1988. The disciplinary role of takeovers. Review of Economic Studies 55, 185-199.

Shleifer, A., Summers, L., 1988. Breach of trust in hostile takeovers. In: Alan, A. (Ed.), Corporate Takeovers: Causes and Consequences. Univerity of Chicago Press, Chicago, pp. 33-56.

Shleifer, A., Vishny, R., 1986. Large shareholders and corporate control. Journal of Political Economy 94 (3), 461-488.

Shleifer, A., Vishny, R., 1997. A survey of corporate governance. Journal of Finance 52 (2), $737-$ 783.

Skinner, D., 1994. Why firms voluntarily disclose bad news. Journal of Accounting Research 32, $38-60$.

Sloan, R., 1993. Accounting earnings and top executive compensation. Journal of Accounting and Economics 16, 55-100.

Smith, C., Warner, J., 1979. On financial contracting: an analysis of bond covenants. Journal of Financial Economics 7 (2), 117-161.

Smith, C., Watts, R., 1992. The investment opportunity set and corporate financing, dividend, and compensation policies. Journal of Financial Economics 32, 263-292.

Spence, M., 1973. Job market signaling. Quarterly Journal of Economics 87, 255-274.

Stein, J., 1988. Takeover threats and managerial myopia. Journal of Political Economy 96 (1), 6180.

Stigler, G., 1958. The economies of scale. Journal of Law and Economics 1, 54-71.

Sweeney, A., 1994. Debt-covenant violations and managers' accounting responses. Journal of Accounting and Economics 17 (3), 281-308.

Tadesse, S., 2000. The information and monitoring role of capital markets: theory and international evidence. Working Paper The Darla Moore School of Business, The University of South Carolina.

Tobin, J., 1982. On the efficiency of the financial system. Lloyds Bank Review (July).

Vancil, R., 1978. Decentralization: Managerial Ambiguity by Design. Dow-Jones-Irwin, Homewood, IL.

Verrecchia, R., 2001. Essays on disclosure. Journal of Accounting and Economics 32, 97-180.

Verrecchia, R.E., 1982. Information acquisition in a noisy rational expectations economy. Econometrica 50 (6), 1415-1430.

Wallace, J., 1997. Adopting residual income-based compensation plans: do you get what you pay for? Journal of Accounting and Economics 24, 275-300.

Warner, J., Watts, R., Wruck, K., 1988. Stock prices and top management changes. Journal of Financial Economics 20, 61-492.

Watts, R., 1977. Corporate financial statements, a product of the market and political processes. Australian Journal of Management 2, 53-75.

Watts, R., Zimmerman, J., 1978. Towards a positive theory of the determination of accounting standards. The Accounting Review 53, 112-134. 
Watts, R., Zimmerman, J., 1986. Positive Theory of Accounting. Prentice-Hall, Inc., Englewood Cliffs, NJ.

Watts, R., Zimmerman, J., 1990. Positive accounting theory: a ten year perspective. The Accounting Review 65, 31-156.

Weisbach, M., 1988. Outside directors and CEO turnover. Journal of Financial Economics 20, 431-460.

Williamson, O., 1964. The economics of discretionary behavior: Managerial objectives in a theory of the firm. Englewood Cliffs, NJ: Prentice Hall.

Wurgler, J., 2000. Financial markets and the allocation of capital. Journal of Financial Economics $58(1-2), 187-214$.

Yermack, D., 1995. Do corporations award CEO stock options effectively? Journal of Financial Economics 39, 237-269.

Yermack, D., 1997. Good timing: CEO stock option awards and company news announcements. Journal of Finance 52, 449-476.

Zingales, L., 2000. In search of new foundations. Journal of Finance 55, 1623-1653. 